University of Louisville ThinkIR: The University of Louisville's Institutional Repository

Electronic Theses and Dissertations

$5-2019$

\title{
Use of anodic stripping voltammetry to study the size-selective electrophoretic deposition and aggregation-dependent oxidation of metal nanoparticles.
}

Stacy L. Allen

University of Louisville

Follow this and additional works at: https://ir.library.louisville.edu/etd

Part of the Analytical Chemistry Commons

\section{Recommended Citation}

Allen, Stacy L., "Use of anodic stripping voltammetry to study the size-selective electrophoretic deposition and aggregation-dependent oxidation of metal nanoparticles." (2019). Electronic Theses and Dissertations. Paper 3141.

https://doi.org/10.18297/etd/3141

This Doctoral Dissertation is brought to you for free and open access by ThinkIR: The University of Louisville's Institutional Repository. It has been accepted for inclusion in Electronic Theses and Dissertations by an authorized administrator of ThinkIR: The University of Louisville's Institutional Repository. This title appears here courtesy of the author, who has retained all other copyrights. For more information, please contact thinkir@louisville.edu. 


\title{
USE OF ANODIC STRIPPING VOLTAMMETRY TO STUDY THE SIZE-SELECTIVE ELECTROPHORETIC DEPOSITION AND AGGREGATION-DEPENDENT OXIDATION OF METAL NANOPARTICLES
}

\author{
Stacy L. Allen \\ A Dissertation \\ Submitted to the Faculty of the \\ College of Art and Sciences of the University of Louisville \\ in Partial Fulfillment of the Requirements for the Degree of
}

Doctor of Philosophy in Chemistry

Department of Chemistry

University of Louisville

Louisville, Kentucky

May 2019 
Copyright 2019 by Stacy L. Allen

All rights reserved 



\title{
USE OF ANODIC STRIPPING VOLTAMMETRY TO STUDY THE SIZE-SELECTIVE ELECTROPHORETIC DEPOSITION AND AGGREGATION-DEPENDENT OXIDATION OF METAL NANOPARTICLES
}

\author{
By \\ Stacy L. Allen \\ A Dissertation Approved on \\ April 29 ${ }^{\text {th }}, 2019$ \\ by the following Dissertation Committee:
}

Dissertation Director - Dr. Francis P. Zamborini

Dr. Richard Baldwin

Dr. Craig Grapperhaus

Dr. Gamini Sumanasekera 
"I have not failed. I've just found 10,000 ways that won't work." -Thomas A. Edison

This dissertation is dedicated to my amazingly supportive parents and the one true love of my life - my dog, Helix. 


\section{ACKNOWLEDGEMENTS}

First, I would like to acknowledge my mentor, Dr. Francis P. Zamborini. His guidance and support have led me to this point, and I would not be here without all time and effort he has spent helping me achieve my goals. I have learned so much from him during my time here at the University of Louisville and will forever be indebted to his mentorship.

Second, I would like to thank my dissertation committee, Dr. Richard Baldwin, Dr. Craig Grapperhaus, and Dr. Gamini Sumanasekera, who have provided me with valuable feedback on my projects.

Lastly, I would like to thank the members of my group both past and present for their help and patience. In particular, Dr. Rafael Masitas who mentored me when I first joined the group and taught me the foundations of electrochemistry. 


\section{ABSTRACT \\ USE OF ANODIC STRIPPING VOLTAMMETRY TO STUDY THE SIZE-SELECTIVE ELECTROPHORETIC DEPOSITION AND AGGREGATION-DEPENDENT OXIDATION OF METAL NANOPARTICLES}

Stacy L. Allen

April 29 ${ }^{\text {th }}, 2019$

This dissertation describes how anodic stripping voltammetry (ASV) was used to study size-controlled electrophoretic deposition (EPD) and the aggregation-dependent oxidation properties of citrate-stabilized Au nanoparticles (NPs).

EPD of citrate-coated Au NPs occurs in the presence of hydroquinone (HQ) onto indium-tin-oxide-coated glass electrodes (glass/ITO) at potentials positive of the HQ oxidation potential. HQ oxidation produces protons at the electrode surface, which serve to neutralize the citrate molecules that electrostatically stabilize the Au NPs.

Neutralization leads to the loss of stabilization and deposition onto the electrode. EPD in the presence of ferrocyanide, a non-proton-producing molecule, at oxidation potentials resulted in no deposition of Au NPs, confirming the proton neutralization deposition mechanism. In a solution of $4 \mathrm{~nm}$ and $15 \mathrm{~nm}$ diameter Au NPs, $4 \mathrm{~nm}$ NPs selectively deposit at lower potentials because they are more catalytic for HQ oxidation compared to $15 \mathrm{~nm}$ Au NPs. At slightly higher potentials, however, HQ plus a small amount of $4 \mathrm{~nm}$ 
Au NPs aid in the deposition of NPs that otherwise would not deposit at that potential, including $15 \mathrm{~nm}$ Au NPs, $\sim 5 \mathrm{~nm}$ palladium (Pd) NPs, and titanium dioxide $\left(\mathrm{TiO}_{2}\right)$ NPs. This is termed NP-assisted EPD, which allows the EPD of a wider variety of nanostructures at low potentials without the formation of bubbles at the electrode surface. Chemical modification of the glass/ITO electrode surface with thiol-terminated silane monolayers or thin polymer films also enables size-selective EPD in the presence of HQ by physically blocking larger NPs while allowing smaller NPs to get through. Controlled EPD of nanostructures could be valuable for various electrocatalysis and electrochemical sensing device applications.

ASV provides information about the aggregation-dependent oxidation of $4 \mathrm{~nm}, 15$ $\mathrm{nm}$, and $50 \mathrm{~nm}$ diameter citrate-coated Au NPs. The oxidation potential for wellseparated NPs decreases with decreasing size in the order $4 \mathrm{~nm}<15 \mathrm{~nm}<50 \mathrm{~nm}$. As the $4 \mathrm{~nm}$ and $15 \mathrm{~nm}$ diameter Au NPs aggregate by decreasing the solution $\mathrm{pH}$, their oxidation potential increases towards that of the $50 \mathrm{~nm}$ diameter Au NPs. The shift is due to a decrease in the surface area-to-volume ratio (SA/V) of the NPs upon aggregation. The positive shift depends on aggregate size, and the total positive shift is larger for $4 \mathrm{~nm}$ diameter compared to $15 \mathrm{~nm}$ diameter Au NPs. The oxidation potential of $50 \mathrm{~nm}$ diameter Au NPs does not shift upon aggregation since it already has a very small SA/V ratio. The fundamental understanding of aggregation-dependent oxidation of metal NPs is important for determining the stability and toxicity of metal NPs. In addition, the electrochemical detection of NP aggregation can be used for NP aggregation-based chemical detection that is more sensitive and utilizes a wider variety of NPs compared to NP aggregation-based optical chemical detection. 


\section{TABLE OF CONTENTS}

$\underline{\text { Page }}$

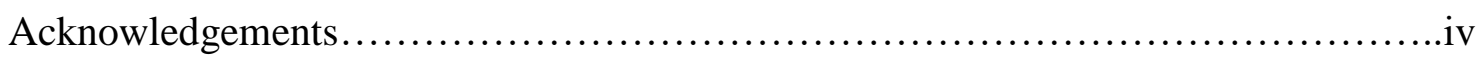

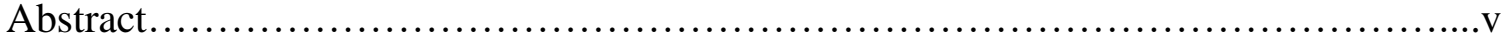

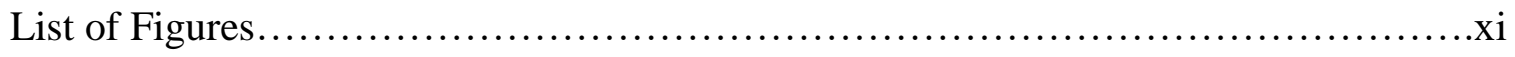

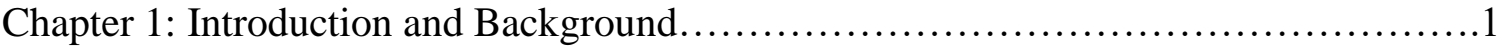

1.1. Main Goals and Summary.......................................

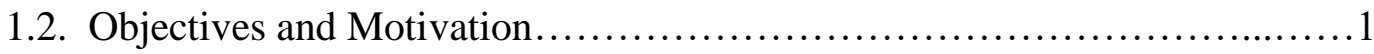

1.3. Importance of Metal Nanoparticle Research..............................2

1.4. Metal Nanoparticle Oxidation...................................... 3

1.4.1. Size-Dependent Oxidation Based on Plieth Theory...............4

1.4.2. Size-Dependent Metal Nanoparticle Oxidation Experiments........6

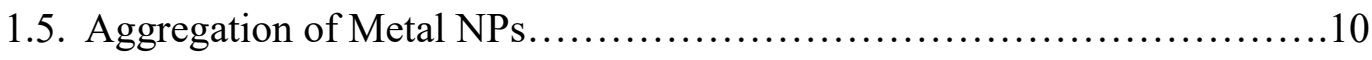

1.6. Electrophoretic Deposition.......................................... 12

1.6.1. Electrophoretic Deposition History, Theory, and Amount

Deposited....................................................12

1.6.2. Electrophoretic Deposition Mechanisms......................14

1.6.3. Electrophoretic Deposition of Metal Nanoparticles...............18

1.7. Summary and Accomplishments.................................21

Chapter 2: Experimental Methods.........................................23

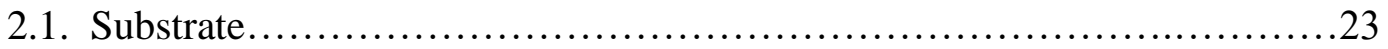




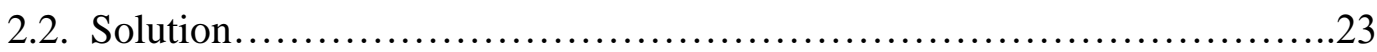

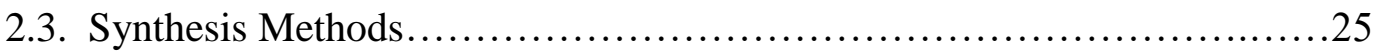

2.3.1. Chemical Synthesis of $4 \mathrm{~nm}$ Average Diameter

Citrate-Stabilized Au Nanoparticles..................................25

2.3.2. Chemical Synthesis of $15 \mathrm{~nm}$ Average Diameter

Citrate-Stabilized Au Nanoparticles.................................26

2.3.3. Chemical Synthesis of $50 \mathrm{~nm}$ Average Diameter

Citrate-Stabilized Au Nanoparticles.....................................26

2.3.4. Functionalization of Glass/ITO with

Aminopropyltriethoxysilane (APTES) ................................29

2.3.5. Preparation of Aggregated Au Nanoparticles at Low $\mathrm{pH}$...........29

2.4. Electrochemistry Experiments........................................33

2.4.1. Anodic Stripping Voltammetry..................................33

2.4.2. Electrophoretic Deposition...................................36

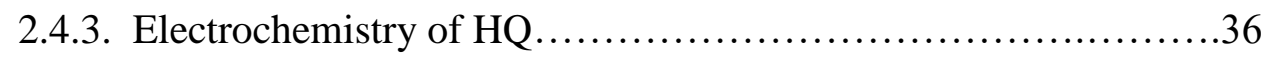

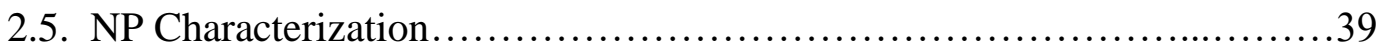

2.5.1. Spectrophotometry ......................................... 39

2.5.2. Anodic Stripping Voltammetry (ASV),..........................39

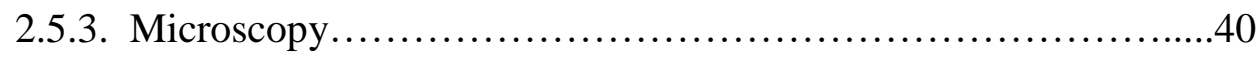

Chapter 3: Size-Selective Electrophoretic Deposition of Gold Nanoparticles

Mediated by the Oxidation of Hydroquinone ........................................43

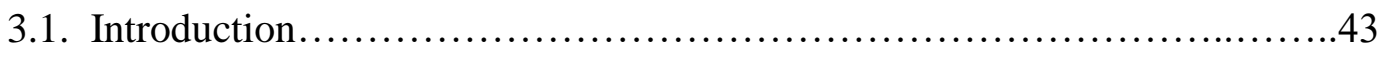

3.2. Experimental Section................................................49 
3.2.1. Chemicals

3.2.2. Chemical Synthesis of $4 \mathrm{~nm}$ Average Diameter

Citrate-Stabilized Au Nanoparticles.

3.2.3. Chemical Synthesis of $15 \mathrm{~nm}$ Average Diameter

Citrate-Stabilized Au Nanoparticles..............................50

3.2.4. Electrophoretic Deposition (EPD) Conditions...................50

3.2.5. Anodic Stripping Voltammetry of the Glass/ITO/Au NPs

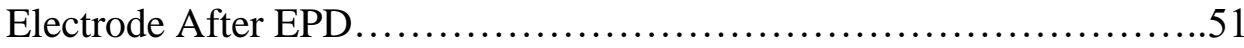

3.2.6. Instrumentation............................................ 52

3.3. Results and Discussion.........................................52

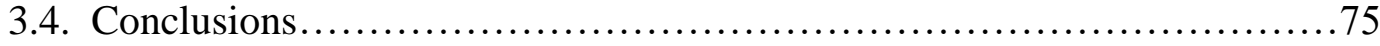

Chapter 4: Nanoparticle (NP)-Assisted Electrophoretic Deposition (EPD)..............77

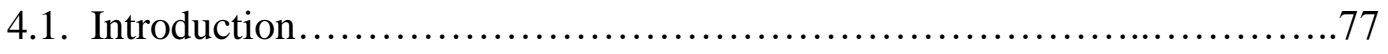

4.2. Experimental................................................. 79

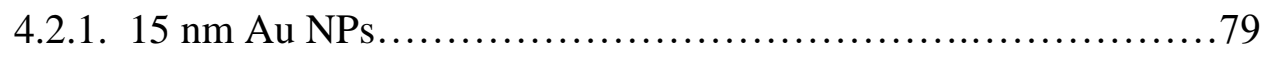

4.2.2. Palladium NPs.............................................81

4.2.3. Titanium Dioxide NPs..................................82

4.3. Results and Discussion.......................................... 82

4.3.1. $15 \mathrm{~nm} \mathrm{Au} \mathrm{NPs............................................} 82$

4.3.2. Pd NPs.................................................. 87

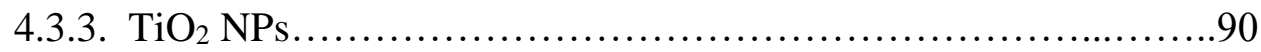

4.4. Conclusions....................................................95

Chapter 5: Size-Selective Electrophoretic Deposition by Functionalization of the 
Working Electrode with Silane Filters on Glass/ITO Substrates.

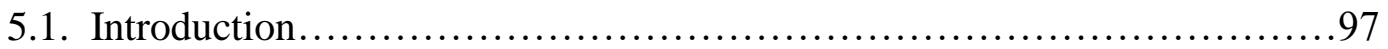

5.2. Experimental.................................................... 97

5.2.1. Chemical Surface Modification.................................97

5.2.2. Selective Attachment of NPs to Electrode Surface.................99

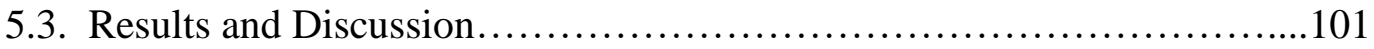

Chapter 6: Aggregation-Dependent Oxidation of Metal Nanoparticles.................105

6.1. Introduction ...................................................... 105

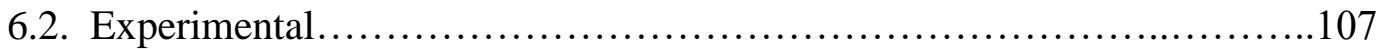

6.2.1. Preparation of Working Electrode..............................107

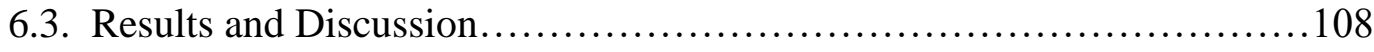

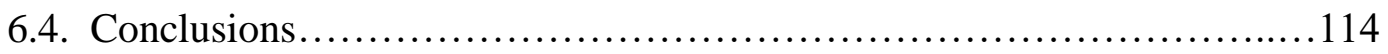

Chapter 7: Summary and Future Directions......................................117

7.1. Summary of Research............................................117

7.2. Future Directions................................................. 118

7.2.1. Sensing of Hazardous Chemicals by Electrochemical

Detection of Aggregating Au NPs..................................118

7.2.1a. Pamidronate Disodium Detection.............................119

7.2.1b. Chromium Detection.......................................120

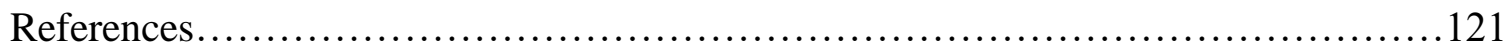

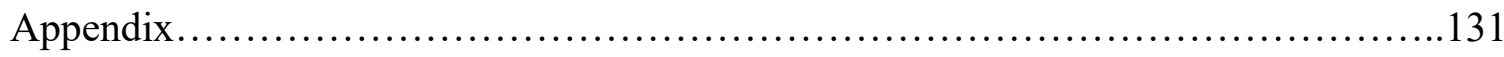

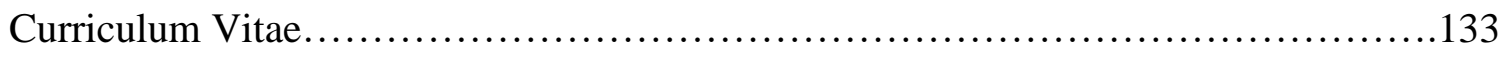




\section{LIST OF FIGURES}

$\underline{\text { Page }}$

Figure 1.1. Change in redox potential based on size of NP.......................

Figure 1.2. EPD scheme................................................

Figure 1.3. EPD mechanism: salting out..................................... 16

Figure 1.4. EPD mechanism: charge reduction/neutralization...................... 17

Figure 1.5. EPD mechanism: direct electrostatic force $\ldots \ldots \ldots \ldots \ldots \ldots \ldots \ldots \ldots \ldots \ldots$

Figure 2.1. General scheme of electrochemistry experiments......................24

Figure 2.2. Synthesis methods for $4 \mathrm{~nm}, 15 \mathrm{~nm}$, and $50 \mathrm{~nm}$ Au NPs..................27

Figure 2.3. UV-vis spectra, ASV, and SEM images of the $4 \mathrm{~nm}, 15 \mathrm{~nm}$,

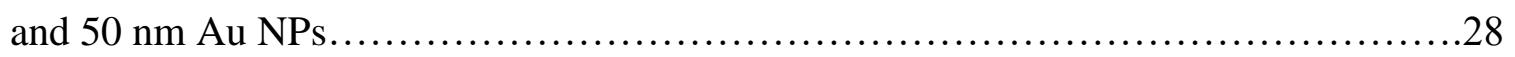

Figure 2.4. (A) Aggregation scheme and (B) pictures of the isolated

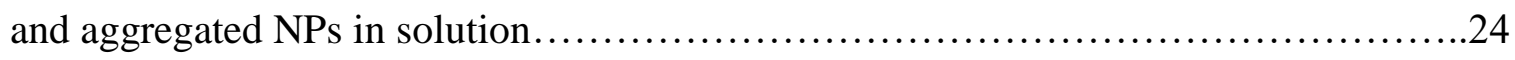

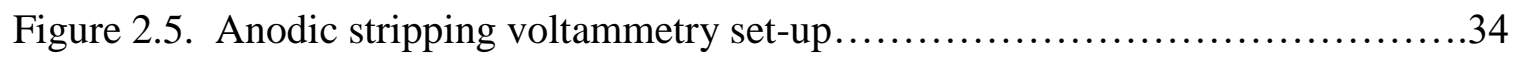

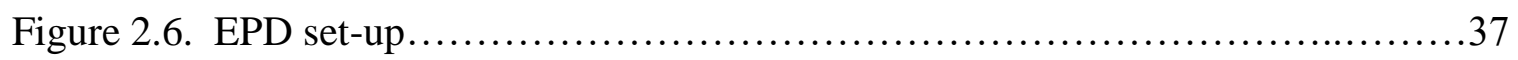

Figure 2.7. Electrochemistry of hydroquinone................................. 38

Figure 2.8. SEM images of $4 \mathrm{~nm}, 15 \mathrm{~nm}$, and $50 \mathrm{~nm}$ Au NPs........................

Figure 3.1. (A) Redox reaction of $\mathrm{HQ}$, (B) scheme of NP neutralization leading to destabilization and deposition onto the electrode, and (C) scheme of ITO protonation

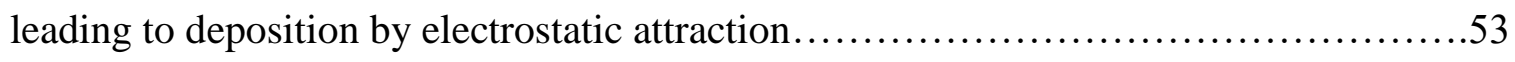


Figure 3.2. ASVs in $0.1 \mathrm{M} \mathrm{KClO}_{4}+0.01 \mathrm{M} \mathrm{KBr}$ of glass/ITO electrodes

following EPD in solutions of $20 \mathrm{~mL}$ water, $5 \mathrm{~mL} \mathrm{Au} \mathrm{NP} \mathrm{solution,}$

and $5 \mathrm{~mL}$ of either 0 M HQ (black), 0.001 M HQ (green), 0.01 M HQ (blue),

or $0.1 \mathrm{M}$ HQ (red). The EPD solution contained (A) $5 \mathrm{~mL}$ of $4 \mathrm{~nm}$ diameter

Au NPs, (B) $5 \mathrm{~mL}$ of $15 \mathrm{~nm}$ Au NPs, and (C) $2.5 \mathrm{~mL}$ of $4 \mathrm{~nm}$ Au NPs and

$2.5 \mathrm{~mL}$ of $15 \mathrm{~nm}$ Au NPs. The EPD was performed for 60 seconds at $1.0 \mathrm{~V}$

vs. $\mathrm{Ag} / \mathrm{AgCl}$ in all cases...................................................... 55

Figure 3.3. ASVs of glass/ITO electrodes in $0.1 \mathrm{M} \mathrm{KClO}_{4}+0.01 \mathrm{M} \mathrm{KBr}$ after EPD of $15 \mathrm{~nm} \mathrm{Au} \mathrm{NPs} \mathrm{at} 0.8 \mathrm{~V}$ for 300 seconds (black), $4 \mathrm{~nm}$ Au NPs at $0.8 \mathrm{~V}$ for 5 seconds, then $15 \mathrm{~nm}$ Au NPs at $0.8 \mathrm{~V}$ for 300 seconds (blue), and $4 \mathrm{~nm} \mathrm{Au}$ NPs at $0.8 \mathrm{~V}$ for 15 seconds, then $15 \mathrm{~nm} \mathrm{Au} \mathrm{NPs} \mathrm{at} 0.8 \mathrm{~V}$ for 300 seconds (red).......57

Figure 3.4. $\mathrm{ASVs}$ in $0.1 \mathrm{M} \mathrm{KClO}_{4}+0.01 \mathrm{M} \mathrm{KBr}$ of glass/ITO electrodes after EPD in solutions containing $20 \mathrm{~mL}$ water, $5 \mathrm{~mL}$ of $0.1 \mathrm{M} \mathrm{HQ}$, and (A) $5 \mathrm{~mL}$ of $4 \mathrm{~nm} \mathrm{Au} \mathrm{NPs,} \mathrm{(B)} 5 \mathrm{~mL}$ of $15 \mathrm{~nm}$ Au NPs, and (C) $2.5 \mathrm{~mL} 4 \mathrm{~nm}$ Au NPs plus $2.5 \mathrm{~mL} 15 \mathrm{~nm}$ Au NPs. The EPD was performed for 60 seconds at a potential of $0.2 \mathrm{~V}$ (black), $0.4 \mathrm{~V}$ (green), $0.6 \mathrm{~V}$ (pink), $0.8 \mathrm{~V}$ (blue), and $1.2 \mathrm{~V}$ (red) vs. an $\mathrm{Ag} / \mathrm{AgCl}$ reference electrode.

Figure 3.5. ASVs of glass/ITO electrodes in $0.1 \mathrm{M} \mathrm{KClO}_{4}+0.01 \mathrm{M} \mathrm{KBr}$ after EPD of (A) $4 \mathrm{~nm} \mathrm{Au} \mathrm{NPs,} \mathrm{and} \mathrm{(B)} 15 \mathrm{~nm}$ Au NPs at $1.0 \mathrm{~V}$ for 30 seconds (black), 60 seconds (green), 120 seconds (pink), 240 seconds (blue), and 480 seconds (red) using 0.1 M HQ.

Figure 3.6. CVs of glass/ITO (black), glass/ITO/Au NPs (4 nm) (blue), and glass/ITO/Au NPs (15 nm) (red) obtained in 0.005 M HQ and 0.1 $\mathrm{M} \mathrm{KClO}_{4}$ at a 
scan rate of $0.01 \mathrm{~V} / \mathrm{s}$

Figure 3.7. (A) ASVs in $0.1 \mathrm{M} \mathrm{KClO}_{4}+0.01 \mathrm{M} \mathrm{KBr}$ after EPD in $4 \mathrm{~nm}$ and $15 \mathrm{~nm}$ Au NPs solution held at $0.4 \mathrm{~V}$ for 1 min (black), 2 min (blue), and $5 \mathrm{~min}$ (red) with 0.1 M HQ. (B) A plot of Au stripping charge in Coulombs as a function of EPD time from the ASVs in (A) .64

Figure 3.8. ASVs in $0.1 \mathrm{M} \mathrm{KClO}_{4}+0.01 \mathrm{M} \mathrm{KBr}$ of glass/ITO electrodes following EPD in solutions of $5 \mathrm{~mL}$ Au NP solution, $5 \mathrm{~mL}$ of $0.1 \mathrm{M} \mathrm{HQ}$, and $20 \mathrm{~mL}$ of $0 \mathrm{M}$ $\mathrm{KClO}_{4}$ (red), $0.001 \mathrm{M} \mathrm{KClO}_{4}$ (blue), or $0.01 \mathrm{M} \mathrm{KClO}_{4}$ (black). The EPD solution contained (A) $5 \mathrm{~mL}$ of $4 \mathrm{~nm}$ diameter Au NPs, (B) $5 \mathrm{~mL}$ of $15 \mathrm{~nm} \mathrm{Au} \mathrm{NPs,} \mathrm{and}$ (C) $2.5 \mathrm{~mL}$ of $4 \mathrm{~nm} \mathrm{Au} \mathrm{NPs} \mathrm{and} 2.5 \mathrm{~mL}$ of $15 \mathrm{~nm} \mathrm{Au} \mathrm{NPs.} \mathrm{The} \mathrm{EPD} \mathrm{was} \mathrm{performed}$ for 60 seconds at $1.0 \mathrm{~V}$ vs. $\mathrm{Ag} / \mathrm{AgCl}$ in all cases .66 Figure 3.9. SEM images of glass/ITO after EPD of $15 \mathrm{~nm}$ Au NPs at $1.0 \mathrm{~V}$ using $5 \mathrm{~mL}$ of $0.1 \mathrm{M}$ HQ for (A) $30 \mathrm{~s}$, (B) $120 \mathrm{~s}$, (C) $240 \mathrm{~s}$, and (D) $480 \mathrm{~s}$ .68 Figure 3.10. Stripping charge from ASVs of glass/ITO obtained in $0.1 \mathrm{M}$ $\mathrm{KClO}_{4}+0.01 \mathrm{M} \mathrm{KBr}$ after EPD of $4 \mathrm{~nm} \mathrm{Au} \mathrm{NPs} \mathrm{(blue)} \mathrm{and} 15 \mathrm{~nm} \mathrm{Au} \mathrm{NPs} \mathrm{(red)}$ at $1.0 \mathrm{~V}$ using $0.1 \mathrm{M} \mathrm{HQ}$ and various EPD time

Figure 3.11. Scanning electron microscopy (SEM) image of glass/ITO after EPD of $4 \mathrm{~nm} \mathrm{Au} \mathrm{NPs} \mathrm{at} 1.0 \mathrm{~V}$ for 480 seconds using $0.1 \mathrm{M} \mathrm{HQ}$ .71 Figure 3.12. (A) SEM image of glass/ITO after EPD in $15 \mathrm{~nm}$ Au NPs at $1.6 \mathrm{~V}$ for 3 hours. (B) SEM image of the same sample as in (A) but magnified. (C) ASV of glass/ITO in $0.1 \mathrm{M} \mathrm{KClO}_{4}+0.01 \mathrm{M} \mathrm{KBr}$ after EPD of $15 \mathrm{~nm} \mathrm{Au} \mathrm{NPs} \mathrm{for} 3$ hours at $1.6 \mathrm{~V}$ with $0.1 \mathrm{M} \mathrm{HQ}$ (red) and without HQ (blue)...

Figure 3.13. ASVs of glass/ITO in $0.1 \mathrm{M} \mathrm{KClO}_{4}$ plus $0.01 \mathrm{M} \mathrm{KBr}$ after EPD 
of $4 \mathrm{~nm} \mathrm{Au} \mathrm{NPs} \mathrm{at} 1.0 \mathrm{~V}$ for 60 seconds using $5 \mathrm{~mL}$ of $0.01 \mathrm{M} \mathrm{HQ}$ (red) and at $1.0 \mathrm{~V}$ for 60 seconds using $5 \mathrm{~mL}$ of $0.02 \mathrm{M} \mathrm{K}_{4} \mathrm{Fe}(\mathrm{CN})_{6}$ (blue) ......................74

Figure 4.1. Scheme showing concept for the NP-assisted EPD. The top diagram shows just $15 \mathrm{~nm}$ Au NPs in the EPD solution and negligible deposition. The bottom diagram shows that with the addition of the $4 \mathrm{~nm}$ Au NPs in the EPD solution, deposition for the $15 \mathrm{~nm}$ Au NPs occurs under the same parameters. This concept is applied to all three NPs analyzed in this chapter: $15 \mathrm{~nm}$ Au NP, Pd NPs,

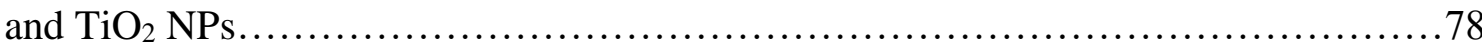
Figure 4.2. HQ voltammetry with $4 \mathrm{~nm}$ and $15 \mathrm{~nm}$ Au NPs on glass/ITO. CVs of glass/ITO/APTES/Au NPs ( $4 \mathrm{~nm}$ or $15 \mathrm{~nm}$ ) in $0.005 \mathrm{M} \mathrm{HQ}$ plus $0.1 \mathrm{M} \mathrm{KClO}_{4}$ scanned from $-0.1 \mathrm{~V}$ to $1.2 \mathrm{~V}$ and back

Figure 4.3. ASVs of the $15 \mathrm{~nm}$ Au NPs alone at $0.8 \mathrm{~V}$ for 5 minutes (orange), $4 \mathrm{~nm} \mathrm{Au} \mathrm{NPs} \mathrm{attached} \mathrm{first} \mathrm{for} 5$ seconds at $0.8 \mathrm{~V}$ and then $15 \mathrm{~nm}$ Au NPs at $0.8 \mathrm{~V}$ for 5 minutes (blue), and $4 \mathrm{~nm}$ Au NPs attached first for 15 seconds at $0.8 \mathrm{~V}$ and then $15 \mathrm{~nm}$ Au NPs at $0.8 \mathrm{~V}$ for 5 minutes (red). Scans were run in $10 \mathrm{mM}$ $\mathrm{KBr}$ and $0.1 \mathrm{M} \mathrm{KClO}_{4}$ at a scan rate of $0.01 \mathrm{~V} / \mathrm{s}$ on glass/ITO slides 84

Figure 4.4. Two-step EPD process. First step involves attaching the $4 \mathrm{~nm} \mathrm{Au}$ NPs to the WE. The second step involves placing the WE with $4 \mathrm{~nm}$ Au NPs into an EPD solution with $15 \mathrm{~nm}$ Au NPs to get the larger size NPs to attach under conditions that would normally not result in deposition .85

Figure 4.5. ASVs of $15 \mathrm{~nm}$ alone at $0.6 \mathrm{~V}$ for 5 minutes (pink), $250 \mu \mathrm{L}$ of $4 \mathrm{~nm}$ Au NPs and $4.75 \mathrm{~mL}$ of $15 \mathrm{~nm}$ Au NPs at $0.6 \mathrm{~V}$ for 5 minutes (red), $500 \mu \mathrm{L}$ of $4 \mathrm{~nm}$ Au NPs and $4.5 \mathrm{~mL}$ of $15 \mathrm{~nm} \mathrm{Au} \mathrm{NPs} \mathrm{at} 0.4 \mathrm{~V}$ for 5 minutes (orange), and $500 \mu \mathrm{L}$ 
of $4 \mathrm{~nm} \mathrm{Au} \mathrm{NPs} \mathrm{and} 4.5 \mathrm{~mL}$ of $15 \mathrm{~nm} \mathrm{Au} \mathrm{NPs} \mathrm{at} 0.6 \mathrm{~V}$ for 5 minutes (blue).

All scans were run in $10 \mathrm{mM} \mathrm{KBr}$ and $0.1 \mathrm{M} \mathrm{KClO}_{4}$ at a scan rate of $0.01 \mathrm{~V} / \mathrm{s}$ on

glass/ITO slides

Figure 4.6. CVs of glass/ITO/APTES/4nmAuNPs (red) and

glass/ITO/APTES/PdNPs in 0.005 M HQ plus $0.1 \mathrm{M} \mathrm{KClO}_{4}$ scanned

from $-0.1 \mathrm{~V}$ to $1.2 \mathrm{~V}$ and back. Controls were run with glass/ITO/APTES

(orange) and glass/ITO (pink)

Figure 4.7. ASVs of $4 \mathrm{~nm}$ Au NPs alone at $0.3 \mathrm{~V}$ for 2 minutes (green), and equal amounts of $4 \mathrm{~nm}$ Au NPs and Pd NPs at $0.25 \mathrm{~V}$ for 2 minutes (pink), $0.24 \mathrm{~V}$ for 5 minutes (orange), $0.23 \mathrm{~V}$ for 8 minutes (blue), and $0.3 \mathrm{~V}$ for 2 minutes (red).

All scans were run in $10 \mathrm{mM} \mathrm{KBr}$ and $0.1 \mathrm{M} \mathrm{HClO}_{4}$ at a scan rate of $0.01 \mathrm{~V} / \mathrm{s}$ on glass/ITO slides

Figure 4.8. ASVs taken after EPD at $0.3 \mathrm{~V}$ for 1 minute with Pd NPs (red plot) and Pd NPs plus $4 \mathrm{~nm}$ Au NPs (blue plot). Scans were run in $10 \mathrm{mM} \mathrm{KBr}$ and $0.1 \mathrm{M}$

$\mathrm{HClO}_{4}$ at a scan rate of $0.01 \mathrm{~V} / \mathrm{s}$ on glass/ITO slides.

Figure 4.9. ASVs taken after EPD at $0.3 \mathrm{~V}$ for 5 minutes with Pd NPs (red plot) and Pd NPs plus $4 \mathrm{~nm}$ Au NPs (blue plot). Scans were run in $10 \mathrm{mM} \mathrm{KBr}$ and $0.1 \mathrm{M} \mathrm{HClO}_{4}$ at a scan rate of $0.01 \mathrm{~V} / \mathrm{s}$ on glass/ITO slides. Figure 4.10. ASVs taken after EPD at $0.3 \mathrm{~V}$ for 10 minutes with Pd NPs (red plot) and Pd NPs plus $4 \mathrm{~nm} \mathrm{Au} \mathrm{NPs} \mathrm{(blue} \mathrm{plot).} \mathrm{Scans} \mathrm{were} \mathrm{run} \mathrm{in} 10 \mathrm{mM} \mathrm{KBr}$ and $0.1 \mathrm{M}$ $\mathrm{HClO}_{4}$ at a scan rate of $0.01 \mathrm{~V} / \mathrm{s}$ on glass/ITO slides.

Figure 4.11. UV-vis spectra of Pd NPs (black and green plots) and Pd NPs plus $4 \mathrm{~nm} \mathrm{Au} \mathrm{NPs} \mathrm{in} \mathrm{the} \mathrm{EPD} \mathrm{solution} \mathrm{(red} \mathrm{and} \mathrm{blue} \mathrm{plots)} \mathrm{after} 60$ seconds at $0.4 \mathrm{~V}$. .94 
Figure 5.1. Scheme of experimental design for size-selection by functionalization of the WE. The first step is the synthesis of NPs of varying sizes. Simultaneously, the glass/ITO substrate surface is functionalized with an organic molecule. Next, we attach the NPs to the functionalized electrode with the objective of selecting a specific size, and then, lastly, run an ASV or CV to correlate the oxidation peak to the specific size NP. .98 Figure 5.2. (A) APTES versus MPTMS functionalization on glass/ITO substrate and (B) Skeletal structural formulas of different organic compounds used as linkers on the glass/ITO substrate .100 Figure 5.3. $4 \mathrm{~nm}$ and $15 \mathrm{~nm}$ Au NPs held at $1.0 \mathrm{~V}$ for 60 seconds on bare (red), APTES (blue), and MPTMS (orange) 102 Figure 5.4. ASVs of $4 \mathrm{~nm}$ and $15 \mathrm{~nm} \mathrm{Au} \mathrm{NPs} \mathrm{at} 1.0 \mathrm{~V}$ for 60 seconds with bare glass/ITO (green), glass/ITO functionalized with MPTMS (pink), MPTES (orange), 3,3,3-Trifluoropropyl-trimethoxysilane (blue), and propyltrimethoxysilane (red) 103 Figure 6.1. General aggregation scheme showing the addition of acid which causes the NPs to aggregate in solution and on the glass/ITO/APTES electrode 109 Figure 6.2. ASVs of glass/ITO/APTES electrodes coated with 4 nm diameter citrate-coated $\mathrm{Au}$ NPs attached from solution at varying $\mathrm{pH}$ values (A), UV-vis spectra of $4 \mathrm{~nm}$ diameter Au NP solutions at same $\mathrm{pH}$ values (B), and SEM images of the glass/ITO/APTES electrode after being immersed in the $\mathrm{Au}$ NP solutions with the indicated $\mathrm{pH}(\mathrm{C}-\mathrm{E})$ 110 Figure 6.3. ASVs of glass/ITO/APTES electrodes coated with $15 \mathrm{~nm}$ diameter citrate-coated Au NPs attached from solution at varying $\mathrm{pH}$ values 
(A), UV-vis spectra of $15 \mathrm{~nm}$ diameter Au NP solutions at same $\mathrm{pH}$ values (B), and SEM images of the glass/ITO/APTES electrode after being immersed

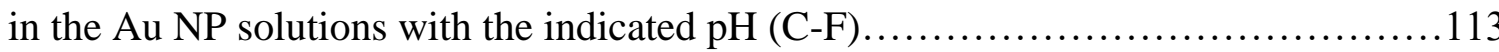
Figure 6.4. ASVs of glass/ITO/APTES electrodes coated with $50 \mathrm{~nm}$ diameter citrate-coated $\mathrm{Au}$ NPs attached from solution at varying $\mathrm{pH}$ values (A), UV-vis spectra of $50 \mathrm{~nm}$ diameter Au NP solutions at same $\mathrm{pH}$ values (B), and SEM images of the glass/ITO/APTES electrode after being immersed in the Au NP solutions with

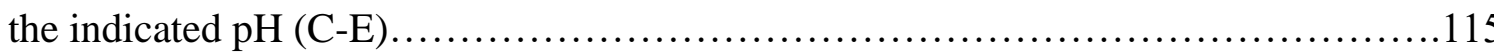




\section{CHAPTER 1: INTRODUCTION AND BACKGROUND}

\subsection{Main Goals and Summary}

The main goals of this research were to utilize anodic stripping voltammetry (ASV) to study size-controlled electrophoretic deposition (EPD) and the aggregationdependent oxidation properties of metal nanoparticles (NPs), particularly Au. Chapter 1 provides background information on size-dependent metal NPs oxidation, the use of ASV for metal NP characterization, EPD of metal NPs, and aggregation-based NP assays for sensing applications. Chapter 2 provides information on the synthesis of the metal NPs as well as the chemicals, substrates, and instrumentation used in this research. Chapter 3 discusses the mechanism of size-selective EPD of Au NPs mediated by hydroquinone (HQ) oxidation at different potentials. ${ }^{1}$ Chapter 4 describes an assisted EPD process that allows EPD of nanostructures at potentials where they normally will not deposit. Chapter 5 describes the size-selective EPD by functionalization of the working electrode with silane and polymer films, which act as filters. Chapter 6 shows that the oxidation potential of Au depends on their varying degrees of aggregation. ${ }^{2}$ And lastly, Chapter 7 summarizes the research and discusses potential future directions.

\subsection{Objectives and Motivation}

The first objective of this research was to fully understand the mechanism responsible for the size-controlled EPD of citrate-coated Au NPs and to utilize the mechanism to develop HQ-mediated EPD in order to control the size of NPs deposited by controlling the potential and electrode functionalization. To understand the mechanism, 
we compared EPD with a proton-generating molecule, hydroquinone (HQ), versus a nonproton-generating molecule, potassium ferrocyanide $\left(\mathrm{K}_{4} \mathrm{Fe}(\mathrm{CN})_{6}\right)$, to determine if protons were responsible for deposition. This research was inspired by previous work published by our group involving EPD of Au NPs in the presence of hydrogen peroxide. Based on that work, we extended our research to include HQ in order to confirm or disprove if protons were responsible for EPD and to better control the reproducibility of EPD. There are several possible EPD mechanisms as discussed later in this chapter. We continued the EPD research to include selective control over the metal NP deposition based on size. Our results showed that we are able to selectively deposit smaller Au NPs by controlling the EPD potential or electrode functionalization. In addition, EPD of nanostructures can occur at potentials not normally possible by incorporating $4 \mathrm{~nm}$ Au NPs into the EPD solution, which lowers the overpotential for HQ oxidation. We term this "Au NPassisted EPD."

The objective of the second project was to determine if the oxidation properties of metal NPs depend on changes in their state of aggregation. Early results on the ASV of Ag NPs from the Compton group showed no change in the oxidation potential for NPs down to $25 \mathrm{~nm}$ in diameter ${ }^{3}$ while our group showed size-dependent shifts. ${ }^{4} \mathrm{We}$ suspected that aggregation caused the discrepancy. By controllably causing the NPs to aggregate by controlled $\mathrm{pH}$, we were able to observe a clear positive shift in oxidation potential with different degrees of aggregation. ${ }^{2}$ These results may lead to chemical sensing applications by electrochemical detection (ASV) of the aggregation of Au NPs in the presence of the analyte.

\subsection{Importance of Metal Nanoparticle Research}


Metal nanoparticles have been extensively studied and used in various fields such as biology, chemistry, physics, medicine, and engineering due to their unique optical, magnetic, thermal, electronic, catalytic, and electrochemical properties. ${ }^{5}$ All of these properties depend on not only their size and shape, but the distance between particles and the protecting stabilizer used during synthesis. Nano is the scientific term meaning onebillionth, therefore, a nanometer is one-billionth of a meter. To illustrate the size in more applicable terms, a sheet of paper is 100,000 nanometers thick, the average fingernail grows one nanometer every second, and a single blink of the eye is one-billionth of a year. ${ }^{6}$ Nanoscale materials are of great scientific interest because they exhibit different properties compared to their bulk and, more importantly, the properties are size- and shape-tunable. ${ }^{7}$ For example, the melting temperature of metals decreases dramatically below a certain size and exhibits magnetism at nanoscale sizes. ${ }^{7}$ In terms of optical properties, Au is a highly reflective, yellow color in bulk form, but exhibits sizedependent plasmonic properties, which leads to its red-wine colored appearance in the 5 to $50 \mathrm{~nm}$ range. ${ }^{8}$ The oxidation potential of metal NPs depends on their size ${ }^{9-10}$ and aggregation state. ${ }^{11}$ Certain metal NPs interact with light differently through a process called localized surface plasmon resonance (LSPR), which is the excitation and oscillation of conduction electrons in resonance with the light frequency. ${ }^{12}$ Also, since catalysis happens on the surface of a particle, the smaller the particle is the more surface area it has and therefore the more catalytic the NP will usually be when normalized to the total amount. ${ }^{13}$ This is one motivation for using EPD to isolate NPs of small size onto electrodes. We feel they may find use in electrocatalysis applications.

\subsection{Metal Nanoparticle Oxidation}




\subsubsection{Size-Dependent Oxidation Based on Plieth Theory}

Previous work has been conducted on the size-dependent oxidation of metal NPs. Initially, Henglein discussed the dependence of the standard redox potential on particle size $^{14}$ and Plieth developed equations to describe the shift of the reversible redox potential of small metal particles with size to discuss their electrochemical properties. ${ }^{15}$ Henglein showed that although the $\mathrm{E}^{0}$ for bulk $\mathrm{Ag}$ is $0.799 \mathrm{~V}$, the $\mathrm{E}^{0}$ for a single $\mathrm{Ag}$ atom is $-1.8 \mathrm{~V}$. Plieth later derived an equation based on thermodynamics describing the shift in redox potential of small metal NPs relative to bulk size, predicting that it is proportional to the reciprocal radius (1/r). Commonly referred to as Plieth's theory, the following equation shows the relationship between the shift in oxidation potential and particle radius:

\section{$\Delta_{\mathrm{ED}}=-2 \gamma \mathrm{V}_{\mathrm{m}} / \mathrm{zFr}$}

Where $\triangle_{E D}$ is the shift in oxidation potential between the bulk metal and NPs of a particular size, $V$ is surface stress, $V_{m}$ is molar volume, $z$ is the number of electrons passed per oxidized atom, $F$ is Faraday's constant, and $r$ is NP radius. NPs smaller than $20 \mathrm{~nm}$ have the most dramatic change in oxidation potential. Once a radius of $20 \mathrm{~nm}$ is reached, the change in oxidation potential starts to plateau and very little change is observed as the NP gets larger.

The derivation of this equation starts with the equation:

$$
\Delta \epsilon_{\mathrm{D}}=\epsilon_{\mathrm{d}}-\epsilon_{\mathrm{b}}=-\Delta \mathrm{G}_{\mathrm{D}} / \mathrm{zF}
$$

where $\Delta \epsilon_{D}$ is the difference in equilibrium oxidation potentials between the metal dispersed as NPs $\left(\epsilon_{\mathrm{d}}\right)$ and the same amount of metal in the form of bulk metal $\left(\epsilon_{\mathrm{b}}\right)$. In 
order to calculate $\Delta \mathrm{G}_{\mathrm{D}}$, the change in free energy associated with change in the surface area going from bulk metal to smaller dispersed NPs must first be determined, which is given by the following equation:

$$
\mathrm{d} G=\mathrm{\gamma} \mathrm{d} A
$$

Here, $\mathrm{dG}$ is the change in free energy, $\mathrm{dA}$ is the change in surface area, and $\mathrm{V}$ is the surface stress, which is a constant for a particular metal. The change in surface area can be related to the change in radius of the NPs as follows:

$$
\mathrm{d} A=8 \pi r \mathrm{~d} r
$$

This equation is the first derivative of the equation for the surface area of a sphere, which is $A=4 \pi \mathrm{r}^{2}$, where $A$ is the surface area and $r$ is the radius. Next, we obtain an equation for the moles of metal (n) in terms of the volume of the metal NP considered as a sphere $\left(\mathrm{V}_{\mathrm{NP}}=(4 / 3) \pi \mathrm{r}^{3}\right)$ and the molar volume $\left(v_{M}\right)$ of the metal as follows:

$$
\begin{aligned}
& \mathrm{n}=\mathrm{V}_{\mathrm{NP}} / v_{\mathrm{M}} \\
& \mathrm{n}=(4 / 3) \pi \mathrm{r}^{3} / v_{\mathrm{M}} \\
& \mathrm{dn}=\left(4 \pi \mathrm{r}^{2} / v_{\mathrm{M}}\right) \mathrm{dr} \\
& \mathrm{dr}=\left(v_{\mathrm{M}} / 4 \pi \mathrm{r}^{2}\right) \mathrm{dn}
\end{aligned}
$$

Substituting equation (7) into equation (3) gives the following:

$$
\mathrm{d} A=\left(2 v_{\mathrm{M}} / \mathrm{r}\right) \mathrm{dn}
$$

Substituting equation (8) into equation (2) gives the following:

$$
\mathrm{dG}=\left(2 \gamma v_{\mathrm{M}} / \mathrm{r}\right) \mathrm{dn}
$$

Integrating between $n=0$ and $n=1$ gives the surface free energy of 1 mole of metal dispersed into NPs of radius $r$. If you neglect the surface free energy of the bulk metal, then you get the following equation: 


$$
\Delta \mathrm{G}_{\mathrm{D}}=\frac{2 \mathrm{yU}}{r}
$$

Now plugging equation (10) into equation (1), we get Plieth's equation:

$$
\Delta \epsilon_{\mathrm{D}}=-\frac{2 y \mathrm{U}_{\mathrm{M}}}{z F}\left(\frac{1}{r}\right)
$$

In summary, the negative shift in redox potential of small metal NPs compared to the redox potential of the bulk is proportional to the ratio of surface tension (or stress) to the radius $(\mathrm{V} / r)$. Figure 1.1 demonstrates this concept. It shows one large NP being broken down into several small size NPs with the total volume staying the same. As the NP size decreases, the oxidation potential shifts from that of bulk Au to a more negative value. Our group previously demonstrated this concept with different size Au NPs. Ivanova et al. measured the oxidation potential of five different size NPs and the oxidation potentials ranged from a little over $700 \mathrm{mV}$ for $4 \mathrm{~nm}$ Au NPs to $900 \mathrm{mV}$ for $23 \mathrm{~nm} \mathrm{Au} \mathrm{NPs} \mathrm{and} \mathrm{a}$ little over $900 \mathrm{mV}$ for $250 \mathrm{~nm} \mathrm{Au} \mathrm{NPs.}{ }^{16}$ The data showed that as the size of the NP increases, the potential at which it oxidizes also increases. The oxidation of Au occurred in $\mathrm{KBr}$ electrolyte solution and the potentials quoted were versus an $\mathrm{Ag} / \mathrm{AgCl}$ reference electrode.

\subsubsection{Size-Dependent Metal Nanoparticle Oxidation Experiments}

Brainina et al. discussed the theoretical study of metal NP oxidation, and their experiments showed that NPs oxidize at a potential that is less positive than the bulk metal. ${ }^{17}$ She was able to show that there is a strong correlation between the Gibbs surface energy and the NP radius. 

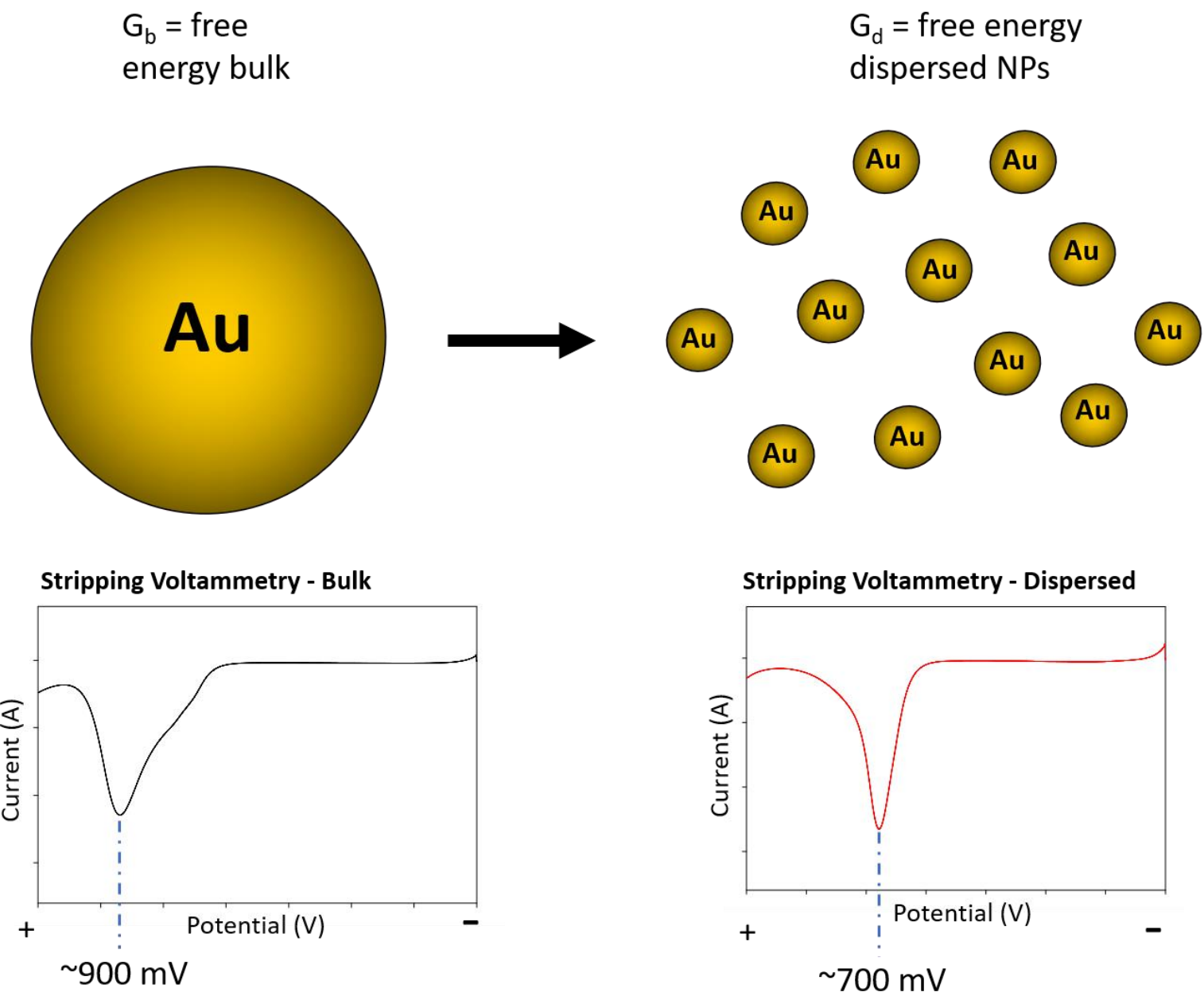

Stripping Voltammetry - Dispersed

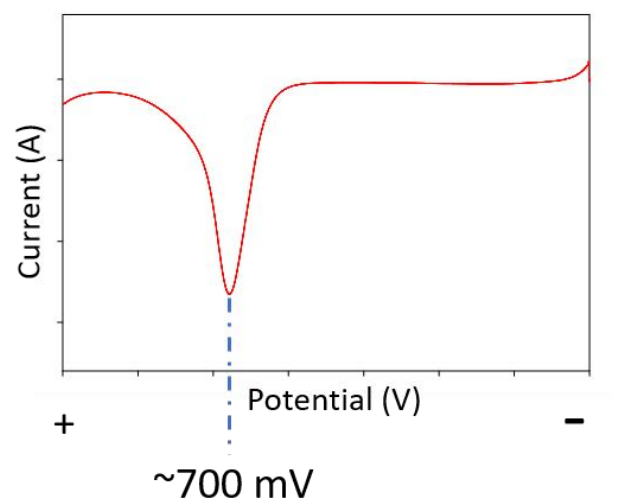

Figure 1.1. Change in redox potential based on size of the NP. One large NP is broken down into smaller size NPs and the resulting ASVs. As the NP gets smaller, the oxidation potential is more negative. The total volume is the same. 
Compton and co-workers analyzed Ag NPs and studied the electrochemical oxidation potentials of sizes ranging from 25 to $100 \mathrm{~nm}$ in diameter. ${ }^{18}$ They attached the Ag NPs to a basal plane pyrolytic graphite electrode in $0.1 \mathrm{M} \mathrm{NaClO}_{4}$ and found that the oxidation potentials did not show any dependence on the NP size. In another paper, their group studied a single crystal $\mathrm{Au}$ (111) electrode with hemispherical deposits of bismuth attached to it and analyzed the oxidation under electrochemically irreversible conditions. ${ }^{19}$ The results lead them to conclude that the difference in voltammetry is mainly due to the morphology and orientation of the bismuth deposits. These deposits resulted in a change of kinetics as well as the thermodynamics of the stripping process.

Brainina et al. also performed experiments to show how the substrate can affect the electrochemistry of metal NPs. ${ }^{20}$ Their group reported that the interaction between the metal and electrode will affect the NP oxidation resulting in a shift along the potential axis. Strong interactions resulted in a positive shift as compared to the bulk, whereas the electrooxidation of NPs localized on the inert electrode surface occurs at a lower potential as compared to the bulk metal. In other words, they showed that the electrooxidation peak of metal NPs is at a more negative (less positive) potential than that of bulk Au. ${ }^{17}$

Our group was the first to show size-dependent oxidation of $\mathrm{Ag}$ and $\mathrm{Au}$ by voltammetry. Ivanova and Zamborini described how the oxidation potential of Ag NPs is in direct correlation with the size of the NP. ${ }^{4}$ Their experimental linear sweep voltammograms (LSVs) matched fairly well with their theoretical ones showing that as the radius of the Ag NP decreased, so did its oxidation potential. ${ }^{4}$ Their other paper analyzed Au NPs attached to glass/ITO and showed that the oxidation potential of Au 
NPs shifted negative as the size of the NP decreased. ${ }^{16}$ They concluded that the oxidation of Au NPs is a combination of 1 and 3 electron processes. Also in support of this concept, Masitas et al. demonstrated that the oxidation potential of Au NPs with a diameter of 1-2 $\mathrm{nm}$ shifted $850 \mathrm{mV}$ negative relative to the oxidation potential of bulk $\mathrm{Au}^{21}$ These experiments are in agreement with the Plieth equation which states that the shift in the redox potential of a small metal nanoparticle is proportional to the reciprocal radius $(1 / \mathrm{r}){ }^{15}$ In other words, the smaller the size of the NP, the more negative its oxidation potential will be.

Other groups have studied the relationship between metal NP oxidation and size. For instance, Sieradzki and co-workers used scanning tunneling microscopy to show that Pt NPs are unstable between 1-3 nm in size as a function of applied potential. ${ }^{22-23}$ Buttry synthesized water-soluble Pd NPs and observed a size-dependent shift in oxidation potential for anodic dissolution of the Pd NPs. ${ }^{24}$ Their results were also in excellent agreement with the Plieth model, but for sizes less than $1 \mathrm{~nm}$, the Pd NPs shifted in a way that represented destabilization of the NP at the small of a size.

More recent work by our group involved synthesizing sub-2 $\mathrm{nm}$ Au NPs with a weak stabilizer attached, tetrakis(hydroxymethyl)phosphonium chloride (THPC). ${ }^{25}$ The results showed that the THPC $\mathrm{Au}_{2 \mathrm{~nm}}$ NPs oxidize at a potential about $250 \mathrm{mV}$ more negative than the citrate-coated $4 \mathrm{~nm}$ Au NPs. They also have a higher electrocatalytic activity toward $\mathrm{CO}_{2}$ reduction as compared to the $4 \mathrm{~nm}$ Au NPs. After repetitive oxidation and reduction cycles in acidic solution, the $4 \mathrm{~nm}$ Au NPs remained stable in size after 20 cycles, however, the THPC $\mathrm{Au}_{2 \mathrm{~nm}}$ NPs grew in size after just one cycle. The 
importance of this data shows the difference in reactivity and size stability between different size NPs.

The importance of the Plieth equation and these papers is that they show a clear relationship between size and oxidation potential, and this is significant because we can use that relationship of size-dependence to determine what size NPs are deposited using EPD. Our ultimate goal is to control the size of the NPs deposited by altering the EPD parameters. It would be easier to monitor the EPD process by ASV than by electron microscopy techniques.

\subsection{Aggregation of Metal NPs}

The aggregation of Au and Ag NPs has been heavily utilized for optical detection of many different types of molecules, especially biomolecules. ${ }^{26-27}$ The Au and Ag have different optical behavior in an aggregated state, which can be exploited for detection if an analyte of interest can selectively cause NP aggregation. ${ }^{28-29}$ Aggregation can also be undesirable for NPs, causing instability in solution and loss of their desirable properties, especially in catalysis. ${ }^{30-31}$ Aggregation also can occur in single NP collision studies without knowing, which makes it difficult to interpret the sometimes-complicated signals. ${ }^{32}$ Chapter 2 and Figure 2.4 discuss aggregation in more detail experimentally.

Several studies have focused on the aggregation of metal NPs from an optical and electrochemical point of view. For example, Huang et al. reported that when quadruplex DNA is attached to the surface of Au NPs, the NPs display a tendency to aggregate, and they used plasmon resonance light scattering (PRLS) and fluorescence emission to show the aggregation of the Au NPs. ${ }^{33}$ Hu et al. analyzed the aggregation of Ag NPs optically and electrochemically to detect biothiols. ${ }^{34}$ Biothiols such as cysteine, homocysteine, and 
glutathione induced aggregation on Ag NPs. The colorimetric change in the NP solution could be observed both optically with UV-vis spectroscopy and electrochemically with a decrease in electrochemical current due to the oxidation of the Ag NPs.

Rees et al. used anodic particle coulometry to observe and monitor the aggregation of Ag NPs and quantitatively measure clusters up to $150 \mathrm{~nm}$ in diameter. ${ }^{35}$ Ngamchuea et al. used chronoamperometry to estimate the degree of aggregation that occurred while immobilizing NPs onto an electrode surface. ${ }^{36}$ Experiments performed by Cloake et al. revealed incomplete stripping of Ag NPs with the introduction of melamine and aggregation. They synthesized dopamine-capped Ag NPs and added different concentrations of melamine to induce aggregation. They discovered that the oxidation peak area decreased as the aggregation of the NPs increased. They proposed that the incomplete stripping was due to either partial oxidation or inactivation mechanisms. ${ }^{37}$ Our group studied the effect of $\mathrm{pH}$ on the oxidation of $4 \mathrm{~nm}, 15 \mathrm{~nm}$, and $50 \mathrm{~nm}$ diameter citrate-stabilized Au NPs. The results indicated a correlation between the oxidation potential and aggregation state of Au NPs, depending on their size. Our study was unique because it monitored the shift in oxidation potential with aggregation state while other studies monitored the oxidation currents. As the smaller NPs began to aggregate, their oxidation potential became more positive. The sensitivity to aggregation increases as the size of the Au NP decreases. ${ }^{2}$ These results reiterate the concept of size-dependent oxidation potential of metal NPs as well as the theory developed by Plieth. Our results were also the first study to show a shift in peak oxidation potential with aggregation. This defies the idea that local NP curvature is responsible for the shift in oxidation potential. ${ }^{38}$ We show that the oxidation potential is actually more related to the total 
surface area-to-volume ratio (SA/V). These results also explain why previous papers did not observe a shift in oxidation potential for NPs below $40 \mathrm{~nm} .{ }^{18}$

\subsection{Electrophoretic Deposition}

\subsubsection{Electrophoretic Deposition History, Theory, and Amount Deposited}

EPD is a two-step process that involves the migration of NPs toward an electrode and the deposition of said NPs onto the surface. It can be used on any electrically conductive surface and has been widely used for painting processes, such as those used by the Ford Motor Company to coat automobiles. ${ }^{39}$ EPD was first discovered by the Russian scientist Ruess in 1808 when he noticed that applying an electric field caused clay particles in water to move. ${ }^{40}$ Not until the following century was EPD more commonly utilized. In 1933, it was used to deposit thoria particles onto a platinum cathode and in the 1980's Hamaker studied the EPD of ceramics. Today it is a favorable method for depositing NPs due to its high deposition rate, facile set-up, costeffectiveness, and high reproducibility. ${ }^{40}$

Although the basic phenomena of EPD is well-known and has been thoroughly studied, further research is being employed to understand the fundamental mechanisms of EPD and to optimize the working parameters. ${ }^{41}$ EPD is a two-step process with Figure 1.2 illustrating the migration and deposition steps. First, an externally applied electric field causes charged particles suspended in a liquid medium to migrate towards an oppositely charged electrode. This step is known as electrophoresis. The second step involves the deposition of the particles onto the electrode which forms a thin or thick film on the surface. The thickness of the film depends on certain parameters such as the concentration of particles in solution, the applied electric field, and time. ${ }^{41}$ 


\section{Electrophoretic Deposition}
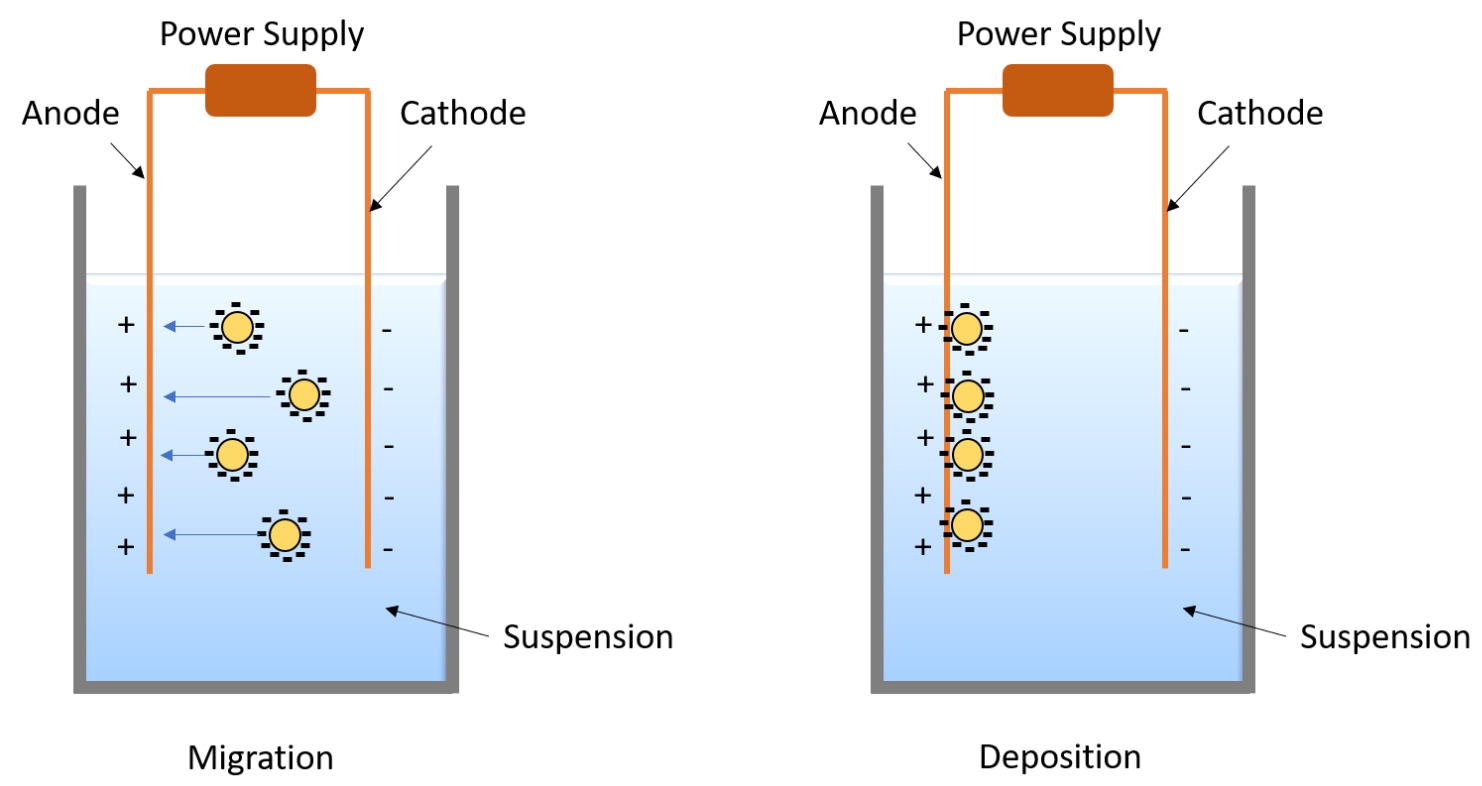

Figure 1.2. General scheme of electrophoretic deposition. Step 1 is the migration of NPs towards the WE, and step 2 is the deposition of NPs onto the electrode surface. 
Applications of EPD, especially with NPs, are continuously expanding but a full understanding of the interaction between the charged particles as they encounter each other as well as the electrode resulting in deposition is incomplete. On the other hand, the kinetic models regarding electrophoresis are well-known and understood. Hamaker provided the first model for describing the EPD process in $1940 .{ }^{42}$ He proposed the following general expression:$$
m=C_{s} \mu A E t
$$

Where $m$ is the mass per area unit $\left(\mathrm{g} \mathrm{cm}^{-2}\right)$ of deposited material, $C_{s}$ is the concentration of solids in the suspension $\left(\mathrm{g} \mathrm{cm}^{-3}\right), \mu$ is the electrophoretic mobility $\left(\mathrm{cm}^{2}\right.$ $\left.\mathrm{V}^{-1} \mathrm{~s}^{-1}\right), E$ is the electric field strength $\left(\mathrm{V} \mathrm{cm}^{-1}\right), A$ is the surface area of the electrode $\left(\mathrm{cm}^{2}\right)$, and $t$ is the deposition time (s). ${ }^{42}$

Other researchers continued to modify and build on Hamaker's first model. In 1996, Sarkar and Nicholson analyzed the dependence of kinetics on some of the experimental conditions. ${ }^{43}$ They considered the change in the particle concentration in the suspension with a longer deposition time, and started with the premise that the mass deposited by EPD is responsible for the change in concentration. Vandeperre and Van der Biest introduced a model that affirmed that the conductivity is attributed to both the particles and the ions surrounding the particles. ${ }^{44}$

\subsubsection{Electrophoretic Deposition Mechanisms}

As mentioned previously, the electrophoresis step is better understood as

compared to the deposition step of EPD. Electrophoresis occurs when charged particles in a bulk solution move towards an electrode in response to an applied electric field. If 
the particle suspension in the bulk and the particle suspension at the electrode are under the same solution conditions, then no deposition will occur because particles that are stable in the bulk will remain stable at the electrode surface, assuming there is no strong chemical attraction to the electrode. However, if changes occur at the electrode surface that cause the particles to become unstable as a suspension in solution, then they may deposit on the electrode surface. This is what is thought to occur during EPD. By comparing mechanisms for stabilizing particles in the bulk solution to changes in the suspension which can be induced at the electrode, one can deduce possible mechanisms for EPD. There are numerous possible mechanisms for the deposition of particles onto an electrode surface. The following sections describes some of the more common ones.

Ion Depletion Enhanced Electrostatic. The electrochemical depletion of one ion next to the electrode leads to a drop in the total ionic concentration, which in turn results in a rise in the voltage gradient. As long as the particles retain their surface charge, this is an excellent way to achieve very uniform, thin particulate layers. ${ }^{45}$

Salting Out. This mechanism is the opposite of the previous one and is shown in Figure 1.3. It was proposed by Koelmans and Overbeek for the deposition of $\mathrm{MgO} .{ }^{46}$ It results from an increase in ionic concentration at the electrode which thins out the electrostatic boundary layers on the particles causing them to become unstable and deposit. $^{45}$

Charge Reduction/Neutralization. Changing the $\mathrm{pH}$ or producing a strongly adsorbed ion could result in a change in the ionic composition of the solvent. This change leads to the reduction of the stabilizing surface charge on the particle. ${ }^{45}$ Figure 1.4 illustrates this example of how a modification in the EPD solution could cause the 


\section{Salting Out}

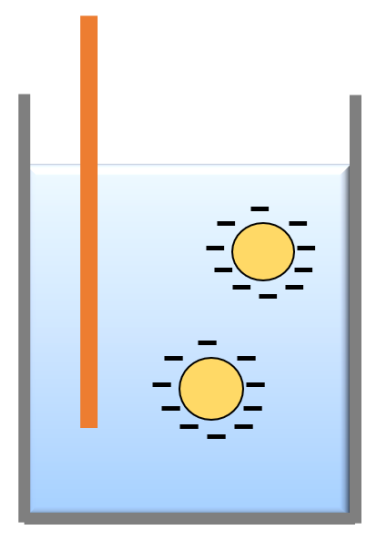

1). Negatively-charged NPs in EPD solution

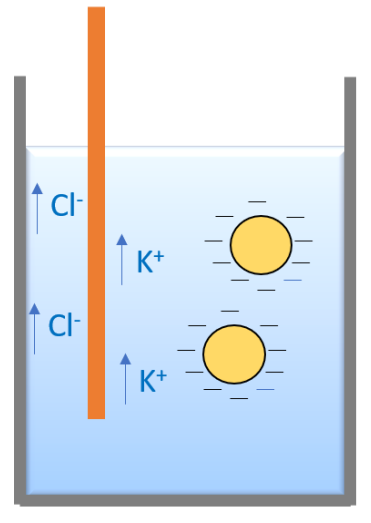

2). An increase in ionic concentration at the electrode surface thins out the electrostatic boundary layers on the NPs

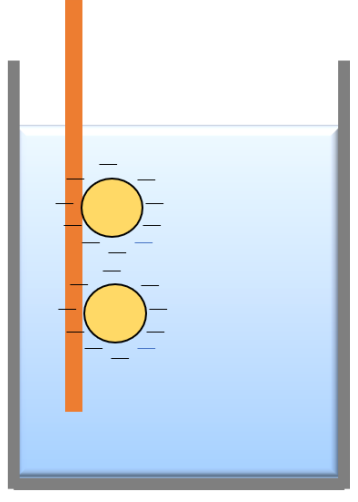

3). NPs become unstable and deposit onto the electrode surfac $\epsilon$

Figure 1.3. Possible EPD mechanism that involves an increase in the ionic concentration at the electrode. This thins out the boundary layers around the NPs causing them to become unstable and deposit onto the electrode surface. 


\section{Charge Reduction/Neutralization}

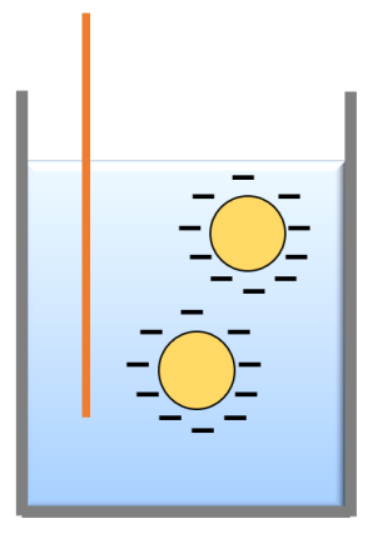

1). Negatively-charged NPS in EPD solution

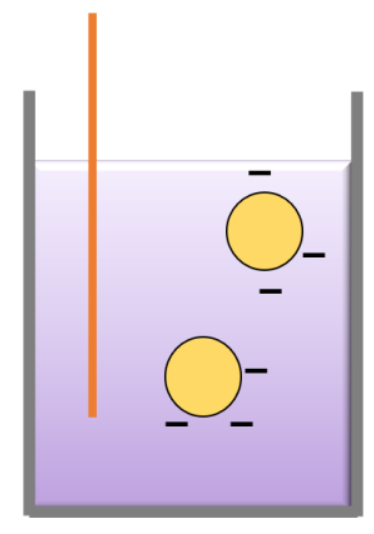

2). Change in the ionic composition of the EPD solution (e.g. change in $\mathrm{pH}$ ) results in reduction of the stabilizing surface charge

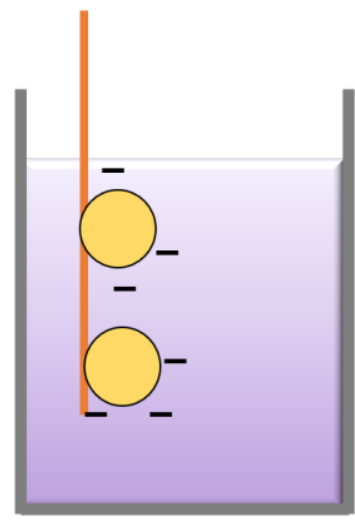

3). Destabilization of surface charge results in deposition onto the electrode surface

Figure 1.4. Possible EPD mechanism that involves a change in the ionic composition of the EPD solution which results in the destabilization of the surface charge around the NP leading to deposition. 
deposition of a negatively-charged NP by neutralizing the charge and destabilizing it in solution.

Desorption of Neutral/Charged Polymer. Changing the solvent ionic composition or concentration could alter the surface adsorption equilibrium on the particles causing desorption of stabilizing polymer molecules. ${ }^{45}$

Direct Electrostatic Force. This involves applying a potential high enough to overcome the interparticle electrostatic repulsion as shown in Figure 1.5. Since the NPs are negatively-charged, they want to repel each other which prevents them from sticking to the electrode surface with a high coverage. There will still be deposition onto the electrode but because the NPs stay a certain distance away from each other, only a certain amount can deposit without any interference from an external source. If a potential is applied to the electrode that is high enough to surpass that repulsion, it will lead to higher deposition of the NPs onto the surface. ${ }^{45}$

\subsubsection{Electrophoretic Deposition of Metal NPs}

While EPD has been used to deposit many different types of charged particles, the EPD of metal NPs is most relevant to the work in this dissertation. For example, Černohorský et al. used EPD to form Pt NP monolayers from nonpolar solvents. ${ }^{47}$ The technique allowed them to identify the mechanisms by which the NPs were incorporated into $2 \mathrm{D}$ and $3 \mathrm{D}$ films, which was determined by altering the amount of surfactant and applying a one-cycle or two-cycle centrifugation procedure. The deposition behavior they observed was characteristic of the layer-by-layer or Frank van der Merwe growth mechanism. Hollow $\mathrm{TiO}_{2}$ NPs formed a scattering layer for dye-sensitized solar cells 


\section{Direct Electrostatic Force}

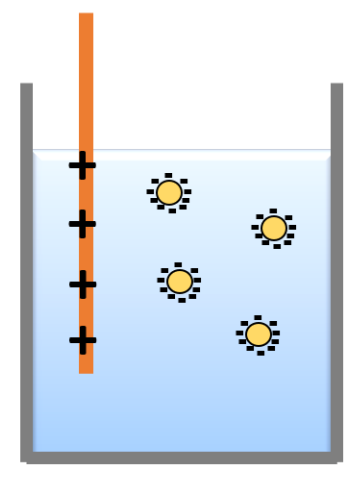

1). Negatively-charged NPs in EPD solution

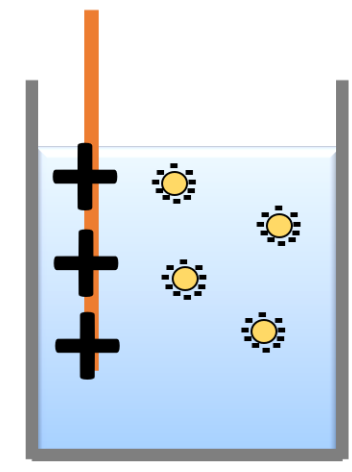

2). Applied potential is high enough to overcome the interparticle repulsion, thus driving the NPs to the electrode

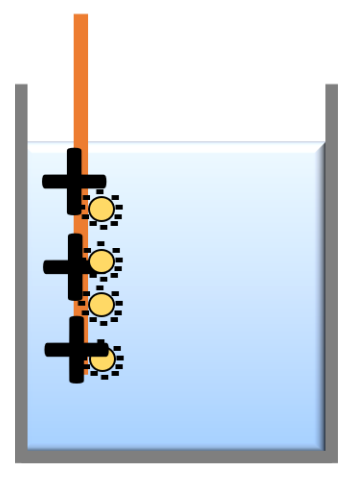

3). Increased deposition occurs due to higher potential

Figure 1.5. Possible EPD mechanism that occurs when an applied potential is high enough to overcome the interparticle repulsion of the NPs causing them deposit onto the electrode with a higher coverage. 
after EPD was applied to the colloidal solution. ${ }^{48}$ The use of EPD is of particular interest when it comes to solar cell fabrication because of the deposition of uniform films and thickness control on large surface area substrates. In fact, the creation of thin films via EPD is one of its more ubiquitous accomplishments. Bennett et al. used EPD to form thin films of hematite NPs on transparent conductive substrates. ${ }^{49}$ They then used atomic force and scanning electron microscopy to confirm the adherent, uniform, and crack-free deposits of the NPs and established a relationship between film thickness and deposition time at fixed voltages and particle concentrations.

The EPD of Au NPs has also been used for a variety of experiments. For example, Giersig and Mulvaney used EPD to prepare ordered two-dimensional (2D) gold colloid lattices onto carbon-coated copper grids for transmission electron microscopy (TEM). ${ }^{50-51}$ Leordean et al. used EPD to deposit Au NPs onto a digital virtual disk (DVD) template for SERS application. ${ }^{52}$ The positively charged DVD caused the negatively charged Au NPs to self-assemble onto the surface which in turn led to 10-fold additional enhancement of the Raman signal. They attributed the enhancement to the additional electromagnetic field created between the Au NPs and the DVD metallic film. Zhang et al. used Au-doped self-assembled NPs to decorate an electrode surface using EPD. ${ }^{53}$ This coating served as an electrochemical sensor for L-tryptophan. Zarazúa et al. used the EPD of Au NPs to enhance the performance of cadmium sulfide quantum dots (CdS QDs) sensitized $\mathrm{TiO}_{2}$ solar cells. ${ }^{54}$ The presence of Au NPs simultaneously reduced the photocurrent and increased the open circuit voltage and Fill Factor, which ultimately led to an increase of the photoconversion efficiency. 
The use of HQ with EPD was studied by Sakurada et al. when they deposited negatively-charged zirconia particles onto palladium substrates using an aqueous zirconia suspension and various concentrations of HQ. ${ }^{55}$ Their results showed that with a concentration of HQ less than $0.01 \mathrm{M}$, no deposition occurred due to a large number of bubbles generated on the electrode. However, with a HQ concentration greater than 0.05 M, a bubble-free deposition was observed for various times depending on the concentration of HQ (310, 1100, $2000 \mathrm{~s}$ for $0.05,0.1$, and $0.15 \mathrm{M} \mathrm{HQ}$, respectively). They concluded that HQ was an effective additive for EPD due to the bubble-free zirconia layers that were prepared from the basic zirconia suspensions. Chapter 3 describes our use of HQ for the size-selective EPD of citrate-stabilized Au NPs.

\subsection{Summary and Accomplishments}

Overall, this work utilizes ASV to study size-controlled EPD and the aggregationdependent oxidation properties of metal NPs. Our work has led to a better understanding of aggregation and curvature on the oxidation properties and the ability to measure NP size by ASV using the principles of Henglein ${ }^{56}$ and Plieth ${ }^{15}$ allowed us to study EPD mechanisms and develop methods for size-selective EPD of NPs using electrochemicallydriven NP neutralization. The ASV technique allows for high throughput analysis and the ability to try many different conditions and obtain good statistics. This would be very tedious if electron microscopy was exclusively used for size analysis and certain sizes would not be within the resolution of the SEM on an electrode surface. In addition, this dissertation focuses on the use of a proton-producing molecule (HQ) to cause NPs to deposit onto an electrode surface by neutralizing the negative charge around the NP. This neutralization is facilitated by the electrooxidation of HQ at the NP surface. 
The second focus of this dissertation is based on aggregation-dependent shifts in oxidation potentials. Our paper showed that the aggregation of NPs resulted in a more positive shift in the oxidation potential. The results indicated that there is excellent correlation between the oxidation potential and aggregation state of Au NPs, depending on their size. The sensitivity to aggregation increased as the size of the Au NPs decreased. Based on this data, we explored the possibility of using ASV to detect chemicals at a level too low for optical-based detection of aggregated NPs.

Our goals range from using EPD to decorate an electrode surface densely enough to create thin/thick films to being able to detect an analyte at levels more sensitive than optical measurements. 


\section{CHAPTER 2: EXPERIMENTAL METHODS}

Figure 2.1 shows the general scheme of the experiments performed for this dissertation. The main steps involved are (1) synthesis of metal nanoparticles (NPs), (2) attaching the NPs to the electrode surface, (3) performing electrochemical anodic stripping voltammetry (ASV), and (4) analyzing the ASV data. All of these steps will be described in detail in this chapter.

\subsection{Substrate}

Indium tin oxide (ITO) is a clear, conductive film that coats a glass slide which has a peak-to-peak surface roughness of $<0.2 \mu \mathrm{m} / 20 \mathrm{~mm} .{ }^{57}$ The slides used in all the experiments were purchased from Delta Technologies, LTD and were made of unpolished float (soda-lime) glass. The ITO coated one side of the glass $\left(\mathrm{SiO}_{2}\right)$ slide and had a resistance of 8-12 ohms. The ratio of indium (III) oxide $\left(\operatorname{In}_{2} \mathrm{O}_{3}\right)$ to tin (IV) oxide $\left(\mathrm{SnO}_{2}\right)$ is usually $90: 10$ by weight. Its electrical conductivity and optical transparency make glass/ITO slides desirable for electrochemical experiments. The glass/ITO slides were cut using a diamond pen into a rectangular shape $25 \mathrm{~mm}$ in length and $7 \mathrm{~mm}$ in width. Once cut, the slides were sonicated in a progressive order of acetone, ethanol, and 2-propanol each for 20 minutes. After sonication was complete, the slides were placed in a vial and then filled with 2-propanol until used.

\subsection{Solution}

Aqua regia solution is a mixture of hydrochloric acid $(\mathrm{HCl})$ and nitric acid $\left(\mathrm{HNO}_{3}\right)$ in a 3:1 ratio, respectively. It is used to dissolve any metal impurities present 


\section{Step 1: NP Synthesis}

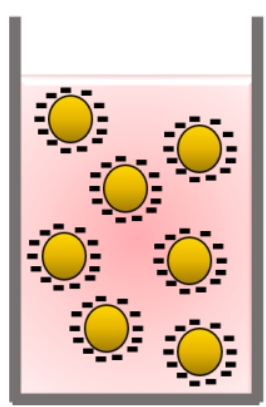

$4 \mathbf{~ n m ~ A u ~ N P ~ S y n t h e s i s : ~} 18.5 \mathrm{~mL}$ water $+0.5 \mathrm{~mL} 0.01 \mathrm{M}$ TRIS + $0.5 \mathrm{~mL} 0.01 \mathrm{M}$ $\mathrm{HAuCl}_{4}+0.6 \mathrm{~mL} 0.1 \mathrm{M} \mathrm{NaBH}_{4}$

\section{Step 2: Attachment to Electrode}

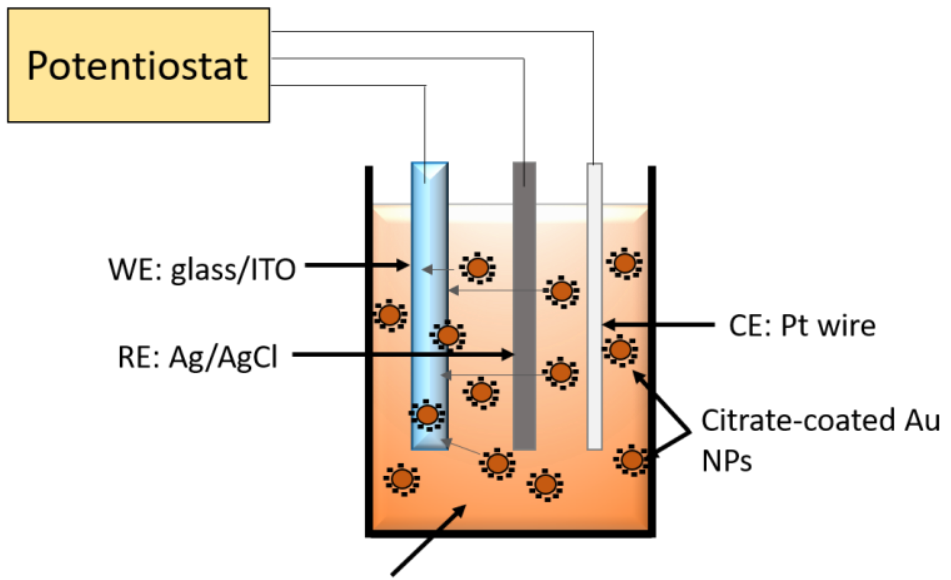

- EPD solution: $20 \mathrm{~mL}$ nanopore water $+5 \mathrm{~mL} 0.1 \mathrm{M} \mathrm{HQ}+5 \mathrm{~mL}$ Au NPs

- Various potentials are applied for a certain amount of time (e.g. $1.0 \mathrm{~V}$ for $60 \mathrm{~s}$ )

\section{Step 3: Performing ASV}

Step 4: Analysis of ASV

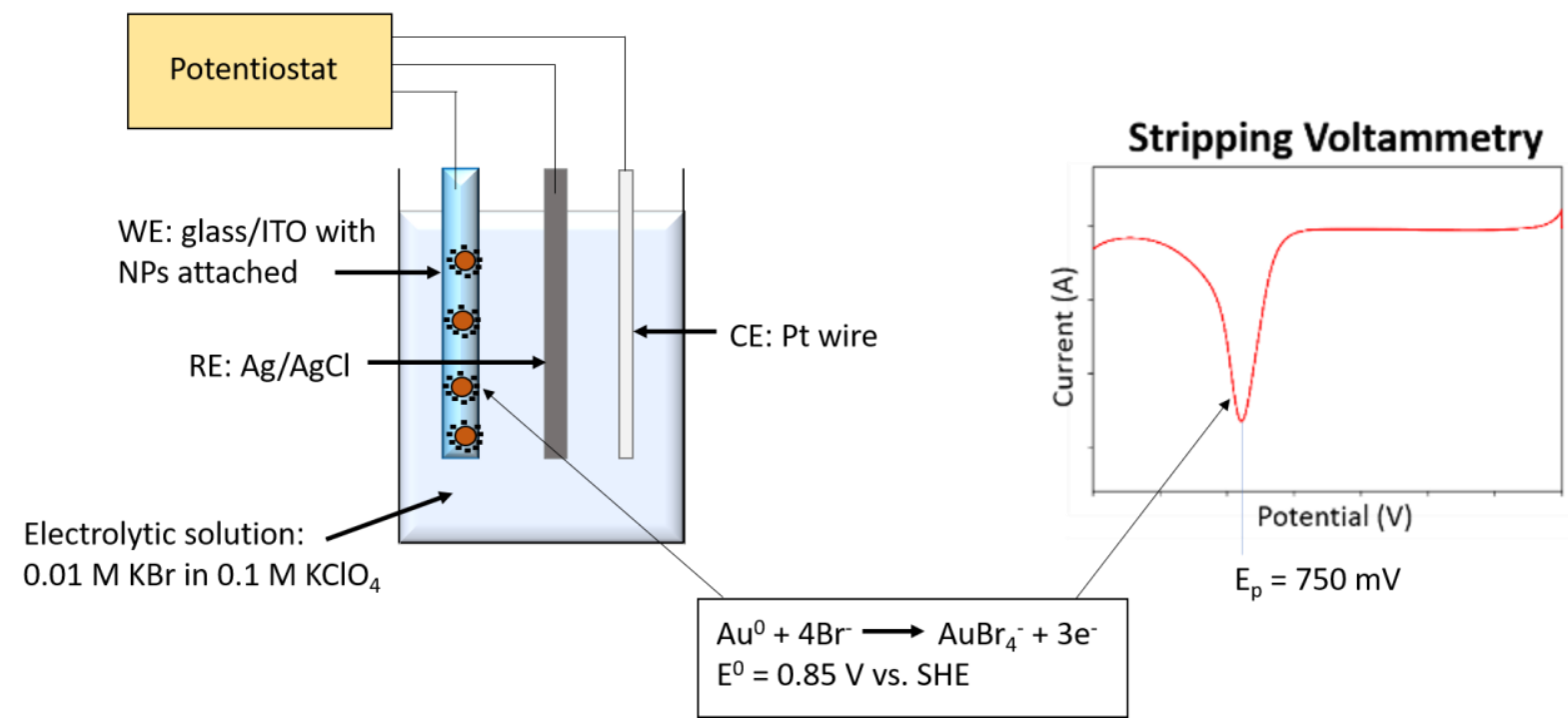

Figure 2.1. General scheme of electrochemistry experiments. Step 1 is the NP synthesis. Step 2 is the attachment of NPs to the WE through EPD. Step 3 is performing the ASV. Step 4 is the analysis of the ASV. 
from the glassware and stir bars used in the experiments. The solution is prepared ahead of time and then poured into the used glassware. After about 30 minutes of soaking, the aqua regia is then poured back into the original preparation bottle and the used glassware is rinsed with deionized water from a squirt bottle. After which, the glassware/stir bars were taken to the sink and washed with detergent and DI water and then left to air dry. All operations (excluding the washing with detergent) were performed in the fume hood.

\subsection{Synthesis Methods}

\subsubsection{Chemical Synthesis of $4 \mathrm{~nm}$ Average Diameter Citrate-Stabilized Au}

Nanoparticles. Solutions of $4 \mathrm{~nm}$ diameter Au NPs were synthesized using the method developed by Murphy and co-workers. ${ }^{58}$ It starts with adding $0.5 \mathrm{~mL}$ of $0.01 \mathrm{M}$ trisodium citrate salt and $0.5 \mathrm{~mL}$ of $0.01 \mathrm{M} \mathrm{HAuCl}_{4} \cdot 3 \mathrm{H}_{2}$ Oto $18.5 \mathrm{~mL}$ of nanopure water. Then, $0.6 \mathrm{~mL}$ of ice-cold $0.1 \mathrm{M}$ sodium borohydride $\left(\mathrm{NaBH}_{4}\right)$ was added to the solution and continued to stir for 2 hours. The solution color is initially orange immediately after the addition of $\mathrm{NaBH}_{4}$ which serves as the reducing agent, thus indicating the creation of smaller sized NPs. Fast reduction leads to many nuclei in solution and smaller NPs. After two hours of stirring, the color changes to a red color, representative of $4 \mathrm{~nm}$ sized NPs. The citrate serves as the capping agent which produces a negative charge around the NPs, thus stabilizing them through electrostatic repulsion, which prevents the NPs from aggregating. The final concentration of Au in the $4 \mathrm{~nm}$ Au NPs is $0.25 \mathrm{mM}$. The hydrogen tetrachloroaureate trihydrate $\left(\mathrm{HAuCl}_{4} \bullet 3 \mathrm{H}_{2} \mathrm{O}\right)$ was synthesized in our lab following the procedure described by B.P. Block. ${ }^{59}$ The trisodium citrate and sodium borohydride were used as purchased from Bio-Rad Laboratories and Sigma-Aldrich, respectively. 


\subsubsection{Chemical Synthesis of 15 nm Average Diameter Citrate-Stabilized Au}

Nanoparticles. This synthesis utilized a revised version of the Turkevich method. ${ }^{60}$

First, $0.500 \mathrm{~mL}$ of $0.01 \mathrm{M} \mathrm{HAuCl}_{4} \cdot 3 \mathrm{H}_{2} \mathrm{O}$ was added to $17.0 \mathrm{~mL}$ of nanopure water and heated to a rapid boil. Once the solution came to a full boil, then $2.5 \mathrm{~mL}$ of $0.01 \mathrm{M}$ citric acid, trisodium salt solution was added and the solution continued to stir for 10 minutes before being removed from the hotplate and allowed to cool. For this synthesis, the citrate is both the stabilizer and reducing agent. Citrate is a weaker reducing agent as compared to sodium borohydride, which leads to slow reduction and the need for boiling. Slow reduction leads to fewer nucleation sites and larger size NPs. The solution turns a bright red color indicating the formation of $15 \mathrm{~nm}$ Au NPs with a final Au concentration of $0.25 \mathrm{mM}$. This recipe includes the same chemicals as the $4 \mathrm{~nm} \mathrm{Au} \mathrm{NPs} \mathrm{with} \mathrm{the}$ exception of no $\mathrm{NaBH}_{4}$. The absence of a strong reducing agent results in the synthesis of a larger size NP.

\subsubsection{Chemical Synthesis of $50 \mathrm{~nm}$ Average Diameter Citrate-Stabilized Au}

Nanoparticles. The synthesis of $50 \mathrm{~nm}$ Au NPs involves a seed-mediated growth process adopted from Wang and co-workers. ${ }^{61}$ First, $0.500 \mathrm{~mL}$ of $0.01 \mathrm{M} \mathrm{HAuCl}_{4} \cdot 3 \mathrm{H}_{2} \mathrm{O}$ and $1.0 \mathrm{~mL}$ of $0.01 \mathrm{M}$ trisodium citrate were added to $18.0 \mathrm{~mL}$ of $30 \mathrm{wt} \% \mathrm{H}_{2} \mathrm{O}_{2}$ while stirring. Then, $0.500 \mathrm{~mL}$ of the as-prepared $15 \mathrm{~nm} \mathrm{Au} \mathrm{NPs} \mathrm{was} \mathrm{added.} \mathrm{The} \mathrm{solution} \mathrm{color}$ turned to a pink-purple color, indicating the formation of larger Au NPs. The hydrogen peroxide is a weak reducing agent but does not require boiling or heating to reduce $\mathrm{HAuCl}_{4} \cdot 3 \mathrm{H}_{2} \mathrm{O}$ because the reduction is catalyzed by the existence of $15 \mathrm{~nm} \mathrm{Au}$ seed NPs.

Figures 2.2-2.3 show the synthesis steps for three sizes of NPs along with corresponding UV-vis spectra, ASV, and SEM images. The UV-vis spectra in Figure 


\section{$4 \mathrm{~nm}$ Au NP}

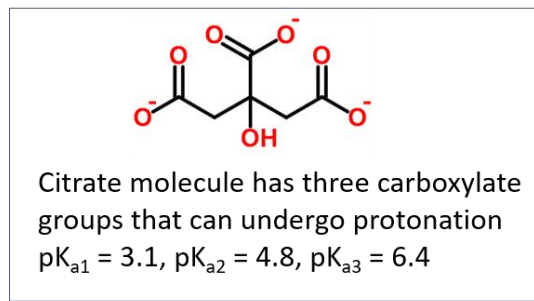

- $19.5 \mathrm{~mL}$ Nanopure water + 0.5 mL 0.01 M TRIS + 0.5 mL 0.01 M HAuCl $4+0.6 \mathrm{~mL} \mathrm{NaBH}_{4}$

- Let stir for two hours - red color indicates formation of $4 \mathrm{~nm}$ Au NPs

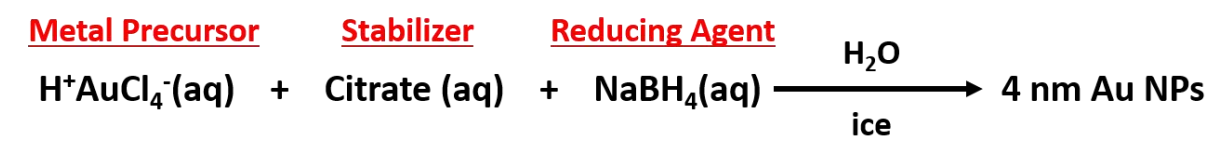

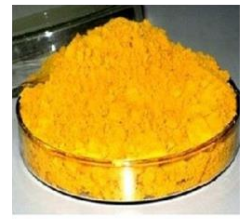

$\mathrm{HAuCl}_{4}$

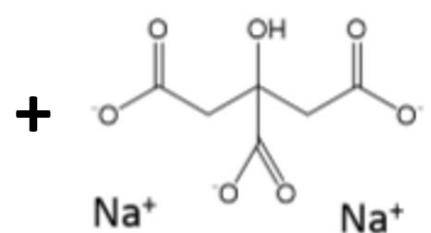

$\mathrm{Na}^{+}$

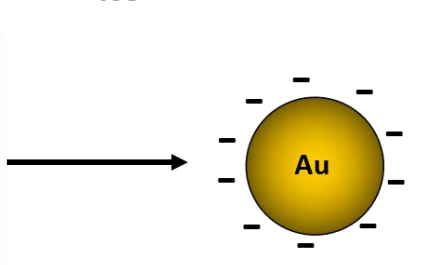

\section{$15 \mathrm{~nm} \mathrm{Au} \mathrm{NP}$}

- $17 \mathrm{~mL}$ Nanopure water $+0.5 \mathrm{~mL} 0.01 \mathrm{M} \mathrm{HAuCl}_{4}$ - bring to a rolling boil - then add $2.5 \mathrm{~mL} 0.01 \mathrm{M}$ TRIS

- Continue to stir on hot plate for 10 minutes - bright red color indicates formation of $15 \mathrm{~nm}$ Au NPs

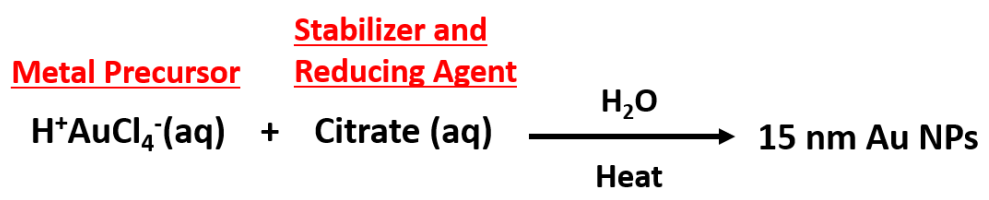

\section{$50 \mathrm{~nm}$ Au NP}

- $18 \mathrm{~mL}$ hydrogen peroxide $+0.5 \mathrm{~mL} 0.01 \mathrm{M} \mathrm{HAuCl}_{4}+1.0 \mathrm{~mL} 0.01 \mathrm{M} \mathrm{TRIS}+0.5 \mathrm{~mL}$ as-prepared $15 \mathrm{~nm} \mathrm{Au}$ NP seed solution

- Continue to stir - pink/purple color indicates formation of $50 \mathrm{~nm}$ Au NPs

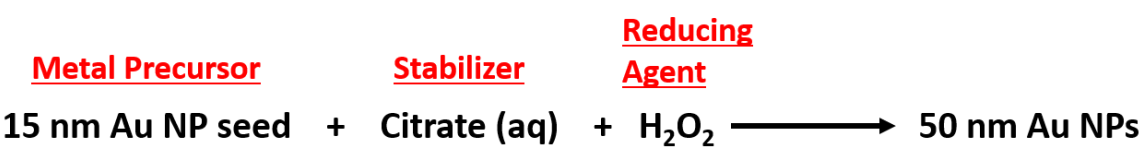

Figure 2.2. Synthesis of $4 \mathrm{~nm}, 15 \mathrm{~nm}$, and $50 \mathrm{~nm}$ Au NPs. The $4 \mathrm{~nm}$ Au NP synthesis is adopted from Murphy et al., the $15 \mathrm{~nm}$ Au NP synthesis is a revised version of the Turkevich method, and the $50 \mathrm{~nm}$ Au NP synthesis was adopted from Wang et al. 

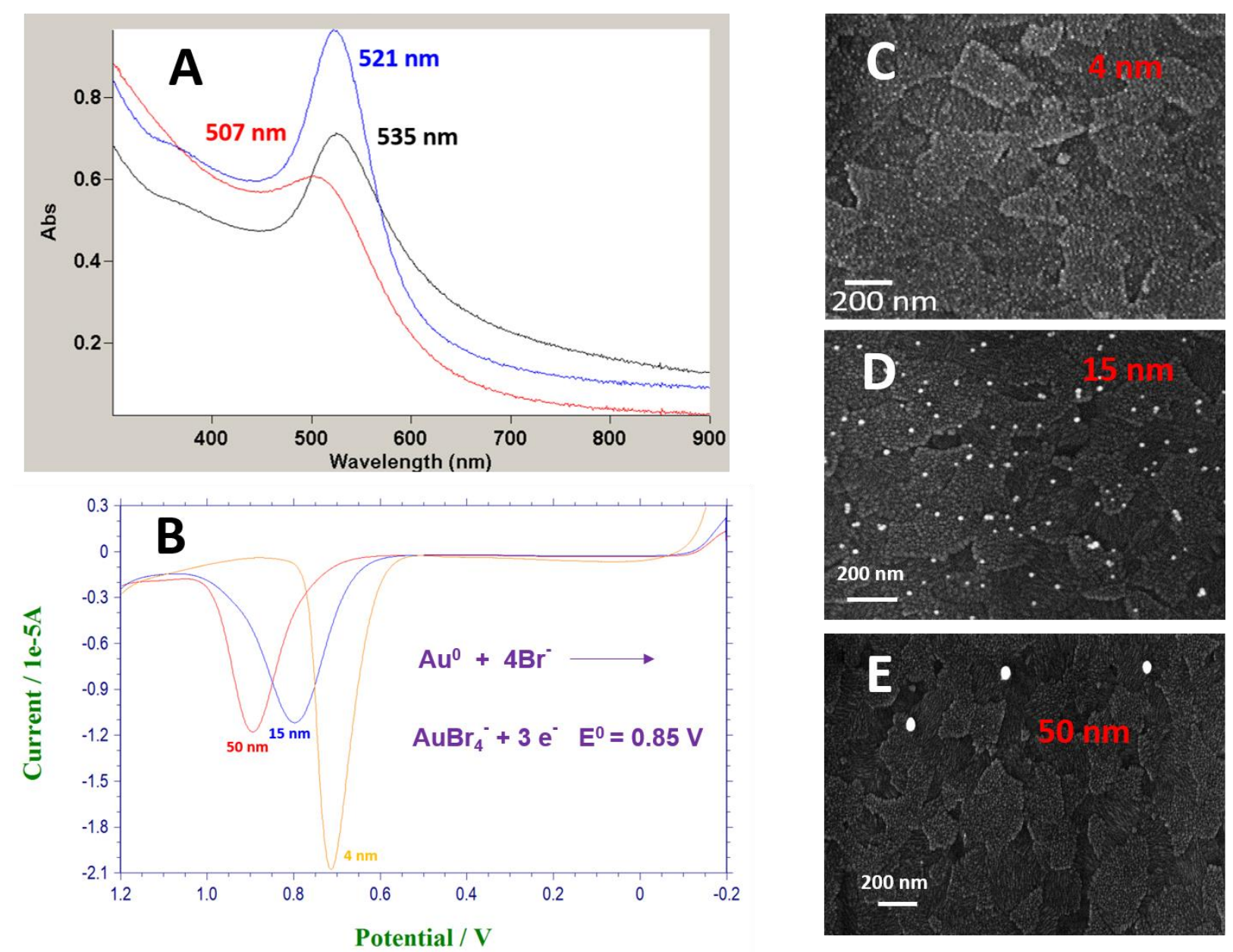

Figure 2.3. (A) shows the UV-vis spectra of the three different size Au NPs: $4 \mathrm{~nm}$ at $507 \mathrm{~nm}$ (red plot), $15 \mathrm{~nm}$ at $521 \mathrm{~nm}$, and $50 \mathrm{~nm}$ Au NPs at $535 \mathrm{~nm}$ (black plot). (B) is the ASV data and (C) is the SEM images of the same sizes. 
2.3A shows the absorbance for $4 \mathrm{~nm}$ (red plot), $15 \mathrm{~nm}$ (blue plot), and $50 \mathrm{~nm}$ (black plot) at 507, 521, $535 \mathrm{~nm}$, respectively. As the size of the NP increases, the absorbance band red shifts to a more positive value. Figure 2.3B is an overlay of ASVs for all three size NPs. The orange plot is of $4 \mathrm{~nm}$, the blue plot is of $15 \mathrm{~nm}$, and the red plot is $50 \mathrm{~nm} \mathrm{Au}$ NPs, and their respective oxidation potentials are $\sim 720,800$, and $900 \mathrm{mV}$. Figure 2.3C-E are the SEM images of the $4 \mathrm{~nm}, 15 \mathrm{~nm}$, and $50 \mathrm{~nm}$ Au NPs and show the different sizes on a glass/ITO substrate.

\subsubsection{Functionalization of Glass/ITO with Aminopropyltriethoxysilane}

(APTES). Indium-tin-oxide (ITO)-coated glass slides were sonicated in acetone, ethyl alcohol, and 2-propanol in that order with a final drying under nitrogen. Then the slides were heated at $90{ }^{\circ} \mathrm{C}$ for thirty minutes in a solution consisting of $10 \mathrm{~mL}$ of 2-propanol, $100 \mu \mathrm{L}$ of APTES, and about 3 drops of nanopure water. After heating, the slides were rinsed with 2-propanol and dried with nitrogen. This procedure leads to binding of APTES to glass/ITO through a covalent siloxane bond. The resulting glass/ITO/APTES is functionalized with terminal amine groups that can electrostatically attract citratestabilized Au NPs.

2.3.5. Preparation of Aggregated Au Nanoparticles at Low pH. The $\mathrm{pH}$ of the different Au NP solutions was lowered by adding $10.0 \mu \mathrm{L}$ of different concentrations of perchloric acid ( $8 \mathrm{M}, 6 \mathrm{M}, 5 \mathrm{M}, 4 \mathrm{M}, 3 \mathrm{M}, 2 \mathrm{M}$, or $1 \mathrm{M}$ ) to $10 \mathrm{~mL}$ of the particular size Au NPs. Figure 2.4 illustrates the mechanism by which aggregation occurs. The citrate ligand surrounding the NP has $-\mathrm{COO}^{-}$groups initially, but as acid is added to the NP solution and the $\mathrm{pH}$ drops, those $-\mathrm{COO}^{-}$groups become $-\mathrm{COOH}$ and what was once wellseparated NPs become aggregated NPs. The table in Figure 2.4A shows the initial and 


\section{A}

\section{Au NP size $(\mathrm{nm}) \quad$ Initial pH value $\quad$ Final pH value}

4

15

50
8.71

5.94

3.68
2.47

2.41

1.45

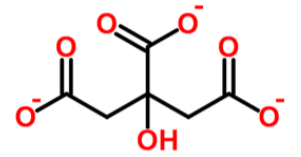

Citrate molecule has three carboxylate groups that can undergo protonation $\mathrm{pK}_{\mathrm{a} 1}=3.1, \mathrm{pK}_{\mathrm{a} 2}=4.8, \mathrm{pK}_{\mathrm{a} 3}=6.4$

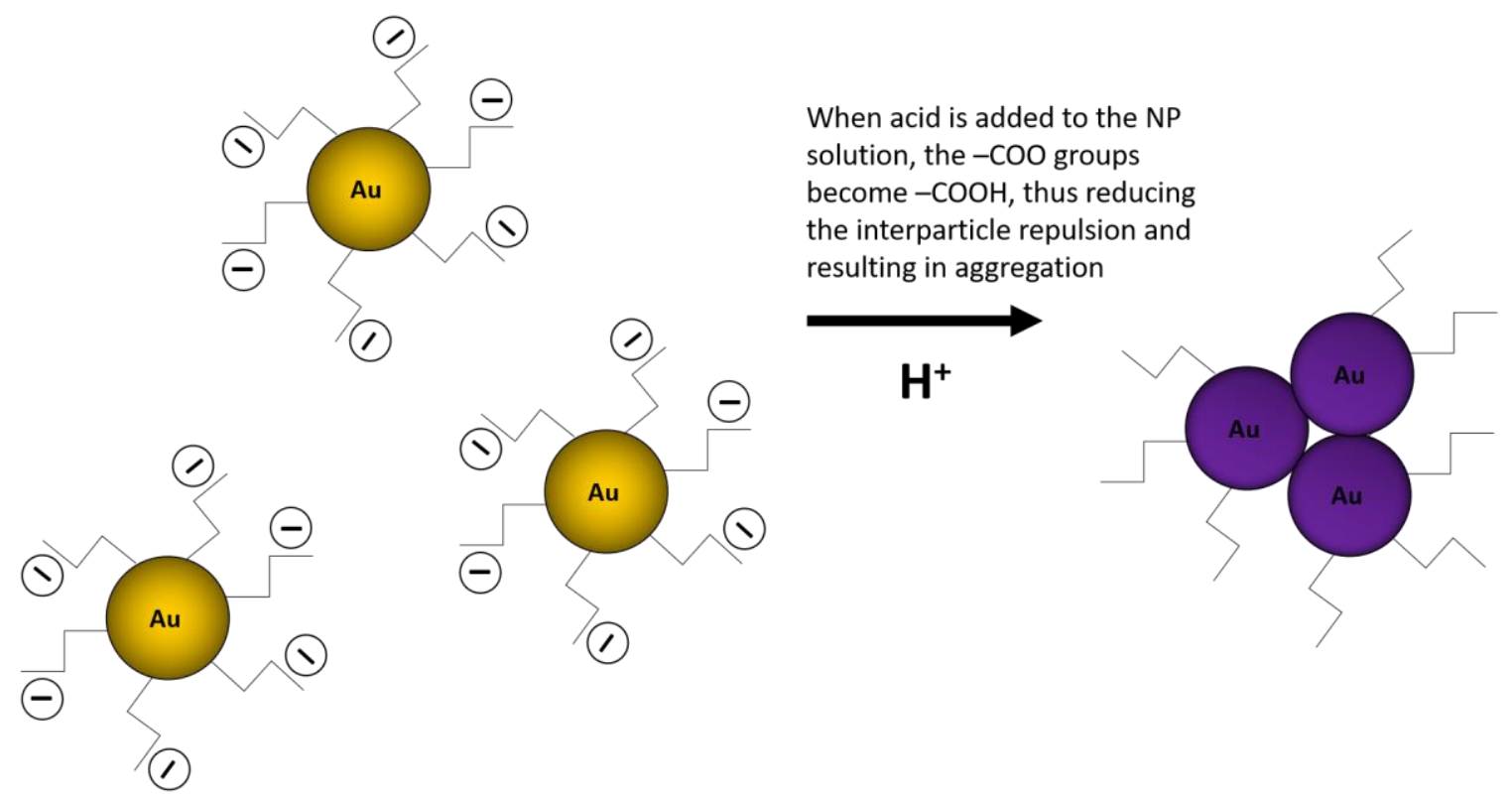

Figure 2.4. (A) Table representing the initial and final $\mathrm{pH}$ values of the $4 \mathrm{~nm}, 15 \mathrm{~nm}$, and $50 \mathrm{~nm}$ Au NPs before and after addition of $\mathrm{HClO}_{4}$ and overall scheme showing how aggregation occurs through the protonation of the carboxylate groups of the citrate molecule. 


\section{2-3 minutes}

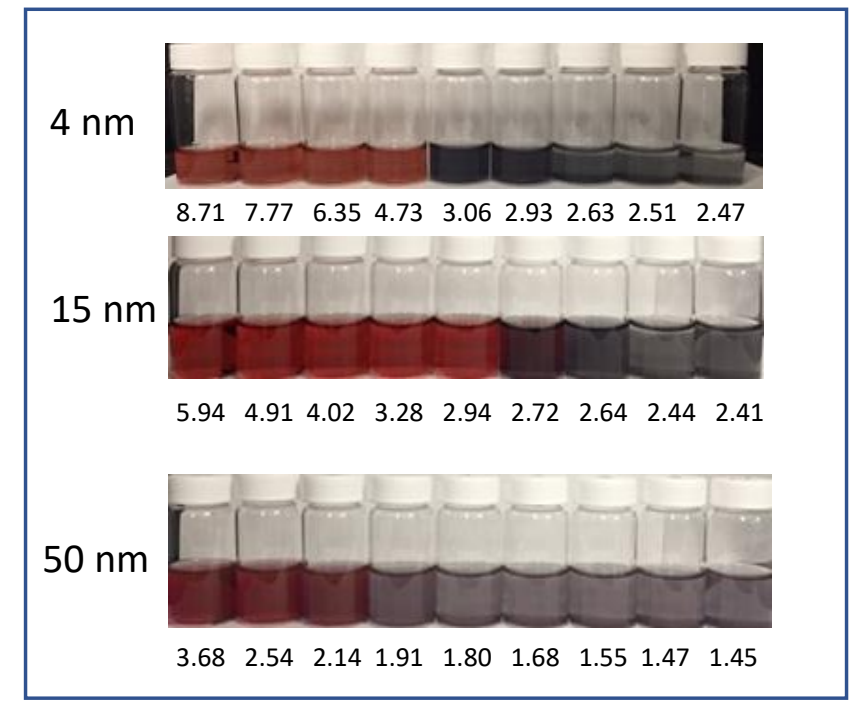

\section{1 hour}

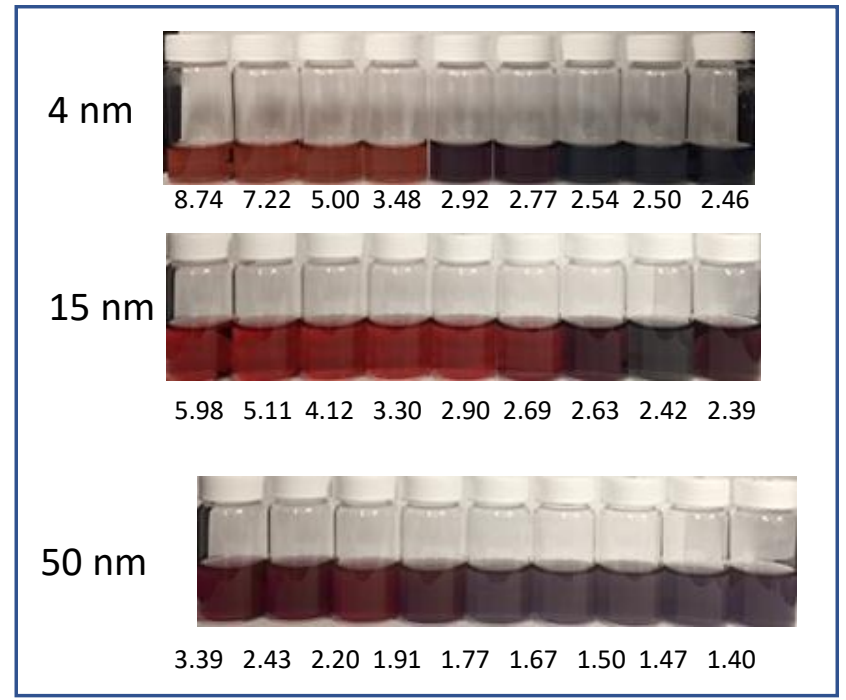




\section{4 hours}

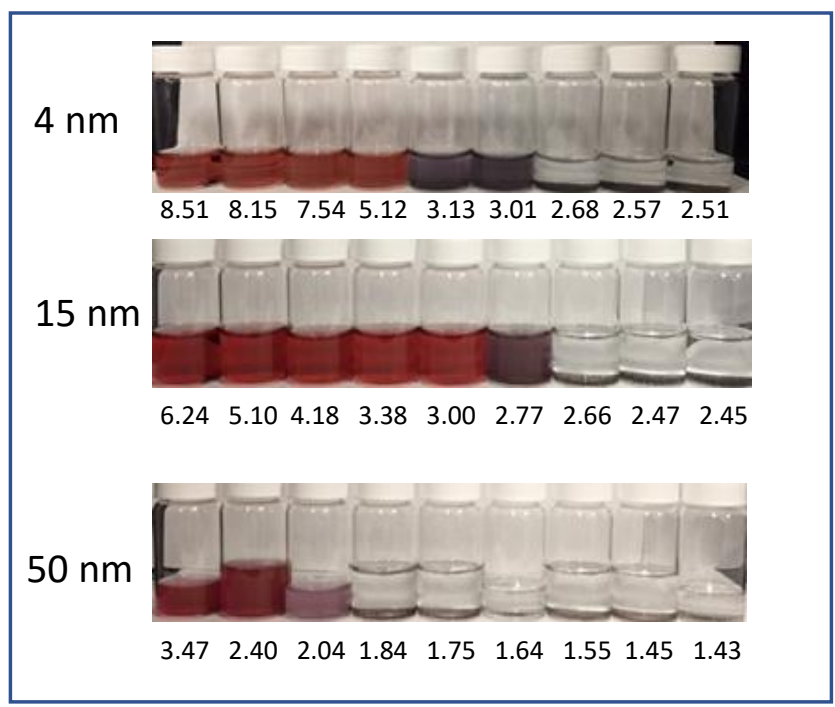

\section{8 hours}

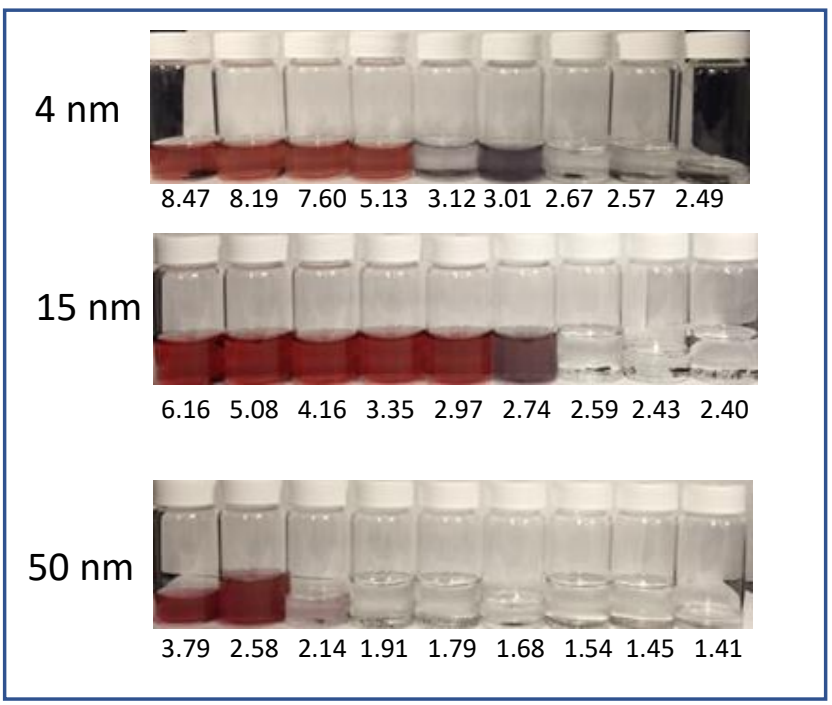

Figure 2.4. (B) pH stability of $4 \mathrm{~nm}, 15 \mathrm{~nm}$, and $50 \mathrm{~nm}$ citrate-coated Au NPs. Vials contain $10 \mathrm{~mL}$ of $\mathrm{Au}$ NP solution plus the addition of varying concentrations of $10 \mu \mathrm{L}$ of $\mathrm{HClO}_{4}$. The concentration added to the Au NP solution from right to left is as follows: $0 \mathrm{M}, 1 \mathrm{M}, 2 \mathrm{M}, 3 \mathrm{M}, 4 \mathrm{M}, 5 \mathrm{M}, 6 \mathrm{M}, 8 \mathrm{M}, 9.2 \mathrm{M}$. 
final $\mathrm{pH}$ values for the $4 \mathrm{~nm}, 15 \mathrm{~nm}$, and $50 \mathrm{~nm} \mathrm{Au} \mathrm{NPs} \mathrm{before} \mathrm{and} \mathrm{after} \mathrm{the} \mathrm{addition} \mathrm{of}$ $10 \mu \mathrm{L}$ of $9.2 \mathrm{M} \mathrm{HClO}_{4}$. The varying concentrations of acid were added to the Au NP solutions, stirred for a few seconds, and then $\mathrm{pH}$ readings were collected after one hour, 24 hours, and 48 hours to correlate the aggregation with the $\mathrm{pH}$. Figure $2.4 \mathrm{~B}$ shows pictures of all the Au NP/acid solutions and the color change that occurs. The ASV was obtained from some of these solutions following attachment of the NPs to a glass/ITO/APTES electrode.

\subsection{Electrochemistry Experiments}

2.4.1. Anodic Stripping Voltammetry. The electrochemical cell consisted of a three-electrode set-up: working, counter, and reference electrode. Figure 2.5 illustrates this set-up.

1) Working electrode (WE): the electrode surface where the electrochemical reaction occurs. In most cases, the WE was a glass/ITO slide that was either bare, functionalized, or coated with the Au NPs of interest.

2) Counter electrode (CE): the electrode that closes the circuit by passing all the current needed to balance the current observed at the WE, and it was typically a platinum wire. 3) Reference electrode (RE): a half-cell with a known potential. Unlike the CE it does not pass any current. It provides a reference of measuring potential as well as controlling the WE potential. The $\mathrm{RE}$ in all experiments was an $\mathrm{Ag} / \mathrm{AgCl}(3 \mathrm{M} \mathrm{KCl})$ electrode. The $\mathrm{Ag}$ wire is coated in $\mathrm{AgCl}$ and surrounded by a solution of $3 \mathrm{M} \mathrm{KCl}$ and isolated from the cell by a porous glass frit. 


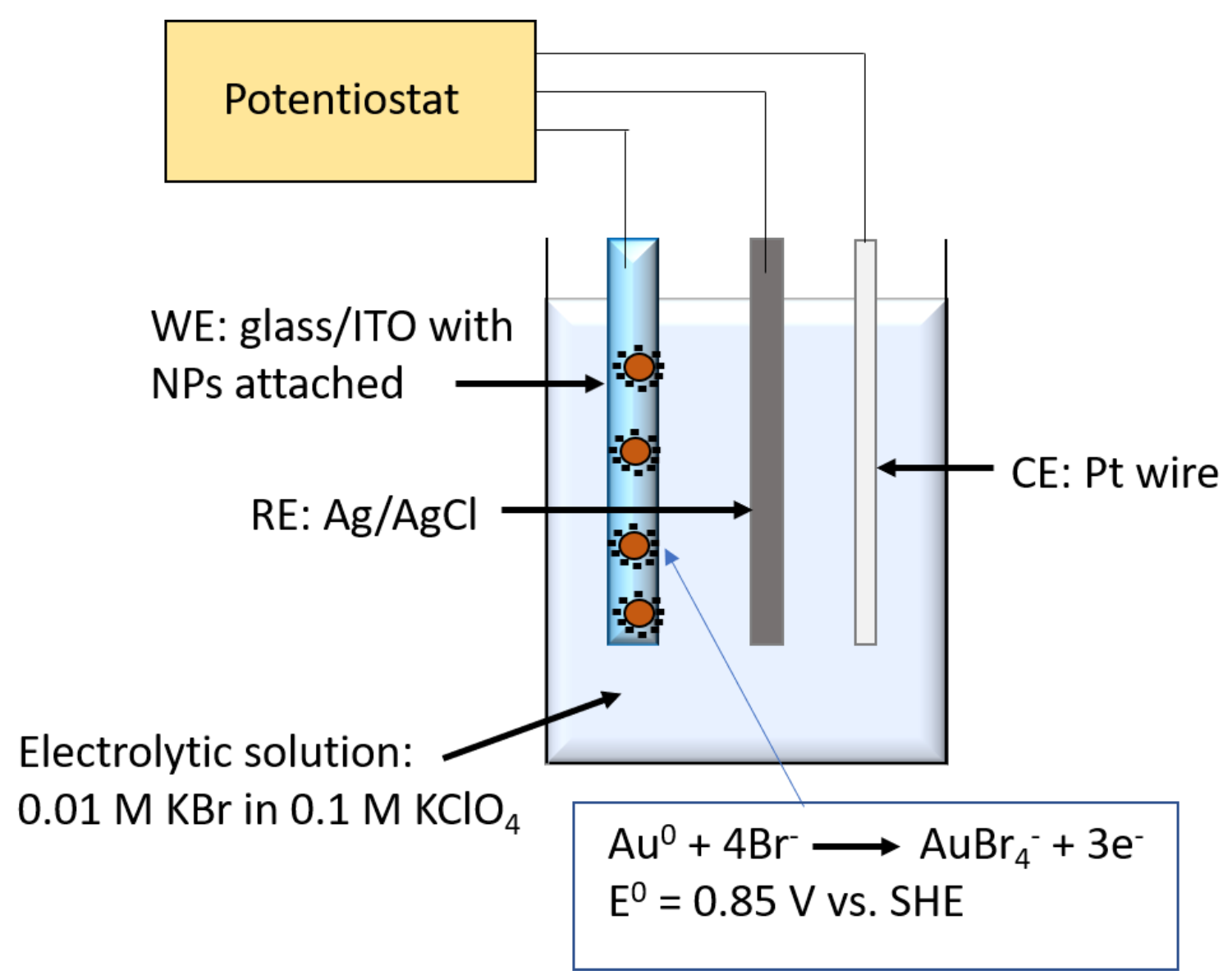

Figure 2.5. ASV cell set-up with the glass/ITO/Au NP as the working electrode, a Pt wire counter electrode, and an $\mathrm{Ag} / \mathrm{AgCl}(3 \mathrm{M} \mathrm{KCl})$ reference electrode. The electrolytic solution is composed of $10 \mathrm{mM} \mathrm{KBr}$ and $0.1 \mathrm{M} \mathrm{KClO}_{4}$. 
The three electrodes were arranged in a triangular fashion inside the cell approximately $1.5 \mathrm{~cm}$ apart with the conductive side of the WE facing the RE.

After attachment of the Au NPs to the electrode, ASV was performed for simple characterization of NP size, the coverage of NPs on the electrode, aggregation state, and type of metal. All electrochemical measurements were performed with a $\mathrm{CH}$ Instruments model 660E (Austin, TX) and an electrolytic solution using ASV or CV mode. The electrolytic solution was $10 \mathrm{mM} \mathrm{KBr}$ in $0.1 \mathrm{M} \mathrm{KClO}_{4}$. Au NPs can be oxidized both chemically and electrochemically by the following reactions:

1). $\mathrm{Au}^{0}+4 \mathrm{Br}^{-} \longrightarrow \mathrm{AuBr}_{4}^{-}+3 \mathrm{e}^{-} \quad \mathrm{E}^{0}=0.85 \mathrm{~V}$ (vs. SHE)

2). $\mathrm{Au}^{0}+2 \mathrm{Br}^{-} \longrightarrow \mathrm{AuBr}_{2}^{-}+1 \mathrm{e}^{-} \quad \mathrm{E}^{0}=0.96 \mathrm{~V}$ (vs. SHE)

3). $2 \mathrm{Au}^{0}+\mathrm{AuBr}_{4}^{-}+2 \mathrm{Br}^{-} \longrightarrow 3 \mathrm{AuBr}_{2}^{-}$(chemical)

The ASV scan was started at a potential of $-0.2 \mathrm{~V}$ with the reference and counter electrodes in the electrolytic solution and the working electrode out of solution. The potential was scanned positive at $0.01 \mathrm{~V} / \mathrm{s}$ and paused when it reaches $-0.1 \mathrm{~V}$, at which time the working electrode was immersed into the electrolyte solution under potential control. The scan resumed at a rate of $0.01 \mathrm{~V} / \mathrm{s}$ until reaching its final potential of $1.6 \mathrm{~V}$. The cyclic voltammetry (CV) scans were ran in a similar fashion with the same cell setup except once its highest potential is reached, the scan returns to its initial potential, -0.2 $\mathrm{V}$, therefore both oxidation and reduction peaks can be observed. ASV and CV were used to determine the oxidation potential (related to size and aggregation state), the total amount of the NPs deposited on the surface of the electrode, and the type of metal deposited. 


\subsubsection{Electrophoretic Deposition. For all EPD experiments, the}

electrochemical cell consisted of the same three electrodes as mentioned above with a glass/ITO working electrode, $\mathrm{Pt}$ wire counter electrode, and $\mathrm{Ag} / \mathrm{AgCl}(3 \mathrm{M} \mathrm{KCl})$ reference electrode, but the difference was the solution. The EPD solution contained 20 $\mathrm{mL}$ of Nanopure water, $5 \mathrm{~mL} 0.1 \mathrm{M} \mathrm{HQ}$, and $5 \mathrm{~mL}$ of Au NP seed solution in a beaker cell on the benchtop in the open air as shown in Figure 2.6. Experiments discussed later with $\mathrm{TiO}_{2}$ had varying amounts of NP solution but the total volume for all EPD experiments was $30 \mathrm{~mL}$. The scans started at $0.0 \mathrm{~V}$ and were paused at varying potentials depending on the experiment. For higher coverage, the scans were paused at higher potentials (e.g. $1.6 \mathrm{~V}$ ) and for lower coverage or size-selectivity, the scans were paused at lower potentials (e.g. $0.2 \mathrm{~V}$ ). The length of time that the EPD was held also varied. For some of the experiments discussed later, some EPD times were as short as 5 seconds, whereas higher coverage thin film experiments were held for three or more hours. Once the scans were completed, the WE was removed from the EPD solution, rinsed with Nanopure water, then dried under a constant stream of $\mathrm{N}_{2}$ and placed in a covered petri dish until ASV was performed. The conductive side of the glass/ITO substrate was always facing the RE in both the ASV and EPD experiments.

\subsubsection{Electrochemistry of $\mathrm{HQ}$}

Figure 2.7 shows the general approach for the HQ-mediated EPD of citrate-coated Au NPs. Figure 2.7a shows the oxidation/reduction reaction for HQ, where the oxidation of HQ results in the liberation of two protons. These protons are then shown in Figure $2.7 \mathrm{~b}$ as being responsible for neutralizing the negative charge around the Au NPs that then results in NP destabilization and ultimately deposition onto the electrode surface. 


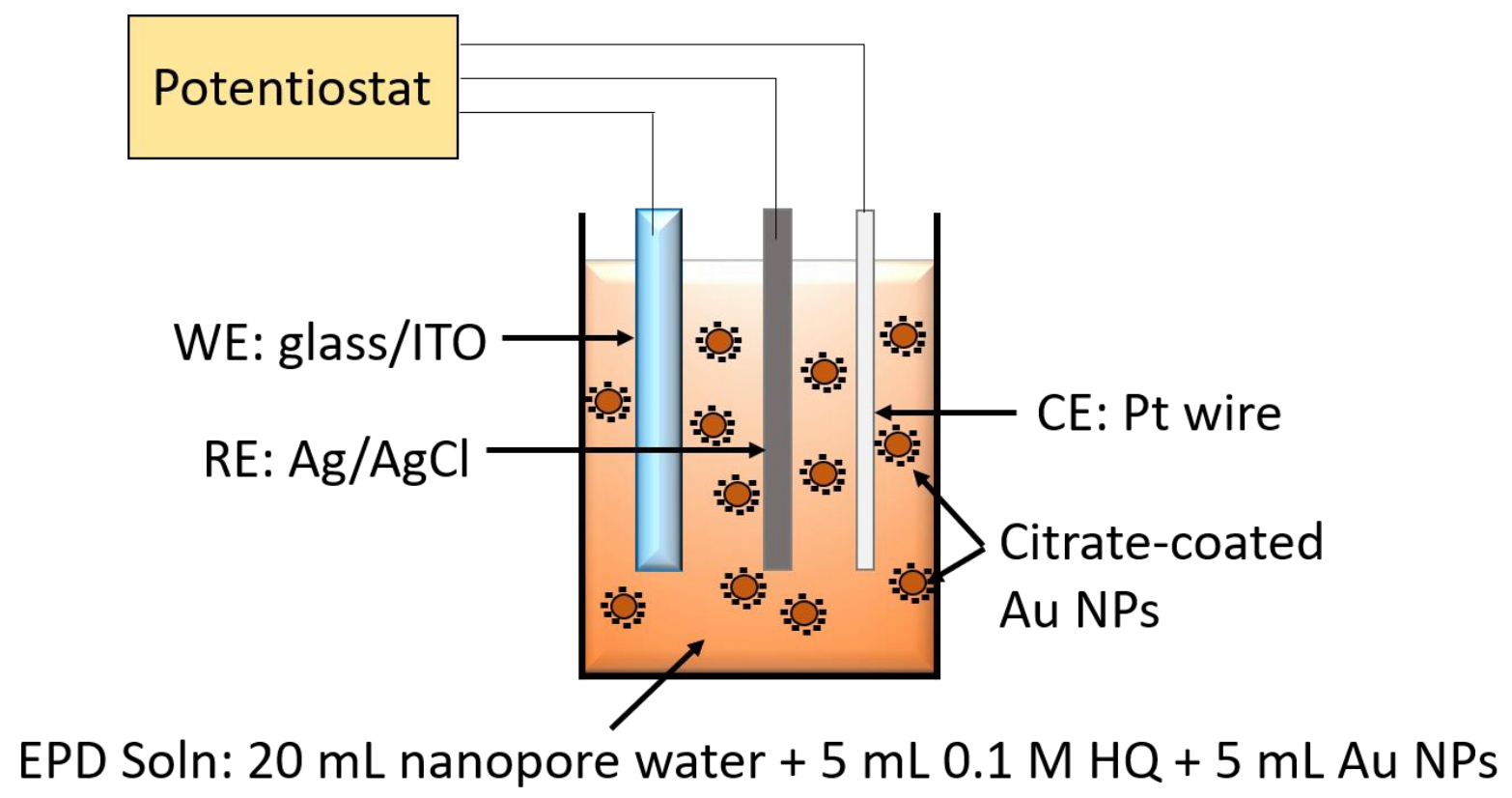

Figure 2.6. EPD set-up with the glass/ITO working electrode, $\mathrm{Pt}$ wire counter electrode, and $\mathrm{Ag} / \mathrm{AgCl}(3 \mathrm{M} \mathrm{KCl})$ reference electrode. The electrodes were placed in a solution containing $20 \mathrm{~mL}$ nanopure water, $5 \mathrm{~mL}$ of Au NP solution, and $5 \mathrm{~mL}$ of $0.1 \mathrm{M}$ hydroquinone (HQ) in a beaker cell on the benchtop in the open air. A specific electrode potential was applied to the glass/ITO working electrode $(0.2 \mathrm{~V}$ to $1.6 \mathrm{~V})$ by starting at $0 \mathrm{~V}$ and scanning positive until the desired potential was reached. Then the scan was paused and held for a certain amount of time (ranging from 30 seconds to a few hours). After the desired time, the glass/ITO electrode was removed from the beaker cell, rinsed immediately with copious amounts of nanopure water, and dried under a gentle stream of nitrogen. 
a).

Hydroquinone

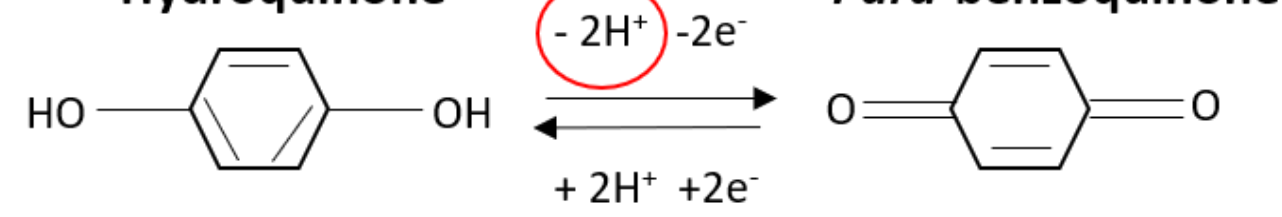

b).
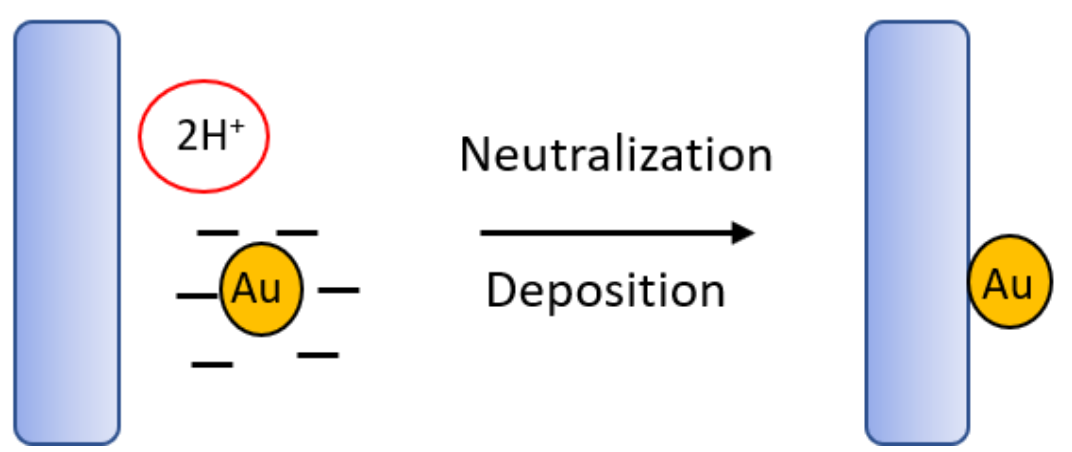

Figure 2.7. (A) Redox reaction of HQ. (B) Scheme of NP neutralization leading to deposition onto the electrode. 
This type of mechanism is a neutralization process as discussed in the Introduction chapter (the charge reduction/neutralization mechanism). EPD is commonly performed by this mechanism, but it is often the oxidation of $\mathrm{H}_{2} \mathrm{O}$ that results in the release of $\mathrm{H}^{+}$. The oxidation of $\mathrm{H}_{2} \mathrm{O}$ also results in the formation of $\mathrm{O}_{2}$ at the electrode, which can create bubbles and negatively affect the film morphology. Our procedure is different than the typical 2-electrode EPD method. With the glass/ITO as the working electrode and a reference and counter electrode in solution, we hold the potential of the working electrode at a value where oxidation of HQ occurs and that is where deposition of the Au NPs will also occur. The mode of Au NP mass transport largely involves migration since the EPD solution does not contain any additional supporting electrolyte other than the Au NP citrate stabilizer at $\mu \mathrm{M}$ concentrations.

\subsection{NP Characterization}

2.5.1. Spectrophotometry. Ultraviolet-visible spectrophotometry (UV-Vis) was performed for the different sized Au NPs at varying $\mathrm{pH}$ values using a Varian instrument, model Cary 50-Bio UV-vis spectrophotometer. All scans were obtained from $300 \mathrm{~nm}$ to $900 \mathrm{~nm}$ at a fast scan rate in a glass cuvette and background subtracted using nanopure water as the blank. UV-vis spectroscopy was used to characterize the optical properties of Au NPs. Based on the location and size of the plasmon band, we are able to gather information about the size, composition, and environment of the NPs. Figure 2.3A show UV-vis spectra of all three sizes of Au NPs. The larger the NP size, the more red-shifted or positive the absorbance band will be.

2.5.2. Anodic Stripping Voltammetry. ASV was performed on the glass/ITO/AuNP electrode to determine the amount and size of the deposited Au NPs 
after EPD was performed. Figure 2.3B shows the oxidation potentials of the three different size Au NPs. The smallest size (4 nm) oxidizes around $720 \mathrm{mV}$, whereas the 15 $\mathrm{nm}$ Au NP oxidize around $800 \mathrm{mV}$, and the largest size $\mathrm{Au}$ NPs $(50 \mathrm{~nm})$ oxidize around that of bulk Au, $900 \mathrm{mV}$. Based on the oxidation potentials, we are able to determine the size of the NP or if aggregation has occurred. The current indicates the amount of NPs deposited onto the electrode. For instance, a higher amount of coverage will result in a larger current value, and a smaller current value indicates less coverage or fewer NPs deposited.

2.5.3. Microscopy. Scanning electron microscopy (SEM) images were obtained at different magnifications using a Carl Zeiss SMT AG SUPRA 35VP field emission scanning electron microscope (FESEM) operating at an accelerating voltage of $15.00 \mathrm{kV}$ and using an in-lens ion annular secondary electron detector. Scanning electron microscopy (SEM) allows direct characterization of the size and shape of the synthesized NPs attached to the electrode and provides a resolution of approximately $3 \mathrm{~nm}$. Figure 2.8 shows examples of SEM images of $4 \mathrm{~nm}, 15 \mathrm{~nm}$, and $50 \mathrm{~nm}$ Au NPs. The instrument software allows the user to draw a line over the NP from one end of the sphere to the other and the distance shown is the diameter of said NP. 

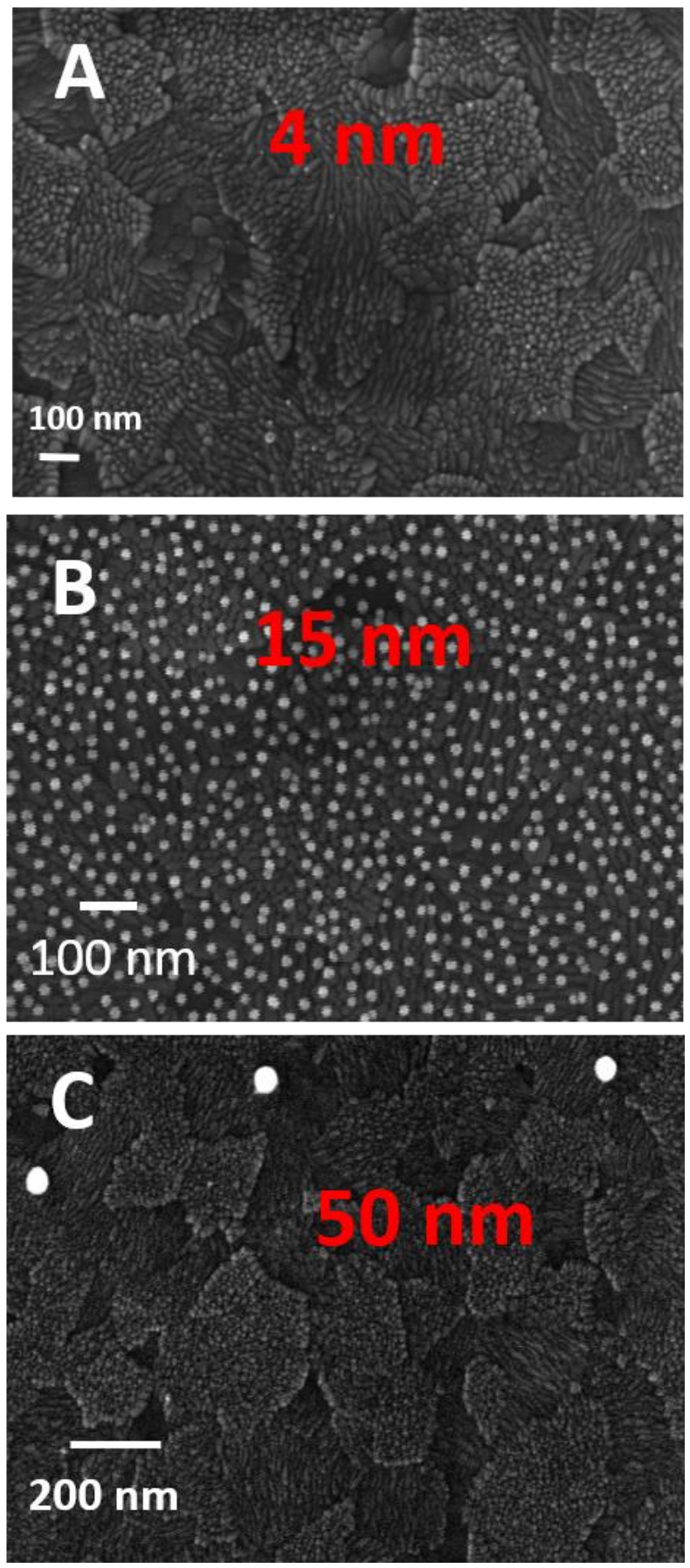

Figure 2.8. SEM images of $4 \mathrm{~nm}, 15 \mathrm{~nm}$, and $50 \mathrm{~nm}$ Au NPs. 
CHAPTER 3:

SIZE-SELECTIVE ELECTROPHORETIC DEPOSITION OF GOLD NANOPARTICLES MEDIATED BY THE OXIDATION OF HYDROQUINONE

\subsection{Introduction}

Here we describe the size-selective, hydroquinone (HQ)-mediated electrophoretic deposition (EPD) of $4 \mathrm{~nm}$ and $15 \mathrm{~nm}$ diameter citrate-stabilized Au nanoparticles (NPs) onto a glass/ITO electrode. Protons liberated from HQ during electrochemical oxidation at the Au NP surface during collisions with the glass/ITO electrode leads to Au NP deposition through neutralization of the citrate stabilizer surrounding the Au NPs, protonation of the glass/ITO electrode, or some combination of the two. Interestingly, the $4 \mathrm{~nm}$ Au NPs deposit at about a 300-400 $\mathrm{mV}$ more negative potential than $15 \mathrm{~nm}$ diameter Au NPs because of faster HQ oxidation kinetics at the $4 \mathrm{~nm}$ NPs, leading to lower overpotentials. This allows for selective deposition of the $4 \mathrm{~nm}$ Au NPs over 15 $\mathrm{nm} \mathrm{Au}$ NPs in a solution containing a mixture of the two by controlling the electrode potential. Controlled $\mathrm{pH}$ experiments indicate that significant NP deposition occurs on glass/ITO at a $\mathrm{pH}$ of $\sim 3$, giving insight into the local $\mathrm{pH}$ needed from HQ oxidation in order to deposit the Au NPs. Experiments performed at different ionic strength confirms that migration is a major mode of mass transport of the NPs to the glass/ITO. Long deposition times lead to films of densely-packed Au NPs that are mostly free from NPNP contact, indicating some electrostatic repulsion between the NPs remains during deposition. This simple method of Au NP deposition may find use for separation of Au 
NPs and electrode device preparation for a variety of sensor and electrocatalysis applications.

Metal nanoparticles (NPs) have been extensively studied over the past few decades, finding use in all areas of science due to their unique optical, magnetic, thermal, electronic, catalytic, and electrochemical properties. ${ }^{5,62-65}$ They are of great scientific interest because they exhibit different properties compared to their bulk and, more importantly, the properties are size- and shape-tunable. ${ }^{7}$ For example, the melting temperature of metals decreases dramatically below a certain size and exhibits magnetism at nanoscale sizes. ${ }^{7}$ In terms of optical properties, Au is a highly reflective, yellow color in bulk form, but exhibits size-dependent plasmonic properties, which leads to its redwine colored appearance in the 5 to $50 \mathrm{~nm}$ range. ${ }^{8}$ The oxidation potential of metal NPs depends on their size ${ }^{9-10}$ and aggregation state. ${ }^{11}$ NPs have an increased surface area-tovolume ratio $(\mathrm{SA} / \mathrm{V})^{66}$ with decreasing size, making them more active on a per weight or per mole basis in sensing or catalytic applications since the chemistry occurs at the surface. ${ }^{7,67-68}$ The activity of a NP in catalysis applications can be improved with decreasing size not only because of increased SA/V, but also because size reduction can lead to favorable changes in electronic properties, ${ }^{69} \operatorname{strain},{ }^{70}$ and exposure of more active corner and edge site atoms on the NP surface. ${ }^{71}$ Our group is interested in fundamental electrochemical properties and applications of metal NPs in electrocatalysis and electrochemical sensing. For these studies, it is important to attach metal NPs of controlled size to an electrode support surface. Electrophoretic deposition (EPD) is a useful way to accomplish that and offers the potential for size selectivity. ${ }^{72}$ 
EPD is a well-known technique used for the deposition of charged particles onto an electrode surface. It was first discovered in the 1740's by the Indian scientist G. M. Bose during a liquid-siphon experiment. ${ }^{73}$ In 1808 , the Russian scientist Ruess noticed that applying an electric field caused clay particles in water to move. ${ }^{74}$ In the 1930 's ${ }^{74}$ thoria particles were deposited onto Pt by EPD and Hamaker studied the EPD of ceramics in $1940 .^{75}$ EPD later began to find more use with advanced materials due to the high deposition rates and controllable, uniform thickness of the resulting films. ${ }^{76}$ A natural development was the use of EPD for the deposition of charged metal NPs. ${ }^{77-78}$ For example, Černohorský et al. used EPD to form Pt NP monolayers onto Si from nonpolar solvents using reverse micelles. ${ }^{79}$ EPD also allowed the deposition of hollow $\mathrm{TiO}_{2} \mathrm{NPs}$ for use as a scattering layer for dye-sensitized solar cells. ${ }^{80} \mathrm{EPD}$ is of particular interest when it comes to solar cell fabrication because it leads to uniform films of controlled thickness over large surface area substrates. Bennett et al. demonstrated thin film deposition of hematite onto transparent conductive substrates by EPD. ${ }^{81}$ Atomic force and scanning electron microscopy confirmed that adherent, uniform, and crack-free deposits of the NPs formed and the researchers established a relationship between film thickness and deposition time at fixed voltages and particle concentrations.

Our work is most relevant to previous work on the EPD of Au NPs specifically. Giersig and Mulvaney used EPD to prepare ordered colloid monolayers and 2D Au colloid lattices. ${ }^{51,82}$ They conducted EPD of citrate- and alkanethiol-stabilized Au NPs onto carbon-coated copper transmission electron microscopy (TEM) grids. In the latter case, the size of the alkane chain controlled the core-to-core interparticle spacing as measured by TEM. ${ }^{51}$ Bailey et al. combined microtransfer molding and EPD to fabricate 
ultra-thin micropatterned colloidal Au films on conductive substrates for use as a transmissive 2D optical diffraction grating. ${ }^{83}$ Zhang et al. used EPD to prepare thin films of hybrid poly(sodium $\gamma$-glutamate)/Au NPs onto an Au electrode by electrochemical generation of protons, which protonated the carboxylate groups of the polymer, leading to deposition. ${ }^{84}$ The polymer also contained dopamine (DA) groups on it and the group found the optimal EPD conditions for the electrochemical sensing of L-tryptophan. ${ }^{84}$ Zarazúa et al. used EPD of Au NPs in combination with the deposition of cadmium sulfide quantum dots (CdS QDs) to enhance the efficiency of dye-sensitized solar cells..$^{85}$ The EPD of Au NPs has also found use in the development of new nanoscale composites for use in electrochromic devices ${ }^{86}$ which are applicable to smart glass and car rearview mirrors. ${ }^{87-89}$ Augusto et al. prepared high-performance electrochromic electrodes by depositing Au-PEDOT NPs onto a glass/ITO substrate by EPD. ${ }^{86}$ The film showed fast ionic diffusion during the redox reactions, leading to switching times that were one order of magnitude lower than other similar systems. Clearly EPD can be useful for the deposition of Au NPs for a variety of applications.

EPD is a two-step process. ${ }^{90}$ First, an externally applied electric field causes charged particles suspended in a liquid medium to migrate towards the oppositelycharged electrode. Second, once the charged particles reach the electrode surface, they then deposit onto the surface by one of a variety of possible mechanisms. The thickness of the deposited film of NPs depends on certain parameters, such as the concentration of particles in solution, the applied electric field, and the deposition time. ${ }^{91}$ The first electrophoresis step is fairly well-understood while the second (deposition) step has been the subject of debate and it can be different in different set ups. There is often a poor 
understanding of the interaction between the charged particles as they encounter each other as well as the electrode surface during deposition. If the NPs are in the same environment in the bulk solution and at the electrode-solution interface, then no deposition should occur because NPs that are stable in the bulk will also remain stable at the electrode, provided there is no strong interaction with the electrode material. However, if changes occur at the electrode surface that cause the NPs to become unstable as a suspension in solution, then they may deposit on the electrode surface. This is generally what is thought to occur during EPD. Therefore, by understanding the mechanisms for de-stabilizing charged particles in bulk solution, one can invoke similar changes electrochemically at an electrode surface in order to cause deposition. This can help to deduce possible mechanisms for the deposition step. There are numerous potential mechanisms, but a few of the more common ones include direct electrostatic force, charge reduction/neutralization, and electrosedimentation. ${ }^{92}$

Direct electrostatic force relies on the electrode physically blocking the electrophoretic motion of the NPs. ${ }^{92}$ When in solution under normal conditions, the NPs are repelled from each other due to the charges around each particle. However, if the applied electric field is strong enough to overcome the interparticle repulsion that keeps the NPs apart, that may lead to deposition of the NPs onto the electrode. To be effective, this mechanism requires both a high electric field (several hundred volts/cm) and a low force gradient between the NPs, such as a thick electrostatic boundary layer. ${ }^{93-94}$ Charge reduction/neutralization occurs when there is a change in the $\mathrm{pH}$ or the production of a strongly adsorbed ion. This change in the ionic composition of the solvent then removes the stabilizing surface charge around the particles. Once the particles become unstable 
near the electrode, they precipitate onto the electrode surface. ${ }^{92}$ Another possible mechanism for deposition was proposed by Hamaker and Verwey, known as electrosedimentation. ${ }^{95}$ Here, the force exerted on the particles is similar to the gravitational force exerted on sediments. The electrostatic force on one particle would not be enough to cause deposition, but with several layers of particles in solution, the innermost layer can deposit because of the force exerted on it by the top layers. These are a few common mechanisms, but others also exist and depend on the specific conditions of the experiment.

The work described here is based on our previous work demonstrating the use of $\mathrm{H}_{2} \mathrm{O}_{2}$ as a proton-releasing molecule for the size-dependent EPD of negatively-charged, citrate-coated $\mathrm{Au}$ NPs. ${ }^{72}$ Electrochemical oxidation of $\mathrm{H}_{2} \mathrm{O}_{2}$ at the Au NP surface as it collided with the electrode liberated protons that neutralized the negative charge of the citrate stabilizer, leading to NP instability and deposition on the surface. This is similar to the charge neutralization mechanism described previously. ${ }^{92}$ Importantly, we discovered that the deposition was size-selective towards smaller Au NPs at lower potentials because they were more catalytic for $\mathrm{H}_{2} \mathrm{O}_{2}$ oxidation. The EPD therefore selectively leads to deposition of the smaller, most catalytic NPs. One problem with $\mathrm{H}_{2} \mathrm{O}_{2}$ as a mediator for deposition is that it is thermodynamically unstable and decomposes to form water and oxygen over time. The rate of decomposition increases with rising temperature, concentration, and $\mathrm{pH}$, and can be catalyzed by transition metals and their compounds. ${ }^{96}$ Because of this, the EPD of citrate-coated Au NPs in the presence of $\mathrm{H}_{2} \mathrm{O}_{2}$ was often irreproducible. To circumvent this problem, we report here on the hydroquinone (HQ)-mediated EPD of citrate-coated Au NPs, which also leads to 
the release of protons and neutralizes the citrate stabilizer. Smaller Au NPs are also more catalytic for HQ oxidation, so this approach is also size-selective. We are able to conveniently follow and characterize the EPD process by anodic stripping voltammetry (ASV), which gives us information about the amount of Au NPs deposited based on the peak size and information about the size of the deposited Au NPs from the peak oxidation potential. ${ }^{9-10}$ The size information is based on theoretical work reported by Henglein ${ }^{97}$ and Plieth, ${ }^{98}$ which was later confirmed by our group, ${ }^{9-10}$ Brainina et al. ${ }^{99}$ and others for a variety of metal NP systems. ${ }^{100-103}$

\subsection{Experimental Section}

\subsubsection{Chemicals}

$\mathrm{HAuCl}_{4} \cdot 3 \mathrm{H}_{2} \mathrm{O}$ was synthesized in our laboratory from $99.99 \%$ metallic $\mathrm{Au}$. Sodium borohydride (Sigma Aldrich, $\geq 98.5$ reagent grade), citric acid, trisodium salt (Bio-Rad laboratories), hydroquinone (Sigma Aldrich, $\geq 99 \%$ reagent grade), potassium ferrocyanide (Merck \& Co. Inc.), potassium perchlorate (Beantown Chemical, 99.0$100.5 \%$ ), potassium bromide (EMD, GR ACS), 2-propanol (Sigma Aldrich, ACS reagent), ethyl alcohol (Pharmco-AAPER, ACS/USP grade), and acetone (PharmcoAAPER, ACS/USP grade) were purchased and used as received. Indium-tin-oxide (ITO)-coated glass slides (CG-50IN-CUV, Rs $=8-12 \Omega$ ) were purchased from Delta Technologies Limited (Stillwater, MN). All solutions were prepared using a NANOpure ultrapure water purification system from Barnstead (resistivity $=18.2 \mathrm{M} \Omega-\mathrm{cm})$.

\subsubsection{Chemical Synthesis of $\mathbf{4} \mathbf{n m}$ Average Diameter Citrate-Stabilized Au}

\section{Nanoparticles}


Aqueous $4 \mathrm{~nm}$ diameter Au NPs were synthesized using the method developed by Murphy and co-workers. ${ }^{104}$ First, $0.500 \mathrm{~mL}$ of $0.01 \mathrm{M} \mathrm{HAuCl}_{4}$ and $0.500 \mathrm{~mL}$ of $0.01 \mathrm{M}$ trisodium citrate were added to $18.5 \mathrm{~mL}$ of nanopure water. Next, $0.6 \mathrm{~mL}$ of ice-cold 10 $\mathrm{mM} \mathrm{NaBH} 4$ was added to the solution and allowed to stir rapidly for 2 hours. The solution color changed to orange immediately after the addition of $\mathrm{NaBH}_{4}$ and then eventually to red shortly after, indicating the formation of Au NPs. The final concentration in terms of Au was $0.25 \mathrm{mM}$.

\subsubsection{Chemical Synthesis of 15 nm Average Diameter Citrate-Stabilized Au}

\section{Nanoparticles}

This synthesis utilized a revised version of the Turkevich method. ${ }^{105}$ First, $0.500 \mathrm{~mL}$ of $0.01 \mathrm{M} \mathrm{HAuCl}_{4} \cdot 3 \mathrm{H}_{2} \mathrm{O}$ was added to $17.0 \mathrm{~mL}$ of nanopure water and heated to a rapid boil. Once the solution came to a full boil, then $2.5 \mathrm{~mL}$ of $0.01 \mathrm{M}$ trisodium citrate was added and the solution continued to stir for 10 minutes before being removed from the hotplate and allowed to cool. The solution turned a final bright red color, indicating the formation of Au NPs. The final concentration in terms of Au was $0.25 \mathrm{mM}$.

\subsubsection{Electrophoretic Deposition (EPD) Conditions}

The experimental set-up consisted of a glass/ITO working electrode (area $=1.4$ $\left.\mathrm{cm}^{2}\right), \mathrm{Pt}$ wire counter electrode, and $\mathrm{Ag} / \mathrm{AgCl}(3 \mathrm{M} \mathrm{KCl})$ reference electrode. The three electrodes were arranged in a triangular pattern within the solution, and they were each spaced approximately $1.5 \mathrm{~cm}$ apart from each other. The conductive side of the glass/ITO working electrode was facing towards the reference and counter electrodes. The electrodes were placed in a solution containing $20 \mathrm{~mL}$ nanopure water, $5 \mathrm{~mL}$ of $\mathrm{Au}$ $\mathrm{NP}$ solution, and $5 \mathrm{~mL}$ of $0.1 \mathrm{M}$ hydroquinone (HQ) in a beaker cell on the benchtop in 
the open air. The final concentration in terms of $\mathrm{Au}$ and HQ was $42 \square \mathrm{M}$ and $17 \mathrm{mM}$, respectively. This is $2.2 \times 10^{-8} \mathrm{M}$ and $4.2 \times 10^{-10} \mathrm{M}$ in terms of $\mathrm{Au}$ NPs for $4 \mathrm{~nm}$ and 15 $\mathrm{nm}$ NPs, respectively. Although there is $\sim 50$ times less $15 \mathrm{~nm}$ Au NPs in the solution compared to $4 \mathrm{~nm}$ Au NPs, there is $\sim 50$ times more Au per $15 \mathrm{~nm}$ NP as compared to 4 $\mathrm{nm} \mathrm{Au}$ NPs, leading to comparable stripping currents in the anodic stripping voltammetry (ASV). A specific electrode potential was applied to the glass/ITO working electrode $(0.2 \mathrm{~V}$ to $1.6 \mathrm{~V})$ by starting at $0 \mathrm{~V}$ and scanning positive until the desired potential was reached. Then the scan was paused and held for a certain amount of time (ranging from 30 seconds to a few hours). After the desired time, the glass/ITO electrode was removed from the beaker cell, rinsed immediately with copious amounts of nanopure water, and dried under a gentle stream of nitrogen. ASV was then performed on the glass/ITO electrode to determine the amount and size of the deposited Au NPs.

\subsubsection{Anodic Stripping Voltammetry of the Glass/ITO/Au NPs Electrode}

\section{After EPD}

The electrochemical cell consisted of a 3-electrode set-up with the glass/ITO/Au NP as the working electrode (area $=1.4 \mathrm{~cm}^{2}$ ), a Pt wire counter electrode, and an $\mathrm{Ag} / \mathrm{AgCl}(3 \mathrm{M} \mathrm{KCl})$ reference electrode in the same arrangement used for EPD. All electrochemical measurements were performed in an electrolyte solution of $0.1 \mathrm{M} \mathrm{KClO}_{4}$

plus $0.01 \mathrm{M} \mathrm{KBr}$ in a beaker cell open to the air on the benchtop. With the reference and counter electrodes in the electrolyte solution and the working electrode out of solution, the potential was scanned positive from $-0.2 \mathrm{~V}$ at $0.01 \mathrm{~V} / \mathrm{s}$ and paused when it reached $0.1 \mathrm{~V}$. At this time the working electrode was immersed into the electrolyte solution 
under potential control. The scan then resumed from $-0.1 \mathrm{~V}$ at a rate of $0.01 \mathrm{~V} / \mathrm{s}$ until reaching its final potential of $1.6 \mathrm{~V}$.

\subsubsection{Instrumentation}

Scanning electron microscopy (SEM) images were obtained at different magnifications using a Carl Zeiss SMT AG SUPRA 35VP field emission scanning electron microscope (FESEM) operating at an accelerating voltage of $15.00 \mathrm{kV}$ and using an in-lens ion annular secondary electron detector. Electrochemical measurements were obtained with a $\mathrm{CH}$ Instruments $660 \mathrm{E}$ electrochemical workstation in either cyclic voltammetry or linear sweep voltammetry mode.

\subsection{Results and Discussion}

Figure 3.1 shows the general approach for the HQ-mediated EPD of citrate-coated Au NPs. Figure 3.1A shows the oxidation/reduction reaction for HQ, where the oxidation of each HQ results in the liberation of two protons. These protons are then shown in Figure 3.1B as being responsible for neutralizing the negative charge around the Au NPs that then results in NP destabilization and ultimately deposition onto the electrode surface. This type of mechanism is a neutralization process as discussed in the Introduction. EPD is commonly performed by this mechanism, but it is often the oxidation of $\mathrm{H}_{2} \mathrm{O}$ that results in the release of $\mathrm{H}^{+}$. The oxidation of $\mathrm{H}_{2} \mathrm{O}$ also results in the formation of $\mathrm{O}_{2}$ at the electrode, which can create bubbles and negatively affect the film morphology. The use of HQ allows for EPD at lower potentials in a bubble-free manner as described previously for the EPD of zirconia suspensions. ${ }^{106}$ It has not been demonstrated for metal NPs or shown to be size-selective as described in this work though. A second possible deposition mechanism is shown in Figure 3.1C. This 
A Hyrdoquinone
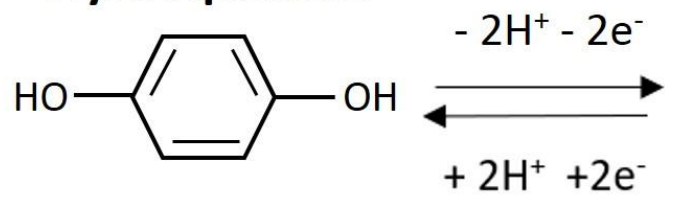

Au NP

B

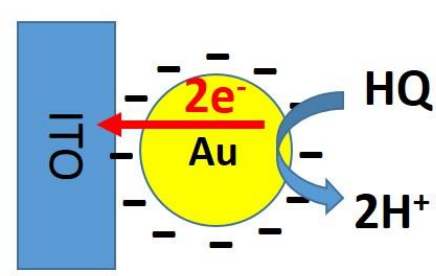

Para-benzoquinone
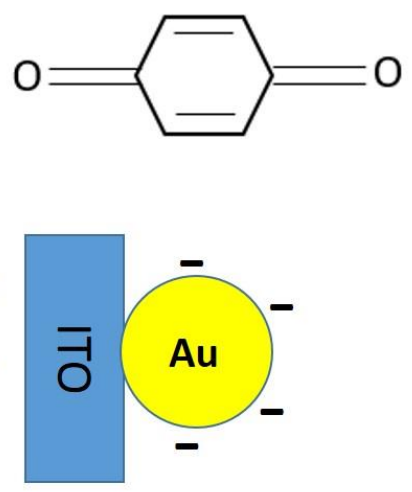
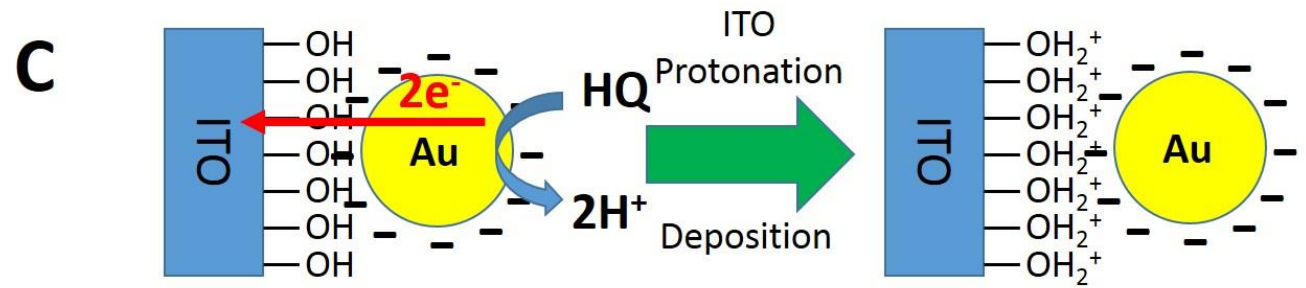

Figure 3.1. (A) Redox reaction of HQ. (B) Scheme of NP neutralization leading to destabilization and deposition onto the electrode. (C) Scheme of ITO protonation leading to deposition by electrostatic attraction. 
involves liberation of protons, which leads to protonation of the ITO surface and subsequent electrostatic attraction of the negatively-charged Au NPs to the positivelycharged ITO. The point of zero charge (pzc) is between pH 6 and 7 for ITO. ${ }^{107}$ Oxidation of $\mathrm{HQ}$ at the Au NPs could lead to a local $\mathrm{pH}$ decrease below this value, protonation of ITO, and electrostatic attraction of the Au NPs. A combination of the mechanisms in $3.1 \mathrm{~B}$ and $3.1 \mathrm{C}$ is also possible.

It is important to note that the procedure described here is different than the typical 2-electrode EPD method. With the glass/ITO as the working electrode and a reference and counter electrode in solution, we can hold the potential of the working electrode at a value where oxidation of HQ occurs and that is where deposition of the $\mathrm{Au}$ NPs will also occur. The mode of Au NP mass transport will be discussed later, but it largely involves migration since the EPD solution does not contain any additional supporting electrolyte other than the Au NP citrate stabilizer at $\mu \mathrm{M}$ concentrations.

Figure 3.2 shows anodic stripping voltammograms (ASVs) of glass/ITO electrodes following EPD of (A) $4 \mathrm{~nm}$ Au NPs, (B) $15 \mathrm{~nm}$ Au NPs, and (C) $4 \mathrm{~nm}$ Au NPs plus 15 $\mathrm{nm}$ Au NPs in solution with varying concentrations of HQ in the EPD solution. The EPD was performed at a potential of $1.0 \mathrm{~V}$ vs. $\mathrm{Ag} / \mathrm{AgCl}$, which is above the oxidation potential for $\mathrm{HQ}(\sim 0.3 \mathrm{~V}$ vs. $\mathrm{Ag} / \mathrm{AgCl})$, for 60 seconds in all cases. The Figure shows the ASVs after EPD with $0 \mathrm{M} \mathrm{HQ}$ (black), $0.001 \mathrm{M} \mathrm{HQ}$ (green), $0.01 \mathrm{M} \mathrm{HQ}$ (blue), and $0.1 \mathrm{M} \mathrm{HQ}$ (red). The results show that with $0 \mathrm{M} \mathrm{HQ}$ and $0.001 \mathrm{M} \mathrm{HQ}$, neither size Au NP deposited onto the surface of the glass/ITO electrode. This is indicated by the lack of any Au oxidation peaks in the ASV. However, with $0.01 \mathrm{M} \mathrm{HQ}$ and $0.1 \mathrm{M}$ HQ in the EPD solutions, the glass/ITO had a significant coverage of both $4 \mathrm{~nm}$ and $15 \mathrm{~nm}$ Au NPs. 

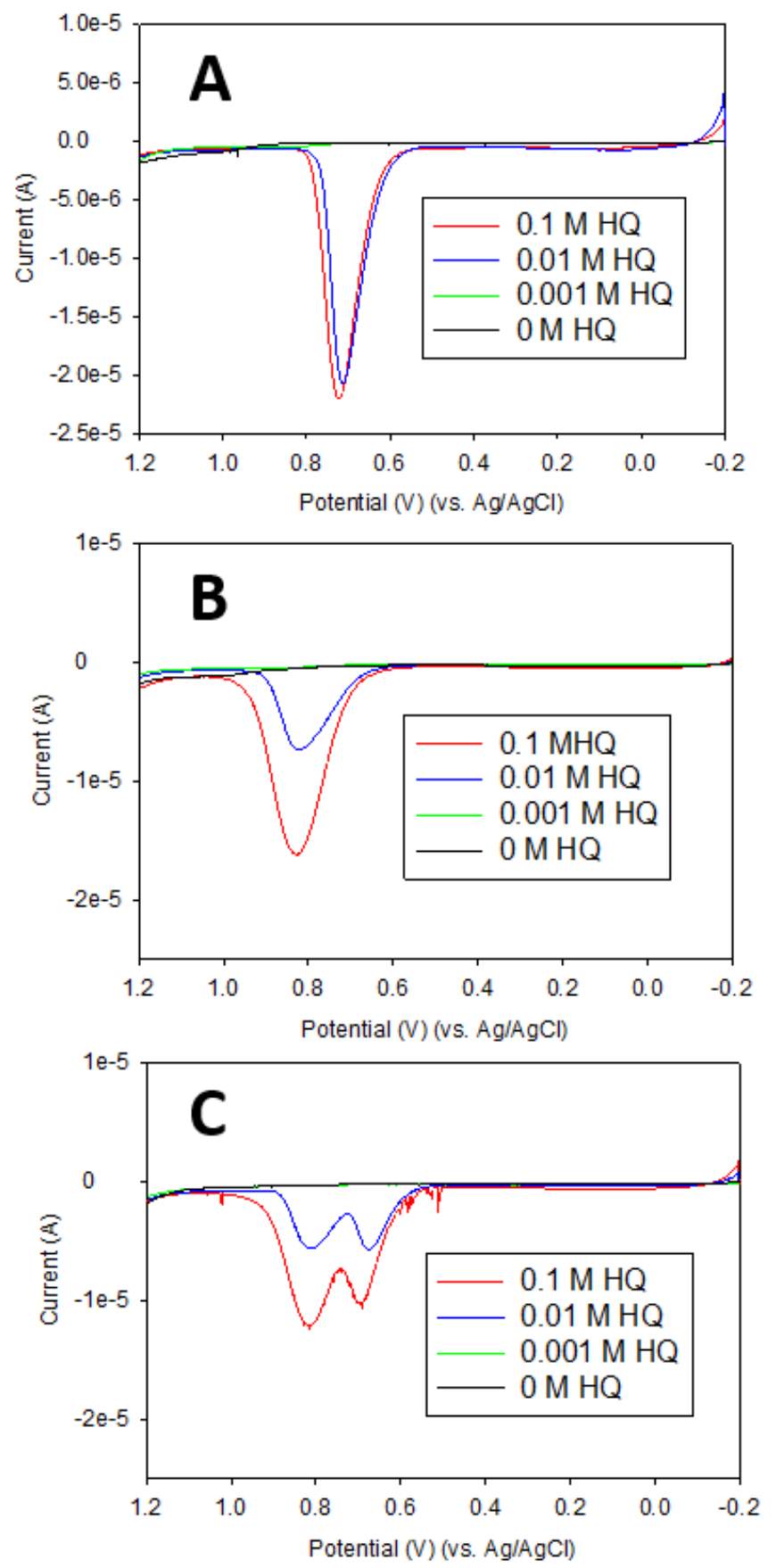

Figure 3.2. ASVs in $0.1 \mathrm{M} \mathrm{KClO}_{4}+0.01 \mathrm{M} \mathrm{KBr}$ of glass/ITO electrodes following EPD in solutions of $20 \mathrm{~mL}$ water, $5 \mathrm{~mL}$ Au NP solution, and $5 \mathrm{~mL}$ of either $0 \mathrm{M}$ HQ (black), $0.001 \mathrm{M} \mathrm{HQ}$ (green), $0.01 \mathrm{M} \mathrm{HQ}$ (blue), or 0.1 M HQ (red). The EPD solution contained (A) $5 \mathrm{~mL}$ of $4 \mathrm{~nm}$ diameter Au NPs, (B) $5 \mathrm{~mL}$ of $15 \mathrm{~nm}$ Au NPs, and (C) $2.5 \mathrm{~mL}$ of $4 \mathrm{~nm}$ Au NPs and $2.5 \mathrm{~mL}$ of $15 \mathrm{~nm}$ Au NPs. The EPD was performed for 60 seconds at $1.0 \mathrm{~V}$ vs. $\mathrm{Ag} / \mathrm{AgCl}$ in all cases. 
This is indicated by the oxidation peak at about $0.7 \mathrm{~V}$ for the $4 \mathrm{~nm}$ diameter Au NPs and at about $0.82 \mathrm{~V}$ for the $15 \mathrm{~nm}$ diameter Au NPs. Since the only difference between the plots in each figure is the concentration of HQ used during EPD, these ASVs show that having a proton-producing molecule present results in deposition of the NPs, whereas not having HQ (or not very much) in the solution results in no deposition of Au NPs.

One or both of the two mechanisms in Figure 3.1 is likely responsible for the $\mathrm{Au}$ NP deposition based on deposition coinciding with HQ oxidation. We further confirmed the importance of $\mathrm{pH}$ for citrate-coated Au NP deposition by soaking clean glass/ITO electrodes in solutions of $4 \mathrm{~nm}$ and $15 \mathrm{~nm}$ Au NPs (without applied potential) at variable pH. Figure 3.3 shows the ASVs obtained after soaking glass/ITO for 60 seconds in a solution of $4 \mathrm{~nm} \mathrm{Au} \mathrm{NPs} \mathrm{at} \mathrm{pH} \mathrm{9.01,} \mathrm{5.86,} \mathrm{and} 3.11$ and $15 \mathrm{~nm} \mathrm{Au}$ NPs at pH 5.88, 3.78, and 3.08. The results show an increasing amount of Au NP deposition on glass/ITO with decreasing $\mathrm{pH}$ for both sizes. The most significant amount of deposition occurred around $\mathrm{pH} 3.1$ for both NPs, where the coverage is comparable to the coverages observed from EPD at similar times. This indicates that HQ oxidation must lead to a local $\mathrm{pH}$ of around 3.1 or lower for significant deposition to occur. This is close to the $\mathrm{pH}$ where aggregation occurs in solution, which we recently found to be near or below 3 in a recent study. ${ }^{11}$ The point of zero charge (pzc) for ITO has been found to be between pH 6 and $7,{ }^{107}$ so a $\mathrm{pH}$ of 3.1 would result in a significant positive charge on the ITO surface.

While this $\mathrm{pH}$ value is consistent with a positively-charged ITO surface, it is also near the $\mathrm{pK}_{\mathrm{a} 1}$ value of citric acid (3.15) where about half of the citrate would be fully protonated and half in the -1 charge state. It is therefore not possible to determine if citrate neutralization or ITO protonation is most responsible for the Au NP deposition. It is 

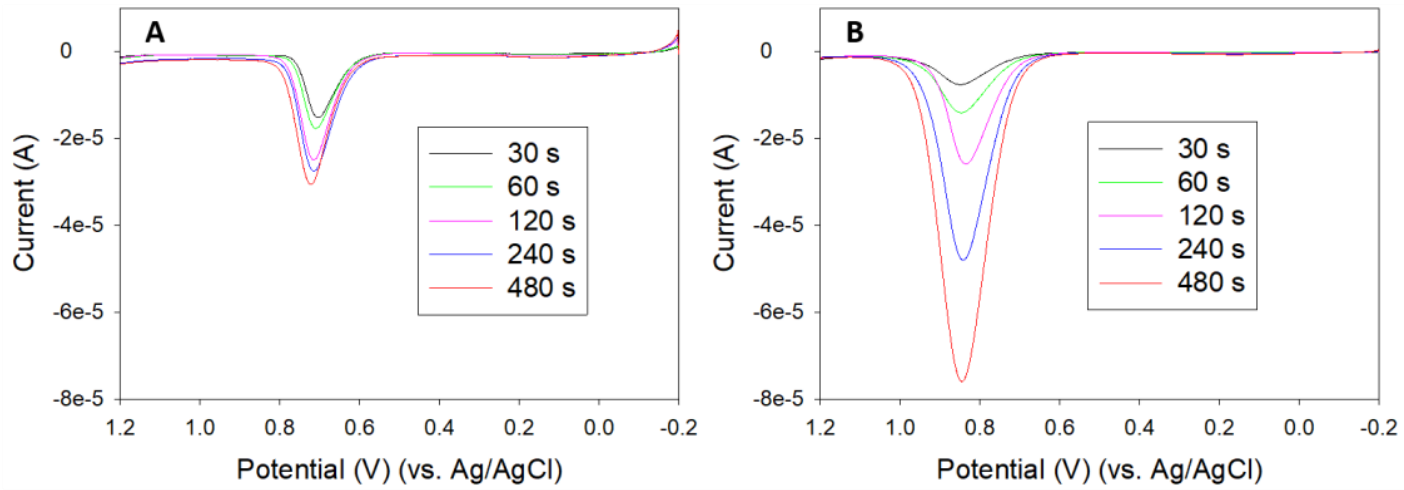

Figure 3.3. ASVs of glass/ITO electrodes in $0.1 \mathrm{M} \mathrm{KClO}_{4}+0.01 \mathrm{M} \mathrm{KBr}$ after EPD of (A) $4 \mathrm{~nm} \mathrm{Au}$ NPs, and (B) $15 \mathrm{~nm}$ Au NPs at $1.0 \mathrm{~V}$ for 30 seconds (black), 60 seconds (green), 120 seconds (pink), 240 seconds (blue), and 480 seconds (red) using $0.1 \mathrm{M} \mathrm{HQ}$. 
likely a combination of both. The concentration of 0.01 to $0.1 \mathrm{M}$ HQ is sufficient to reach these local $\mathrm{pH}$ levels at the electrode surface considering the Au NPs are in the $10^{-}$ ${ }^{10}$ to $10^{-8} \mathrm{M}$ range.

Figures 3.4A-B, and especially Figure 3.4C, shows that the oxidation of $4 \mathrm{~nm} \mathrm{Au}$ NPs and $15 \mathrm{~nm} \mathrm{Au} \mathrm{NPs} \mathrm{occurs} \mathrm{at} \mathrm{different} \mathrm{potentials,} \mathrm{which} \mathrm{allows} \mathrm{us} \mathrm{to} \mathrm{determine}$ which size NP deposits on the surface. This is critically important for the size selection experiments. It allows us to determine which size NP deposits on the electrode surface without having to image by scanning electron microscopy (SEM). This greatly speeds up the experiments and leads to much higher sample throughput, allowing us to explore many more experimental parameters at lower cost than would be possible if we had to rely on SEM imaging only for size analysis.

Figure 3.4 shows the ASVs of glass/ITO samples following EPD for $60 \mathrm{~s}$ in solutions containing $4 \mathrm{~nm}, 15 \mathrm{~nm}$, and $4 \mathrm{~nm}$ and $15 \mathrm{~nm} \mathrm{Au} \mathrm{NPs} \mathrm{in} \mathrm{the} \mathrm{presence} \mathrm{of} 0.1 \mathrm{M}$ $\mathrm{HQ}$ at varying potential, including $0.2 \mathrm{~V}$ (black), $0.4 \mathrm{~V}$ (green), $0.6 \mathrm{~V}$ (pink), $0.8 \mathrm{~V}$ (blue), and $1.2 \mathrm{~V}$ (red). As indicated by the stripping peak potentials and size of the peaks, there is a significant coverage for the $4 \mathrm{~nm}$ Au NPs after EPD at $0.4 \mathrm{~V}$ but no coverage for the $15 \mathrm{~nm}$ Au NPs at that same potential (green plots). The $15 \mathrm{~nm} \mathrm{Au} \mathrm{NPs}$ do not start to show deposition until a potential of $0.8 \mathrm{~V}$. Figure $3.4 \mathrm{C}$ clearly shows that we can selectively deposit $4 \mathrm{~nm}$ diameter Au NPs in the presence of $15 \mathrm{~nm}$ diameter $\mathrm{Au}$ NPs at a potential of $0.4 \mathrm{~V}$. However, $15 \mathrm{~nm}$ Au NPs became deposited in the presence of $4 \mathrm{~nm} \mathrm{Au} \mathrm{NPs}$ at $0.6 \mathrm{~V}$ (Figure 3.4C), but they did not deposit at this potential on their own (Figure 3.4B). This indicates that the smaller $4 \mathrm{~nm}$ Au NPs can be selectively deposited at one potential, but at a slightly higher potential can actually assist in the 

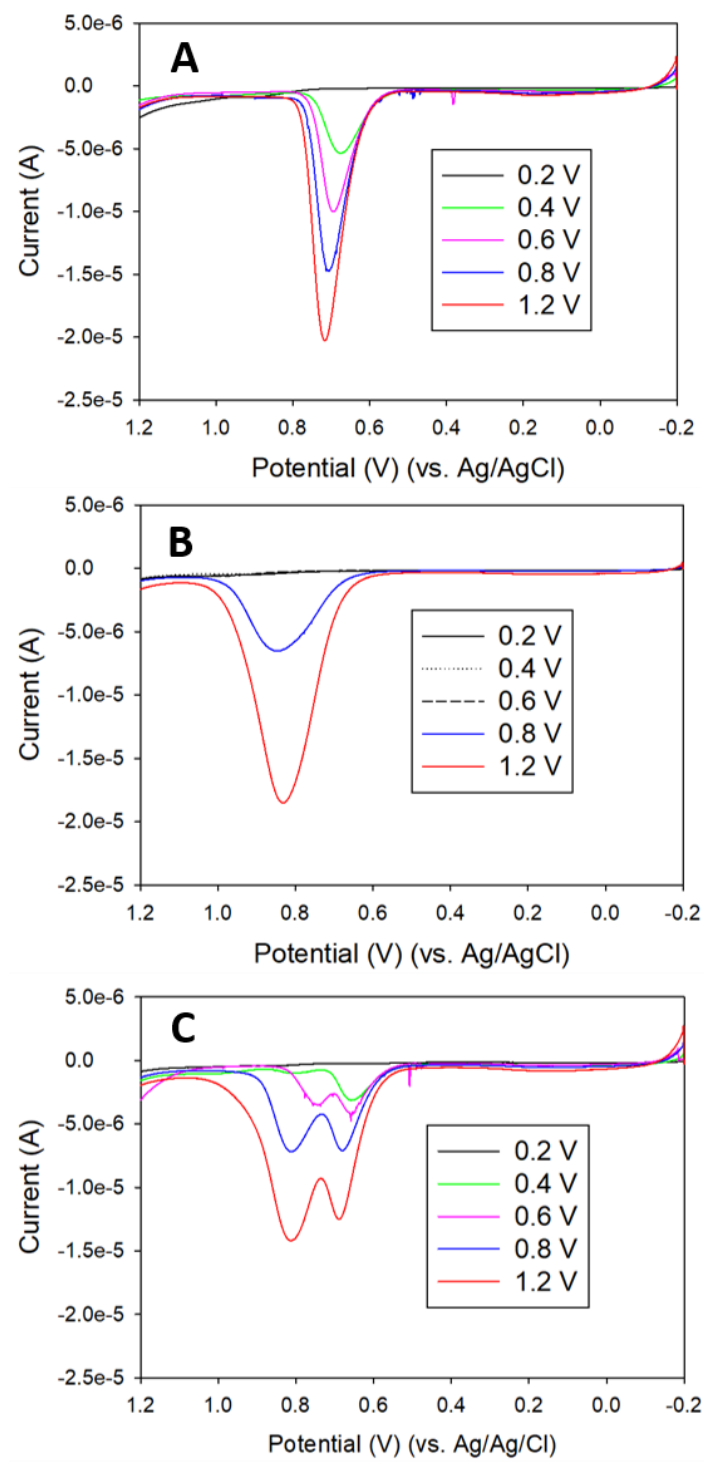

Figure 3.4. ASVs in $0.1 \mathrm{M} \mathrm{KClO}_{4}+0.01 \mathrm{M} \mathrm{KBr}$ of glass/ITO electrodes after EPD in solutions containing $20 \mathrm{~mL}$ water, $5 \mathrm{~mL}$ of $0.1 \mathrm{M} \mathrm{HQ}$, and (A) $5 \mathrm{~mL}$ of $4 \mathrm{~nm} \mathrm{Au} \mathrm{NPs}$, (B) $5 \mathrm{~mL}$ of $15 \mathrm{~nm} \mathrm{Au}$ NPs, and (C) $2.5 \mathrm{~mL} 4 \mathrm{~nm}$ Au NPs plus $2.5 \mathrm{~mL} 15$ $\mathrm{nm}$ Au NPs. The EPD was performed for 60 seconds at a potential of $0.2 \mathrm{~V}$ (black), $0.4 \mathrm{~V}$ (green), $0.6 \mathrm{~V}$ (pink), $0.8 \mathrm{~V}$ (blue), and $1.2 \mathrm{~V}$ (red) vs. an $\mathrm{Ag} / \mathrm{AgCl}$ reference electrode. 
deposition of the larger $15 \mathrm{~nm}$ Au NPs, likely by generating protons nearby the $15 \mathrm{~nm} \mathrm{Au}$ NPs. To demonstrate the ability of smaller Au NPs to assist in the deposition of larger NPs, Figure 3.5 shows that the deposition of $4 \mathrm{~nm}$ Au NPs onto glass/ITO leads to greater subsequent deposition of $15 \mathrm{~nm}$ Au NPs at a relatively low potential. For example, when bare glass/ITO was placed in the $15 \mathrm{~nm}$ Au NP EPD solution for 300 seconds at $0.8 \mathrm{~V}$, the resulting peak ASV current was $1.4 \times 10^{-6} \mathrm{C}$. When $4 \mathrm{~nm}$ Au NPs were first attached to glass/ITO by EPD for just $5 \mathrm{~s}$ at $0.8 \mathrm{~V}$ subsequent EPD of $15 \mathrm{~nm}$ Au NPs (again at 0.8 V for $300 \mathrm{~s}$ ) led to a peak ASV current of $3.6 \times 10^{-6} \mathrm{~A}$. After 15 seconds of EPD with the $4 \mathrm{~nm} \mathrm{Au}$ NPs at $0.8 \mathrm{~V}$, the subsequent EPD of $15 \mathrm{~nm} \mathrm{Au} \mathrm{NPs} \mathrm{increased} \mathrm{further} \mathrm{to} \mathrm{9.2x10-}$ ${ }^{6} \mathrm{~A}$. It is clear that as the amount of $4 \mathrm{~nm}$ Au NPs deposited first increased the amount of $15 \mathrm{~nm}$ Au NPs subsequently deposited increased as well, indicative of an assisted EPD process. This example shows a more catalytically active metal NP assisting the deposition of a less catalytically active metal NP but could also be used to assist in the deposition of an insulating or semiconductor NP with no activity at all.

Figure 3.6 provides electrochemical data showing that the EPD is size-selective by varying the potential due to differences in HQ oxidation kinetics (or different catalytic activity) for the two different sized Au NPs. The figure shows cyclic voltammograms (CVs) of glass/ITO, glass/ITO/Au NPs (4 nm), and glass/ITO/Au NPs (15 nm) obtained in $0.005 \mathrm{M} \mathrm{HQ}$ plus $0.1 \mathrm{M} \mathrm{KClO}_{4}$ solution. The standard potential of $\mathrm{HQ}$ is reported to be at $0.70 \mathrm{~V}$ vs. SHE (pH 1), which would be about $0.32 \mathrm{~V}$ vs. $\mathrm{Ag} / \mathrm{AgCl}$ at $\mathrm{pH} 7$. The CV of glass/ITO (black plot) in Figure 3.6 does not show current until about $0.8 \mathrm{~V}$ vs. $\mathrm{Ag} / \mathrm{AgCl}$ and no clear oxidation/reduction peaks. This is well above the thermodynamic potential, indicating very sluggish kinetics (high overpotential) on glass/ITO for this 


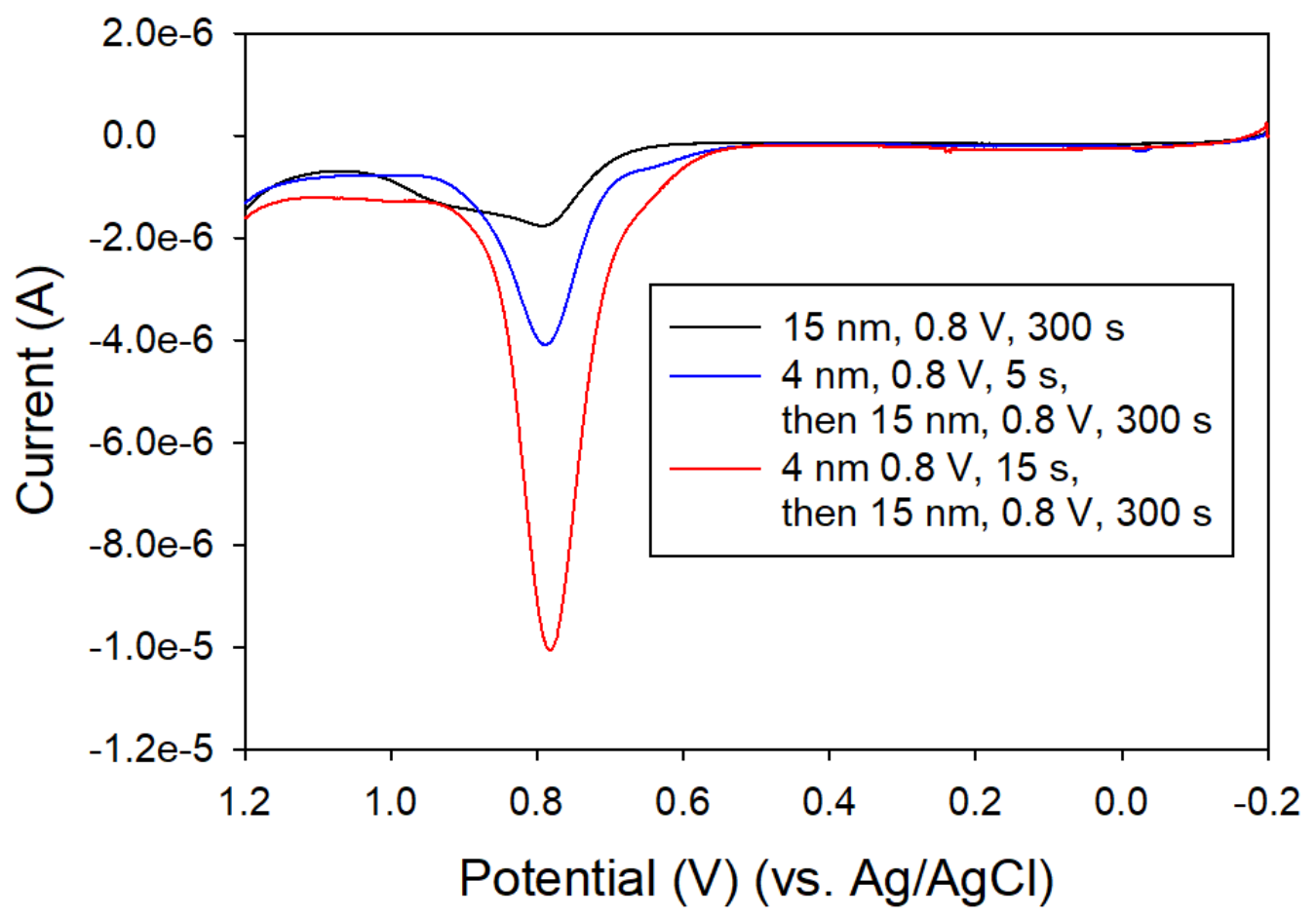

Figure 3.5. ASVs of glass/ITO electrodes in $0.1 \mathrm{M} \mathrm{KClO}_{4}+0.01 \mathrm{M} \mathrm{KBr}$ after EPD of $15 \mathrm{~nm} \mathrm{Au}$ NPs at $0.8 \mathrm{~V}$ for 300 seconds (black), $4 \mathrm{~nm} \mathrm{Au} \mathrm{NPs} \mathrm{at} 0.8 \mathrm{~V}$ for 5 seconds, then $15 \mathrm{~nm} \mathrm{Au} \mathrm{NPs}$ at $0.8 \mathrm{~V}$ for 300 seconds (blue), and $4 \mathrm{~nm} \mathrm{Au} \mathrm{NPs}$ at $0.8 \mathrm{~V}$ for 15 seconds, then $15 \mathrm{~nm}$ Au NPs at $0.8 \mathrm{~V}$ for 300 seconds (red). 


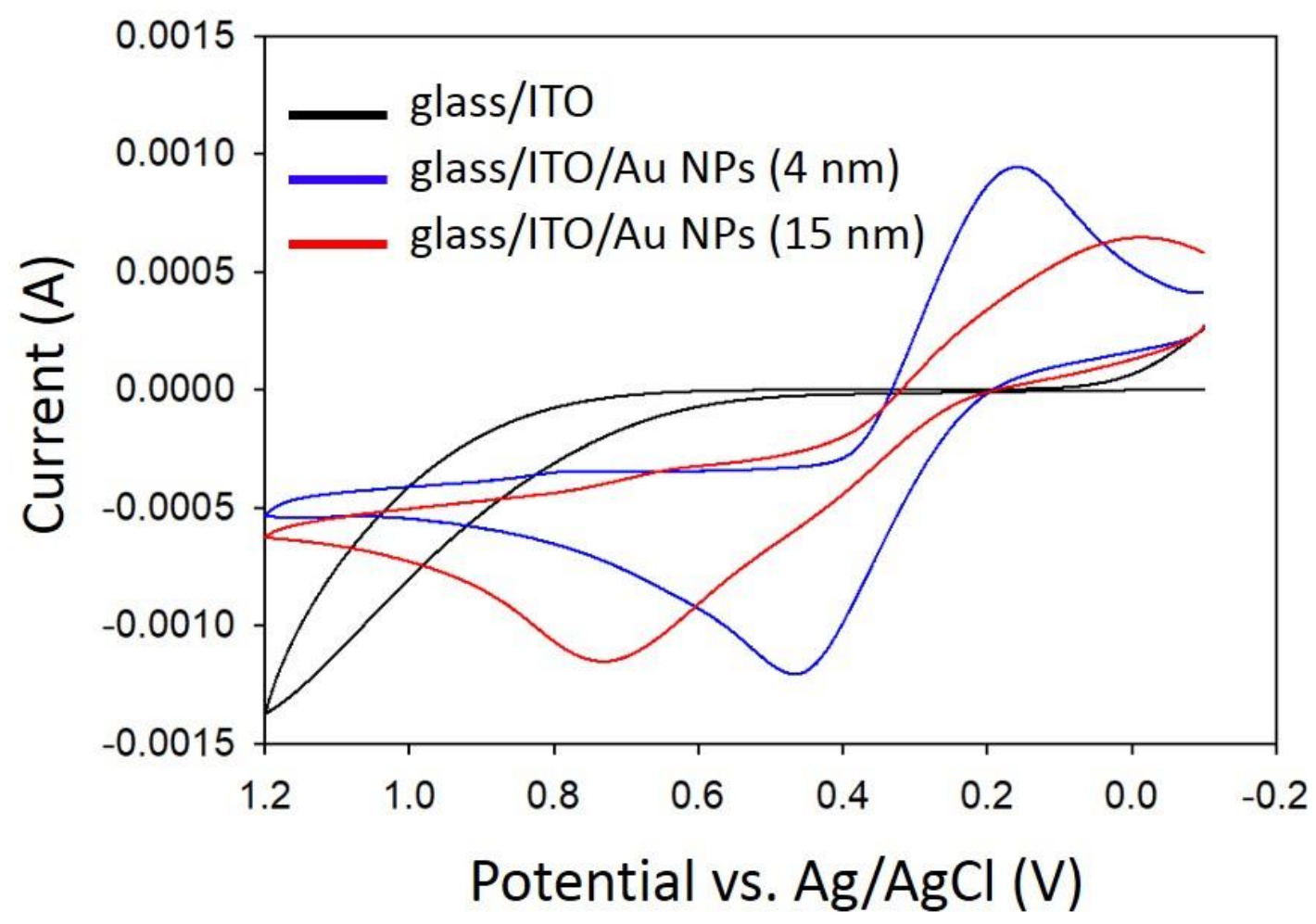

Figure 3.6. CVs of glass/ITO (black), glass/ITO/Au NPs (4 nm) (blue), and glass/ITO/Au NPs (15 nm) (red) obtained in $0.005 \mathrm{M} \mathrm{HQ}$ and $0.1 \mathrm{M} \mathrm{KClO}_{4}$ at a scan rate of $0.01 \mathrm{~V} / \mathrm{s}$. 
reaction. On glass/ITO/Au NPs $(15 \mathrm{~nm})$ (red plot), clear oxidation and reduction peaks appear in the $\mathrm{CV}$, but the peak splitting is very large, the peaks are broad, and the peak oxidation potential is at about $0.75 \mathrm{~V}$, which is still significantly higher than the thermodynamic value. While faster than glass/ITO, this high overpotential still indicates slow kinetics at the $15 \mathrm{~nm}$ diameter Au NPs. On glass/ITO/Au NPs (4 nm) (blue plot), both oxidation and reduction peaks are observed and the peak splitting is significantly smaller than the $15 \mathrm{~nm}$ Au NPs. The peak oxidation potential is at about $0.45 \mathrm{~V}$, which is $0.3 \mathrm{~V}$ more negative of the $15 \mathrm{~nm}$ Au NPs and much closer to the thermodynamic value. While it is not nearly electrochemically reversible for HQ oxidation, the lower overpotential indicates much faster kinetics at the $4 \mathrm{~nm}$ Au NPs compared to the $15 \mathrm{~nm}$ Au NPs. This lower overpotential is the reason for the size-selective EPD of $4 \mathrm{~nm} \mathrm{Au}$ NPs at the lower potential. Since oxidation of HQ is required for NP deposition, the faster kinetics of HQ oxidation at $4 \mathrm{~nm}$ Au NPs allows it to occur at lower potentials relative to $15 \mathrm{~nm}$ Au NPs. The HQ oxidation peak potentials of $0.45 \mathrm{~V}$ and $0.75 \mathrm{~V}$ for 4 $\mathrm{nm}$ and $15 \mathrm{~nm}$ diameter Au NPs, respectively, matches well with the ASV data in Figure 3.4, showing that EPD of $4 \mathrm{~nm}$ Au NPs occurs at about $\sim 0.4 \mathrm{~V}$ and EPD of $15 \mathrm{~nm} \mathrm{Au}$ NPs occurs at $\sim 0.8 \mathrm{~V}$.

While Figure 3.4 shows good size selectivity between $4 \mathrm{~nm}$ and $15 \mathrm{~nm}$ Au NPs at $0.4 \mathrm{~V}$ over $60 \mathrm{~s}$, we wondered if the size selectivity would remain at longer times and higher coverages of the Au NPs. As shown for $0.6 \mathrm{~V}$ in Figure 3.4C, it is possible that oxidative release of protons from $\mathrm{HQ}$ at $4 \mathrm{~nm}$ diameter Au NPs causes deposition of nearby $15 \mathrm{~nm}$ Au NPs. Figure 3.7A shows ASVs of glass/ITO following EPD from a mixture of $4 \mathrm{~nm}$ and $15 \mathrm{~nm} \mathrm{Au} \mathrm{NPs} \mathrm{at} 0.4 \mathrm{~V}$ for 1, 2, and 5 minutes. When going from 1 

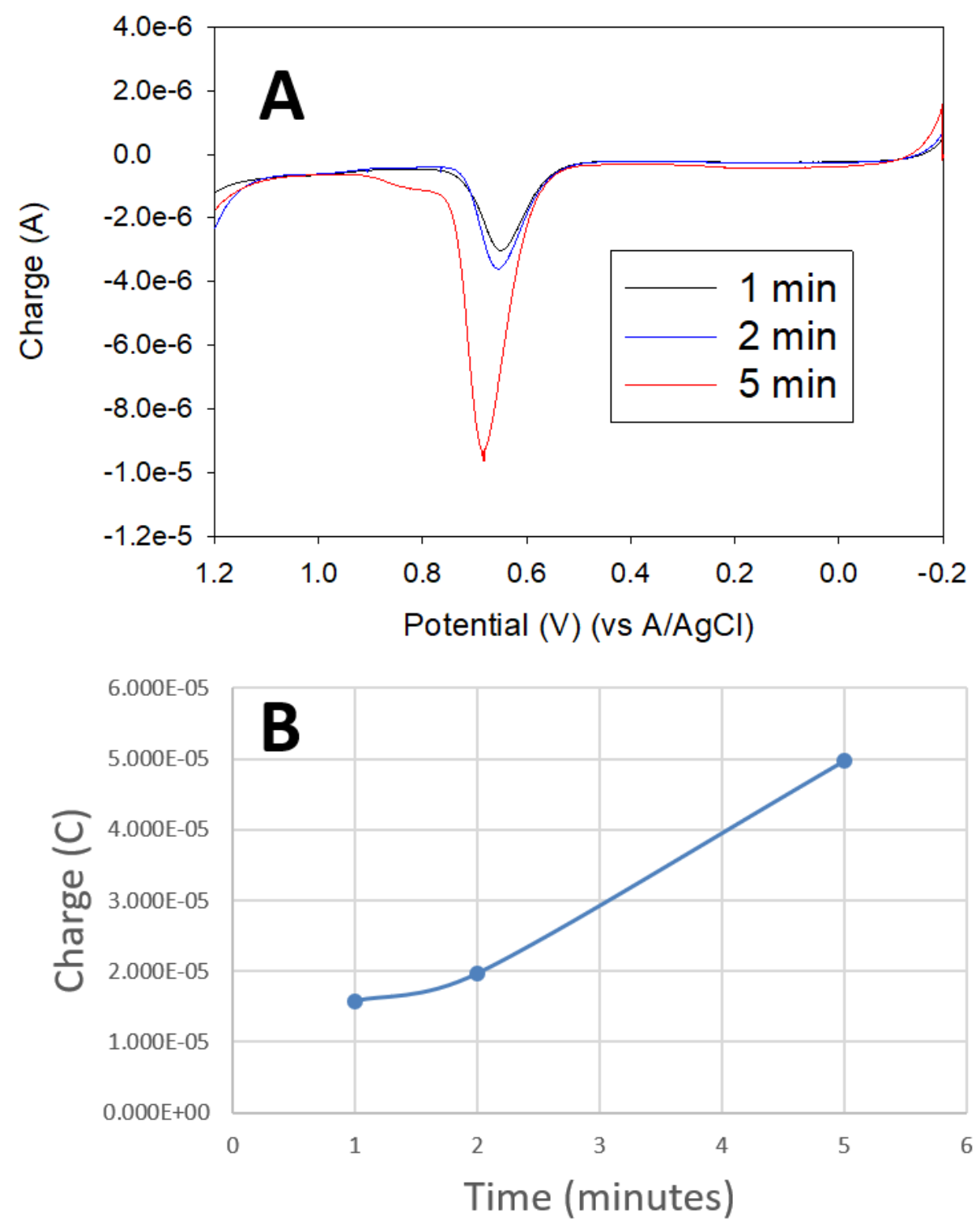

Figure 3.7. (A) ASVs in $0.1 \mathrm{M} \mathrm{KClO}_{4}+0.01 \mathrm{M} \mathrm{KBr}$ after EPD in $4 \mathrm{~nm}$ and $15 \mathrm{~nm} \mathrm{Au}$ NPs solution held at $0.4 \mathrm{~V}$ for $1 \mathrm{~min}$ (black), $2 \mathrm{~min}$ (blue), and $5 \mathrm{~min}$ (red) with $0.1 \mathrm{M}$ HQ. (B) A plot of Au stripping charge in Coulombs as a function of EPD time from the ASVs in (A). 
to 5 minutes, the coverage of $4 \mathrm{~nm}$ Au NPs increased significantly as shown by the increasing peak size at $0.7 \mathrm{~V}$ while the coverage of the $15 \mathrm{~nm}$ Au NPs increased only slightly, as indicated by the very small shoulder peak at $0.82 \mathrm{~V}$. This demonstrates that one can continuously deposit the $4 \mathrm{~nm}$ Au NPs without depositing the larger Au NPs at 0.4 V. Figure 3.7B shows a plot of Coulombs of oxidized Au during ASV as a function of EPD time at $0.4 \mathrm{~V}$. The coverage of the $4 \mathrm{~nm}$ diameter Au NPs clearly increased with EPD time while preventing significant deposition of the $15 \mathrm{~nm}$ diameter Au NPs. It is important to note that the charge of deposited $\mathrm{Au}$ at 5 minutes corresponds to a coverage of about $371 \mathrm{NPs} / \mu \mathrm{m}^{2}$, which is only about $0.6 \%$ coverage of a cubic lattice packed monolayer of $4 \mathrm{~nm}$ diameter NPs. It is likely that much higher coverage would also lead to the deposition of $15 \mathrm{~nm}$ Au NPs as well through the assisted process already described. Figure 3.4C showed that at slightly higher potential $(0.6 \mathrm{~V})$, both $4 \mathrm{~nm}$ and $15 \mathrm{~nm} \mathrm{Au}$ NPs deposit through the assisted process and is no longer size-selective. Size selectivity is therefore highly dependent on both the EPD potential and coverage of the smaller Au NPs.

Figure 3.8 shows ASVs of glass/ITO after EPD at $1.0 \mathrm{~V}$ in a solution with $0.1 \mathrm{M}$ HQ and $4 \mathrm{~nm}$ Au NPs, $15 \mathrm{~nm}$ Au NPs, and a mixture of the two Au NPs with varying concentration of additional electrolyte, which in this case was $0 \mathrm{M} \mathrm{KClO}_{4}$ (red), $0.001 \mathrm{M}$ $\mathrm{KClO}_{4}$ (blue), and $0.01 \mathrm{M} \mathrm{KClO}_{4}$ (black). The data shows that as we increase the electrolyte concentration, there is a decrease in the coverage of both Au NPs. This shows that mass transport of the Au NPs is largely due to migration. As the electrolyte concentration increases, migration becomes more dominated by the $\mathrm{K}^{+}$and $\mathrm{ClO}_{4}{ }^{-}$ions, leading to lower mass transport of Au NPs to the electrode surface. The decrease in 

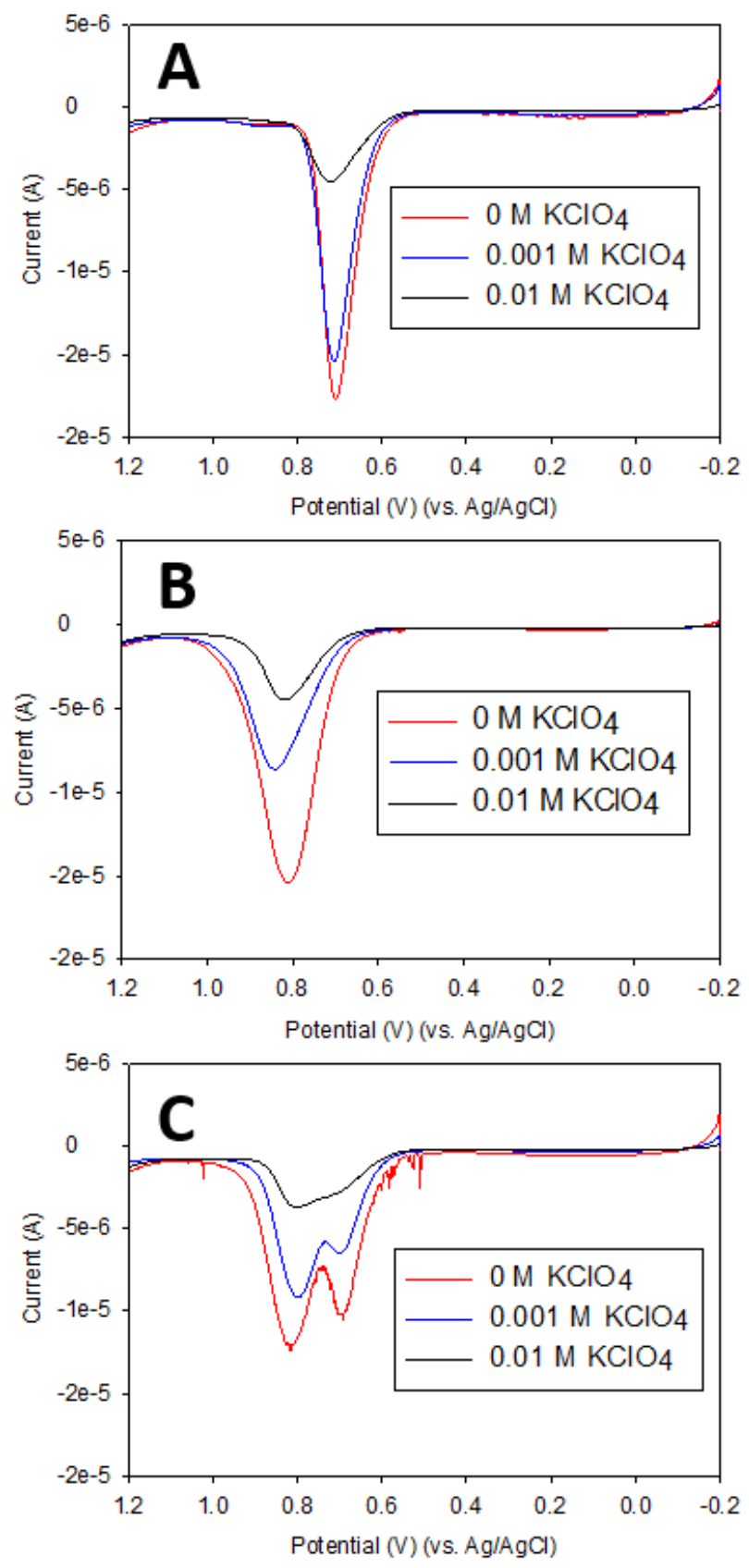

Figure 3.8. ASVs in $0.1 \mathrm{M} \mathrm{KClO}_{4}+0.01 \mathrm{M} \mathrm{KBr}$ of glass/ITO electrodes following EPD in solutions of $5 \mathrm{~mL}$ Au NP solution, $5 \mathrm{~mL}$ of $0.1 \mathrm{M} \mathrm{HQ}$, and $20 \mathrm{~mL}$ of $0 \mathrm{M} \mathrm{KClO}_{4}$ (red), $0.001 \mathrm{M}$ $\mathrm{KClO}_{4}$ (blue), or $0.01 \mathrm{M} \mathrm{KClO}_{4}$ (black). The EPD solution contained (A) $5 \mathrm{~mL}$ of $4 \mathrm{~nm}$ diameter Au NPs, (B) $5 \mathrm{~mL}$ of 15 $\mathrm{nm} \mathrm{Au} \mathrm{NPs}$, and (C) $2.5 \mathrm{~mL}$ of $4 \mathrm{~nm}$ Au NPs and $2.5 \mathrm{~mL}$ of 15 $\mathrm{nm}$ Au NPs. The EPD was performed for 60 seconds at $1.0 \mathrm{~V}$ vs. $\mathrm{Ag} / \mathrm{AgCl}$ in all cases. 
coverage implies that migration does play a major role in NP mass transport to the electrode while the deposition is controlled by the liberation of protons during oxidation of HQ. Figure 3.8 also suggests that iR drop at low electrolyte concentration is not limiting the EPD at $1.0 \mathrm{~V}$. If it was, then we would expect a higher amount of deposition as the electrolyte concentration increased.

In addition to ASVs, we performed SEM imaging on $15 \mathrm{~nm} \mathrm{Au} \mathrm{NPs} \mathrm{with}$ different EPD time trials. Figure 3.9 shows SEM images of glass/ITO following EPD of $15 \mathrm{~nm}$ Au NPs in solution using $5 \mathrm{~mL}$ of $0.1 \mathrm{M}$ HQ at $1.0 \mathrm{~V}$ for 30 seconds (A), 120 seconds (B), 240 seconds (C), and 480 seconds (D). As we increase the EPD time, there was an increase in NP coverage on the surface of the glass/ITO electrode as expected. The NP coverage increased from $15 / \mu \mathrm{m}^{2}$ for 30 seconds to $24 / \mu \mathrm{m}^{2}$ for 120 seconds, $63 / \mu \mathrm{m}^{2}$ for 240 seconds, and $86 / \mu \mathrm{m}^{2}$ for 480 seconds. At this voltage and these times, the Au NPs are deposited as well-separated individual NPs on the surface. There are almost no NPs attached to other NPs on the surface. The coverage may not be large enough for NPs to be attached (aggregated) and some electrostatic repulsion from remaining citrate might keep them from attaching together or depositing close to each other.

Figure 3.5 shows the corresponding ASVs for the same time study described in Figure 3.9. The ASVs and the SEM images correlate well with each other. As the EPD time increases, there is an increase in Coulombs of charge from Au oxidation in the ASVs along with an increase in particle density in the SEM images. Figure 3.10 shows plots of charge (Coulombs) versus time (seconds) for both the $4 \mathrm{~nm}$ and $15 \mathrm{~nm} \mathrm{Au} \mathrm{NPs}$. Both plots show an increase in charge over time. For the $4 \mathrm{~nm}$ Au NPs, the charge at 30 seconds is $7.94 \times 10^{-5} \mathrm{C}$ and ends up at $1.69 \times 10^{-4} \mathrm{C}$ after 480 seconds. The $15 \mathrm{~nm}$ Au NPs 

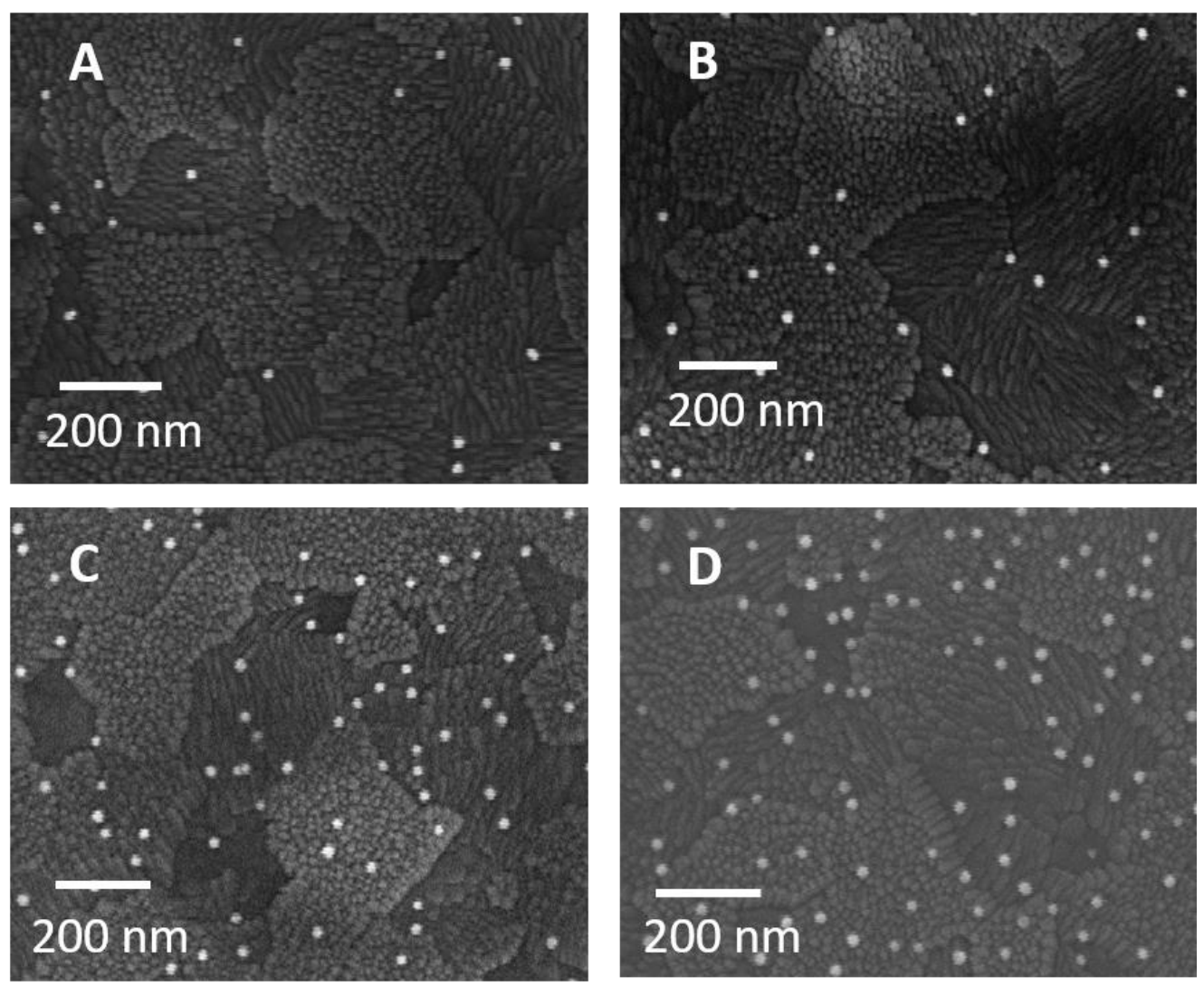

Figure 3.9. SEM images of glass/ITO after EPD of $15 \mathrm{~nm}$ Au NPs at $1.0 \mathrm{~V}$ using $5 \mathrm{~mL}$ of $0.1 \mathrm{M}$ HQ for (A) $30 \mathrm{~s}$, (B) $120 \mathrm{~s}$, (C) $240 \mathrm{~s}$, and (D) $480 \mathrm{~s}$. 


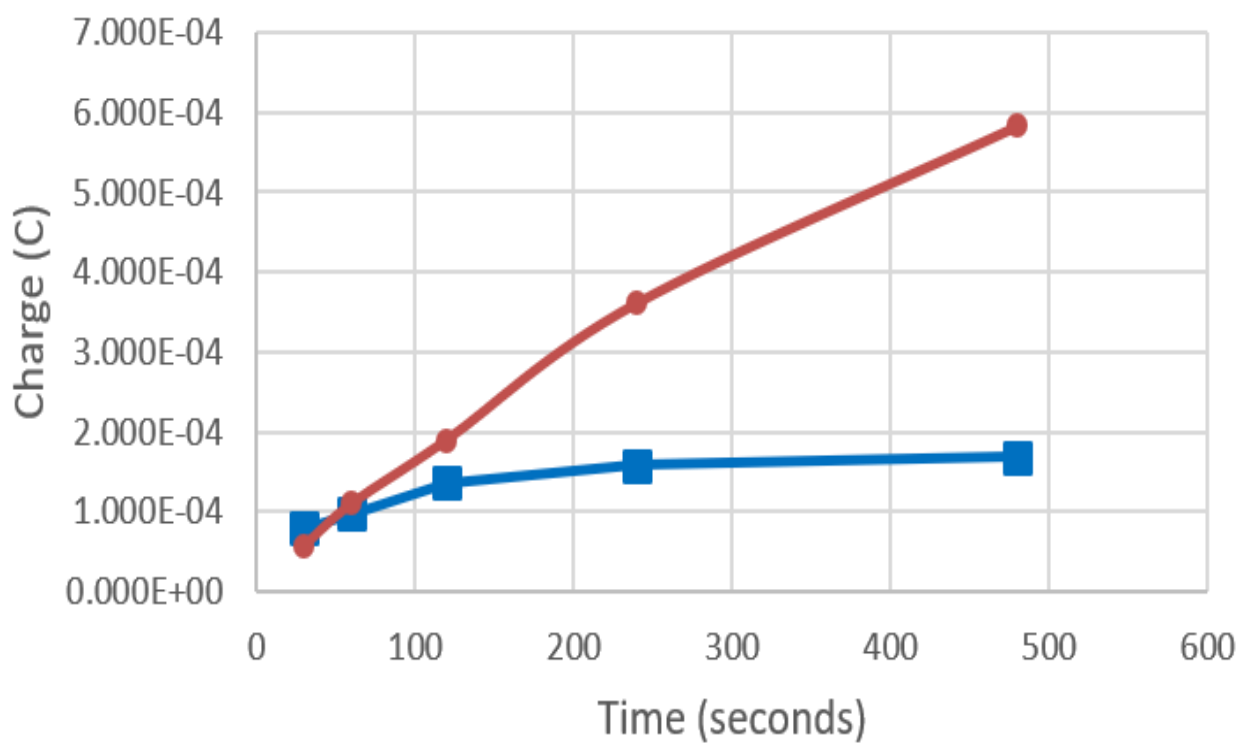

Figure 3.10. Stripping charge from ASVs of glass/ITO obtained in $0.1 \mathrm{M} \mathrm{KClO}_{4}+0.01 \mathrm{M}$ $\mathrm{KBr}$ after EPD of $4 \mathrm{~nm} \mathrm{Au} \mathrm{NPs} \mathrm{(blue)} \mathrm{and} 15 \mathrm{~nm}$ Au NPs (red) at 1.0 V using 0.1 M HQ and various EPD time. 
start with $5.72 \times 10^{-5} \mathrm{C}$ after 30 seconds and end up with $5.83 \times 10^{-4} \mathrm{C}$ after 480 seconds. The charge after 480 seconds corresponds to a coverage of $88 \mathrm{NPs} / \mu \mathrm{m}^{2}(\sim 2 \%$ of a cubic packed monolayer), which is very close to the $86 \mathrm{NPs} / \mu \mathrm{m}^{2}$ measured by SEM. While both sizes increase in Au NP coverage, the $15 \mathrm{~nm}$ Au NPs seem to increase in coverage (in terms of $\mathrm{Au}$ ) at a faster rate over the entire time period, whereas the $4 \mathrm{~nm} \mathrm{Au} \mathrm{NPs}$ coverage levels off and stops depositing. There is a greater amount of Au for every 15 nm diameter Au NP deposited and a full monolayer of $15 \mathrm{~nm}$ Au NPs should end up with a coverage about 4 times larger than a full monolayer of $4 \mathrm{~nm}$ Au NPs based on the relative thicknesses. This is consistent with the coverages shown in Figure 3.10, suggesting that a similar area of glass/ITO is occupied by both sizes, but the amount of total Au is larger for $15 \mathrm{~nm} \mathrm{Au} \mathrm{NPs} \mathrm{due} \mathrm{to} \mathrm{its} \mathrm{greater} \mathrm{height.} \mathrm{Figure} 3.11$ shows an SEM image of glass/ITO after a 480-second EPD of $4 \mathrm{~nm}$ diameter Au NPs. While they are difficult to clearly image by SEM, we observe a general graininess in the image and relatively higher particle density compared to $15 \mathrm{~nm}$ Au NPs, as expected.

Figure 3.12, Frames A and B, shows SEM images of glass/ITO following EPD of $15 \mathrm{~nm} \mathrm{Au} \mathrm{NPs} \mathrm{at} 1.6 \mathrm{~V}$ for 3 hours with $5 \mathrm{~mL}$ of $0.1 \mathrm{M}$ HQ in the EPD solution. This surface correlates with the red plot in the ASV in Figure 3.12C. Figure 3.12A shows a large view of the glass/ITO electrode covered with NPs very uniformly over the entire area. Figure $3.12 \mathrm{~B}$ is of the same slide but magnified to show a closer view of the $15 \mathrm{~nm}$ diameter Au NPs on the surface. The coverage is much larger than in Figure 3.9D, but it is still (1) less than a full cubic packed monolayer ( 15\%) and (2) covered with wellseparated Au NPs with very few NP-NP attachments. This suggests that the citrate is not fully neutralized during EPD. The liberated protons neutralize the citrate enough to cause 


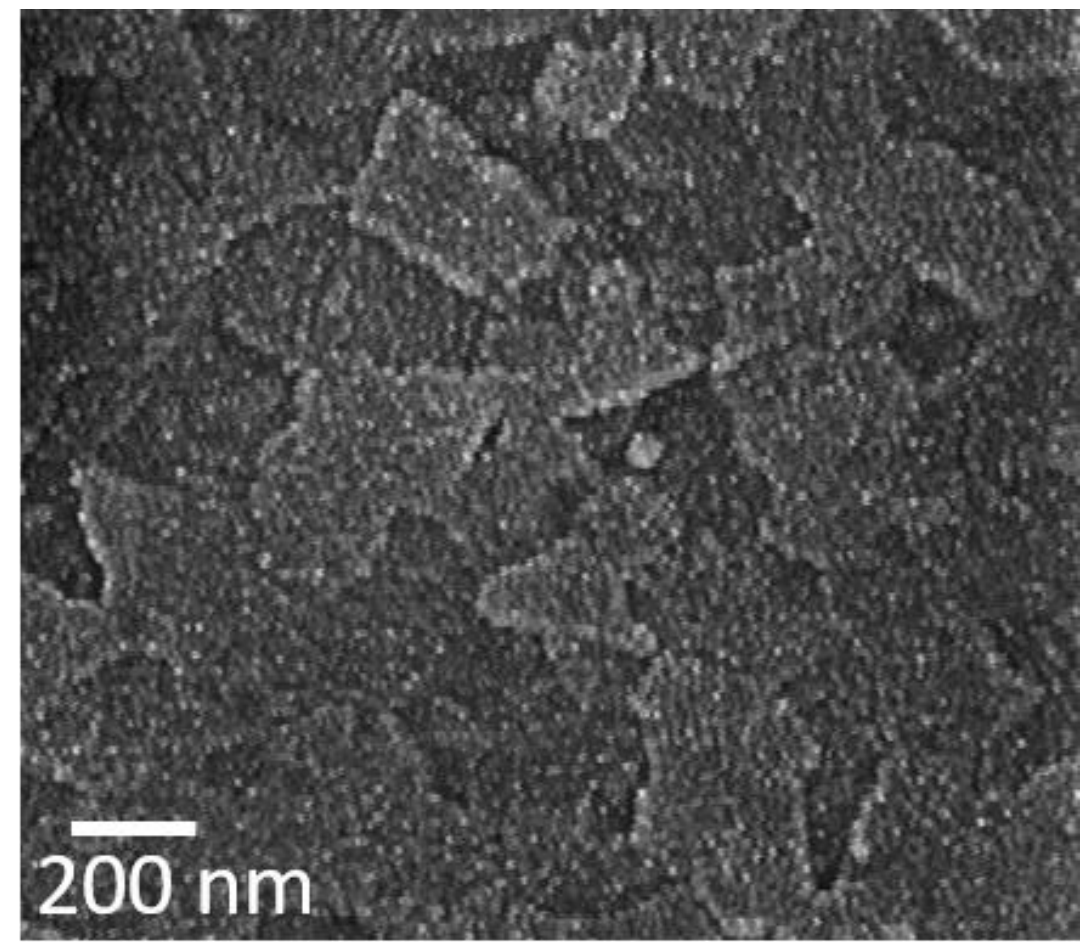

Figure 3.11. Scanning electron microscopy (SEM) image of glass/ITO after EPD of $4 \mathrm{~nm}$ Au NPs at 1.0 V for 480 seconds using 0.1 M HQ. 

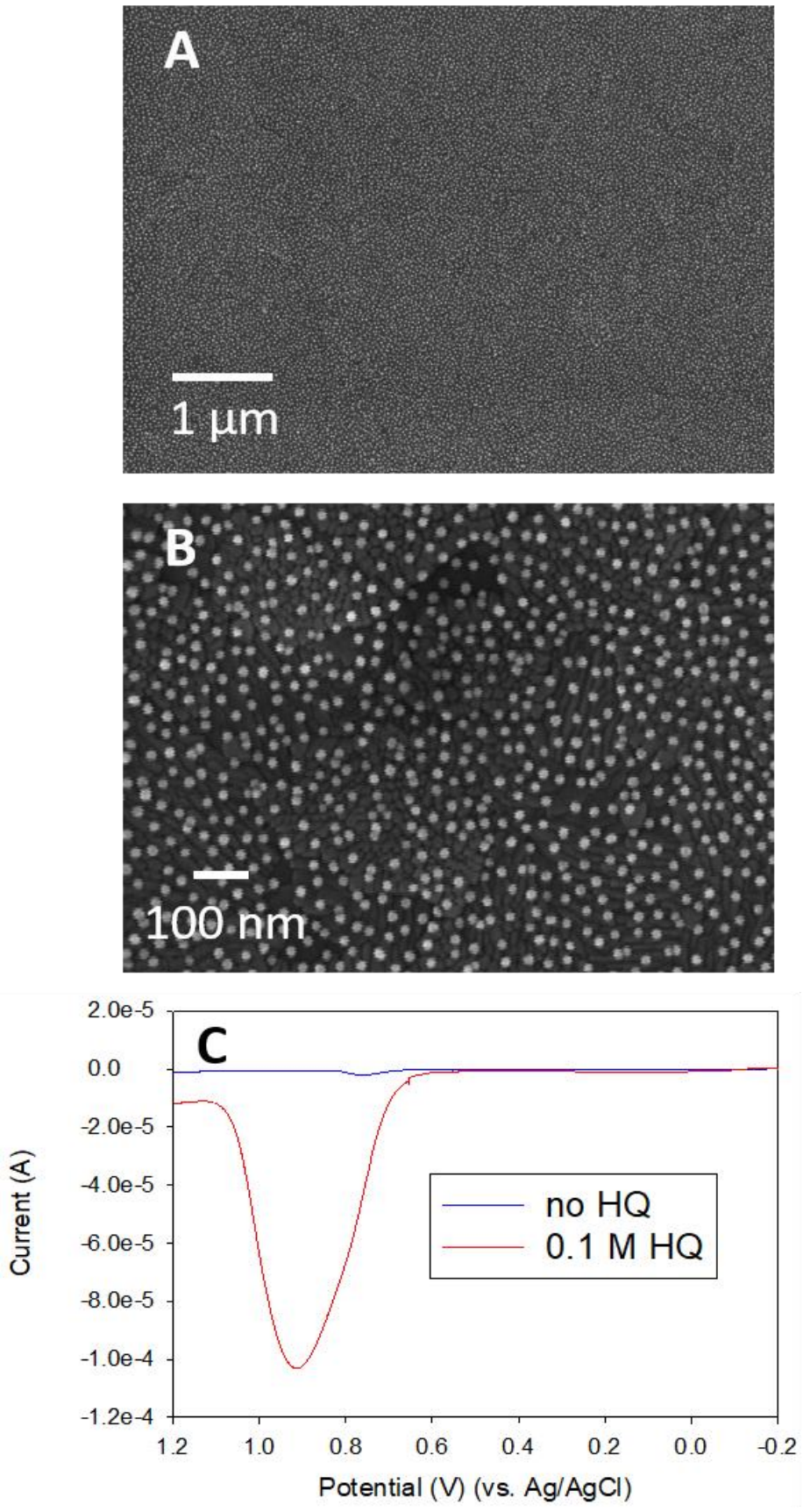

Figure 3.12. (A) SEM image of glass/ITO after EPD in $15 \mathrm{~nm}$ Au NPs at $1.6 \mathrm{~V}$ for 3 hours. (B) SEM image of the same sample as in (A) but magnified. (C) ASV of glass/ITO in $0.1 \mathrm{M} \mathrm{KClO}_{4}+0.01 \mathrm{M} \mathrm{KBr}$ after EPD of $15 \mathrm{~nm}$ Au NPs for 3 hours at $1.6 \mathrm{~V}$ with $0.1 \mathrm{M} \mathrm{HQ}$ (red) and without HQ (blue). 
destabilization or attachment to protonated ITO, but not enough to fully neutralize them. The residual negative charge on the Au NPs likely causes them to remain separated from one another on the glass/ITO surface during deposition and may also prevent multilayer deposition. This interesting phenomenon will be explored in more detail in the future.

In order to confirm that the $\mathrm{HQ}$ is again primarily responsible for the deposition of NPs onto the electrode surface, two additional experiments were performed. First, a control experiment was performed under the same conditions but with $5 \mathrm{~mL}$ of water instead of $5 \mathrm{~mL}$ of $0.1 \mathrm{M} \mathrm{HQ}$ in the EPD solution. Figure 3.12C shows the ASVs of glass/ITO after EPD of $15 \mathrm{~nm}$ Au NPs with HQ (red plot) and without HQ (blue plot) in the EPD solution with a potential of $1.6 \mathrm{~V}$ held for 3 hours. The Au coverage was $1.3 \mathrm{x}$ $10^{-3} \mathrm{C}$ with HQ and $8.9 \times 10^{-6} \mathrm{C}$ without HQ. The second experiment involved substituting HQ in the EPD solution with twice the concentration of potassium ferrocyanide, $\mathrm{K}_{4} \mathrm{Fe}(\mathrm{CN})_{6}$. The purpose of using $\mathrm{K}_{4} \mathrm{Fe}(\mathrm{CN})_{6}$ was to show that the oxidation of a non-proton liberating molecule does not cause EPD. Figure 3.13 shows ASVs of glass/ITO after EPD of $4 \mathrm{~nm}$ Au NPs in the presence of $5 \mathrm{~mL}$ of $0.01 \mathrm{M} \mathrm{HQ}$ solution (red plot) and $5 \mathrm{~mL}$ of $0.02 \mathrm{M}$ potassium ferrocyanide, $\mathrm{K}_{4} \mathrm{Fe}(\mathrm{CN})_{6}$ solution (blue plot). The $\mathrm{K}_{4} \mathrm{Fe}(\mathrm{CN})_{6}$ concentration was doubled because it is only a 1 electron redox couple. The ASV after EPD in HQ shows a peak around $760 \mathrm{mV}$ for Au oxidation, indicating successful EPD as expected. The ASV after EPD in $\mathrm{K}_{4} \mathrm{Fe}(\mathrm{CN})_{6}$ shows a minimal peak for Au oxidation, confirming that a proton-producing redox molecule is needed for significant EPD of citrate-stabilized Au NPs at these fairly low potentials. 


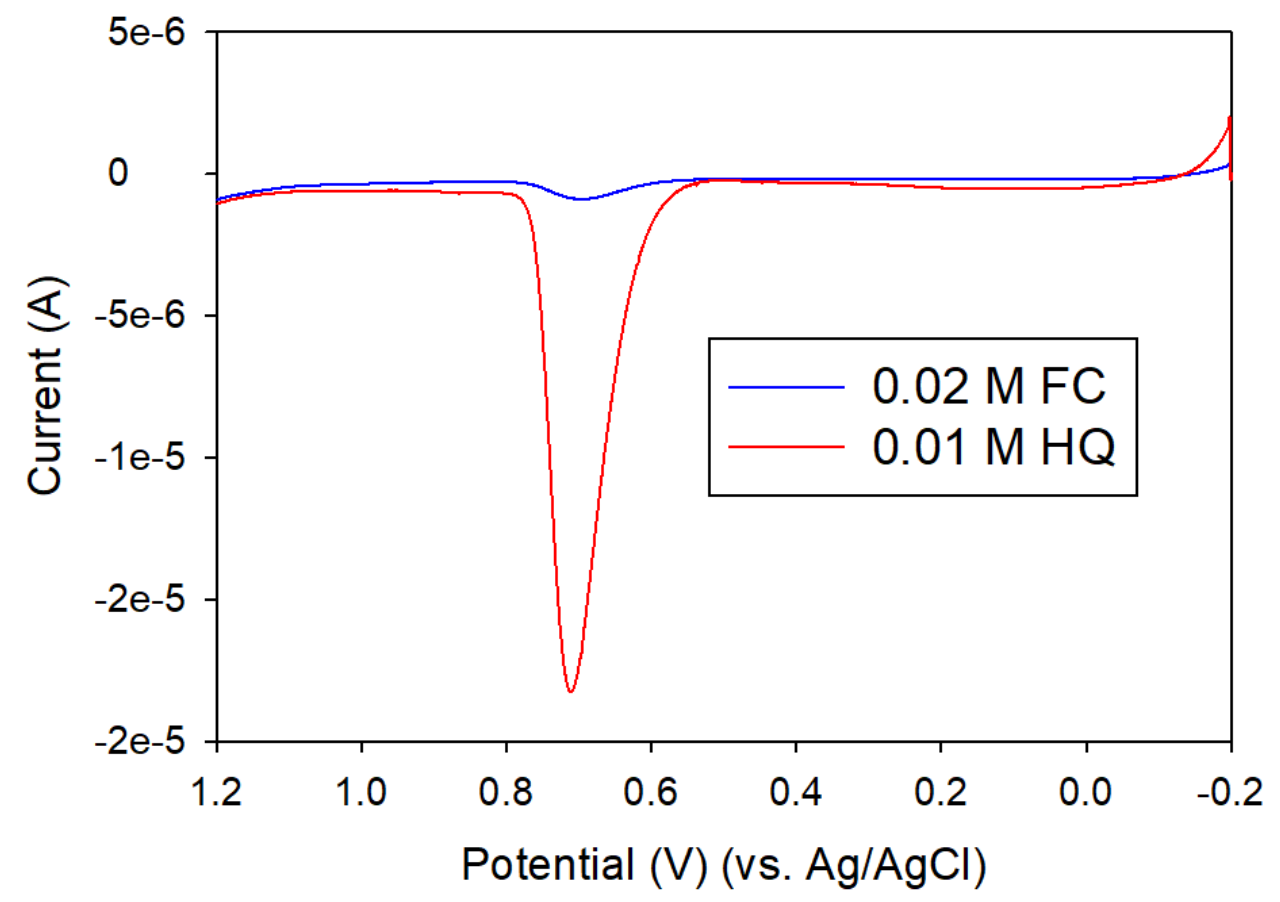

Figure 3.13. ASVs of glass/ITO in $0.1 \mathrm{M} \mathrm{KClO}_{4}$ plus $0.01 \mathrm{M} \mathrm{KBr}$ after EPD of $4 \mathrm{~nm} \mathrm{Au}$ NPs at $1.0 \mathrm{~V}$ for 60 seconds using $5 \mathrm{~mL}$ of $0.01 \mathrm{M} \mathrm{HQ}$ (red) and at $1.0 \mathrm{~V}$ for 60 seconds using $5 \mathrm{~mL}$ of $0.02 \mathrm{M} \mathrm{K}_{4} \mathrm{Fe}(\mathrm{CN})_{6}$ (blue). 


\subsection{Conclusions}

This work shows that the deposition of negatively-charged citrate-stabilized Au NPs can be promoted by the electrochemical release of protons from proton-producing electroactive molecules, such as HQ. The deposition occurs via two possible mechanisms or a combination of them. The first involves neutralization of the negative charge of citrate, leading to destabilization of the Au NPs in solution and deposition on the electrode surface. The second involves protonation of the ITO by a local pH below the pzc, which leads to electrostatic attraction of the citrate-stabilized Au NPs. HQ oxidation must produce an estimated local $\mathrm{pH}$ of 3.1 or less in order for significant deposition to occur. The $4 \mathrm{~nm}$ Au NPs deposit selectively at lower EPD potentials since the electron transfer kinetics of HQ oxidation is faster (more catalytic) at the smaller 4 $\mathrm{nm}$ diameter Au NPs compared to the $15 \mathrm{~nm}$ Au NPs. This work is significant because it addresses issues of NP deposition on electrode surfaces. It will hopefully have a significant impact on our understanding of EPD of nanomaterials and should be of interest when fabricating sensors and electrocatalytic surfaces or manipulating structures at the nanoscale. This work is relevant to both NP electrocatalysis ${ }^{108-109}$ and NP collision studies at microelectrodes as well. ${ }^{110-112}$ 


\section{CHAPTER 4}

NANOPARTICLE (NP)-ASSISTED ELECTROPHORETIC DEPOSITION (EPD)

\subsection{Introduction}

The objective of this project is to use $4 \mathrm{~nm}$ diameter citrate-coated Au NPs as a catalyst in conjunction with hydroquinone (HQ) to aid in the electrophoretic deposition (EPD) of other types of NPs at lower potentials where they normally would not deposit by EPD. Figure 4.1 demonstrates this concept by showing how under certain EPD parameters, the NPs do not stick to the electrode, but once the $4 \mathrm{~nm}$ Au NPs are added to the EPD solution, those NPs do start to deposit. Since catalysis occurs on the surface of a NP, the more surface area a particle has, the more catalytic it is. Therefore, smaller NPs are more catalytic than larger size NPs. Based on this principle, we used the $4 \mathrm{~nm} \mathrm{Au}$ NPs to catalyze reactions with three different types of NPs: $15 \mathrm{~nm}$ Au NPs, palladium (Pd) NP, and titanium dioxide $\left(\mathrm{TiO}_{2}\right)$ NPs. All of these experiments used the $4 \mathrm{~nm} \mathrm{Au}$ NPs to attach another type of NP onto the surface of the glass/ITO substrate at potentials where those NPs normally do not attach. The idea being that by adding a component to the EPD solution that oxidizes HQ at a lower potential than that of the other NPs in the solution, we would be able to collect those NPs under conditions that would typically not lead to deposition. In this case, the component that oxidizes HQ at a lower potential is the $4 \mathrm{~nm} \mathrm{Au} \mathrm{NPs,} \mathrm{and} \mathrm{the} \mathrm{other} \mathrm{NPs} \mathrm{trying} \mathrm{to} \mathrm{be} \mathrm{collected} \mathrm{were} 15 \mathrm{~nm} \mathrm{Au} \mathrm{NPs,} \mathrm{Pd} \mathrm{NPs,}$ and $\mathrm{TiO}_{2}$ NPs. We were able to attach all three NPs to the surface of the electrode under conditions that would normally not result in deposition, but with the assistance of the 4 
$15 \mathrm{~nm}$ Au NPs only in the EPD solution

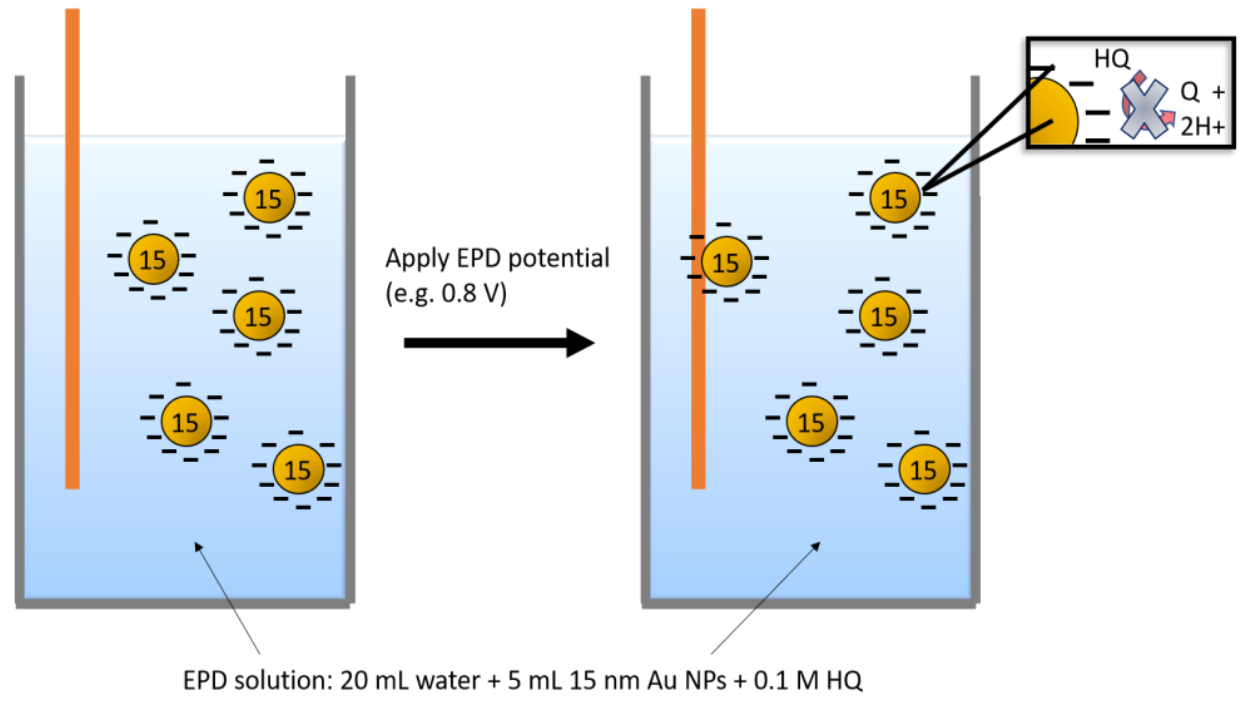

$4 \mathrm{~nm}$ Au NPs plus $15 \mathrm{~nm}$ Au NPs only in the EPD solution

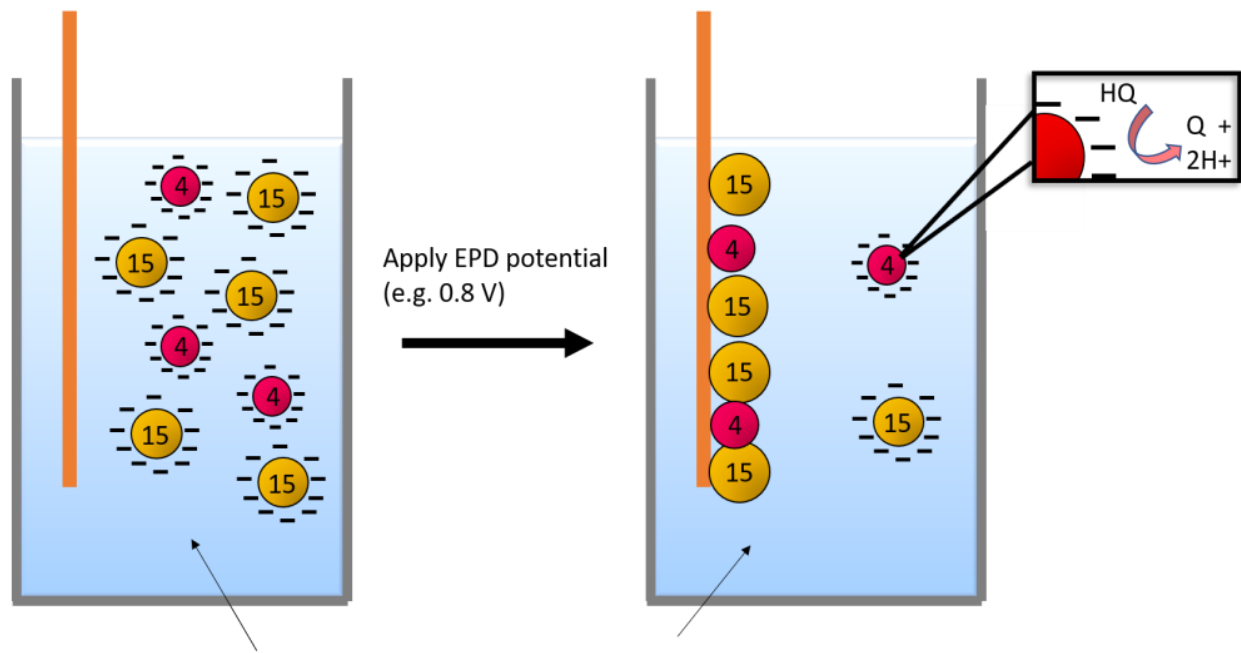

EPD solution: $20 \mathrm{~mL}$ water $+500 \mu \mathrm{L} 4 \mathrm{~nm}$ Au NPs $+4.5 \mathrm{~mL} 15 \mathrm{~nm}$ Au NPs $+0.1 \mathrm{M} \mathrm{HQ}$

Figure 4.1. Scheme showing concept for the NP-assisted EPD. The top diagram shows just $15 \mathrm{~nm}$ Au NPs in the EPD solution and negligible deposition. The bottom diagram shows that with the addition of the $4 \mathrm{~nm}$ Au NPs in the EPD solution, deposition for the 15 $\mathrm{nm}$ Au NPs occurs under the same parameters. This concept is applied to all three NPs analyzed in this chapter: $15 \mathrm{~nm}$ Au NP, Pd NPs, and $\mathrm{TiO}_{2} \mathrm{NPs}$. 
$\mathrm{nm}$ Au NPs in the EPD solution, all three of these NPs were able to be deposited by this NP-assisted EDP process.

\subsection{Experimental}

\subsection{1. $15 \mathrm{~nm}$ Au NPs}

In order to show the catalytic activity of the $4 \mathrm{~nm} \mathrm{Au} \mathrm{NPs,} \mathrm{we} \mathrm{first} \mathrm{had} \mathrm{to} \mathrm{show}$ that the larger size NPs would not deposit on their own under certain EPD parameters. First, $4 \mathrm{~nm}$ Au NPs and $15 \mathrm{~nm}$ Au NPs were synthesized and then attached separately to glass/ITO/APTES slides by soaking the slides in the Au NP solution for two minutes to allow sufficient coverage. The glass/ITO/APTES/AuNP slides were ran in CV mode from -0.1 to $1.2 \mathrm{~V}$ and back in a solution of $0.005 \mathrm{M} \mathrm{HQ}$ plus $0.1 \mathrm{M} \mathrm{KClO}_{4}$ in order to determine the potential at which the two separate sizes oxidize the HQ. After we determined the potential that each size oxidizes HQ, we could then select that potential for deposition of the Au NPs in the EPD solution. As shown in Figure 4.2, the $4 \mathrm{~nm} \mathrm{Au}$ NPs oxidize HQ at $600 \mathrm{mV}$ and the $15 \mathrm{~nm}$ Au NPs oxidize HQ just positive of $800 \mathrm{mV}$. Based on these results, we know that any EPD potential above $600 \mathrm{mV}$ will result in deposition of the $4 \mathrm{~nm} \mathrm{Au} \mathrm{NPs} \mathrm{and} \mathrm{any} \mathrm{potential} \mathrm{above} 800 \mathrm{mV}$ will cause the $15 \mathrm{~nm} \mathrm{Au}$ NPs to deposit.

After the initial CVs of 0.005 M HQ plus $0.1 \mathrm{M} \mathrm{KClO4,} \mathrm{we} \mathrm{performed} \mathrm{EPD} \mathrm{with}$ $20 \mathrm{~mL}$ of nanopore water plus $5 \mathrm{~mL}$ of Au NP solution plus $5 \mathrm{~mL} 0.1 \mathrm{M} \mathrm{HQ}$ at varying potential for varying amounts of time. We started with holding the $15 \mathrm{~nm} \mathrm{Au} \mathrm{NPs} \mathrm{at} 0.8$ $\mathrm{V}$ for 5 minutes and then ran the ASV. The next experiment we did involved attaching the $4 \mathrm{~nm} \mathrm{Au} \mathrm{NPs} \mathrm{to} \mathrm{the} \mathrm{electrode} \mathrm{surface} \mathrm{first.} \mathrm{We} \mathrm{performed} \mathrm{two} \mathrm{separate} \mathrm{EPD} \mathrm{steps:}$ the first was with $4 \mathrm{~nm} \mathrm{Au} \mathrm{NPs} \mathrm{at} 0.8 \mathrm{~V}$ for 5 seconds and the second was with $15 \mathrm{~nm} \mathrm{Au}$ 


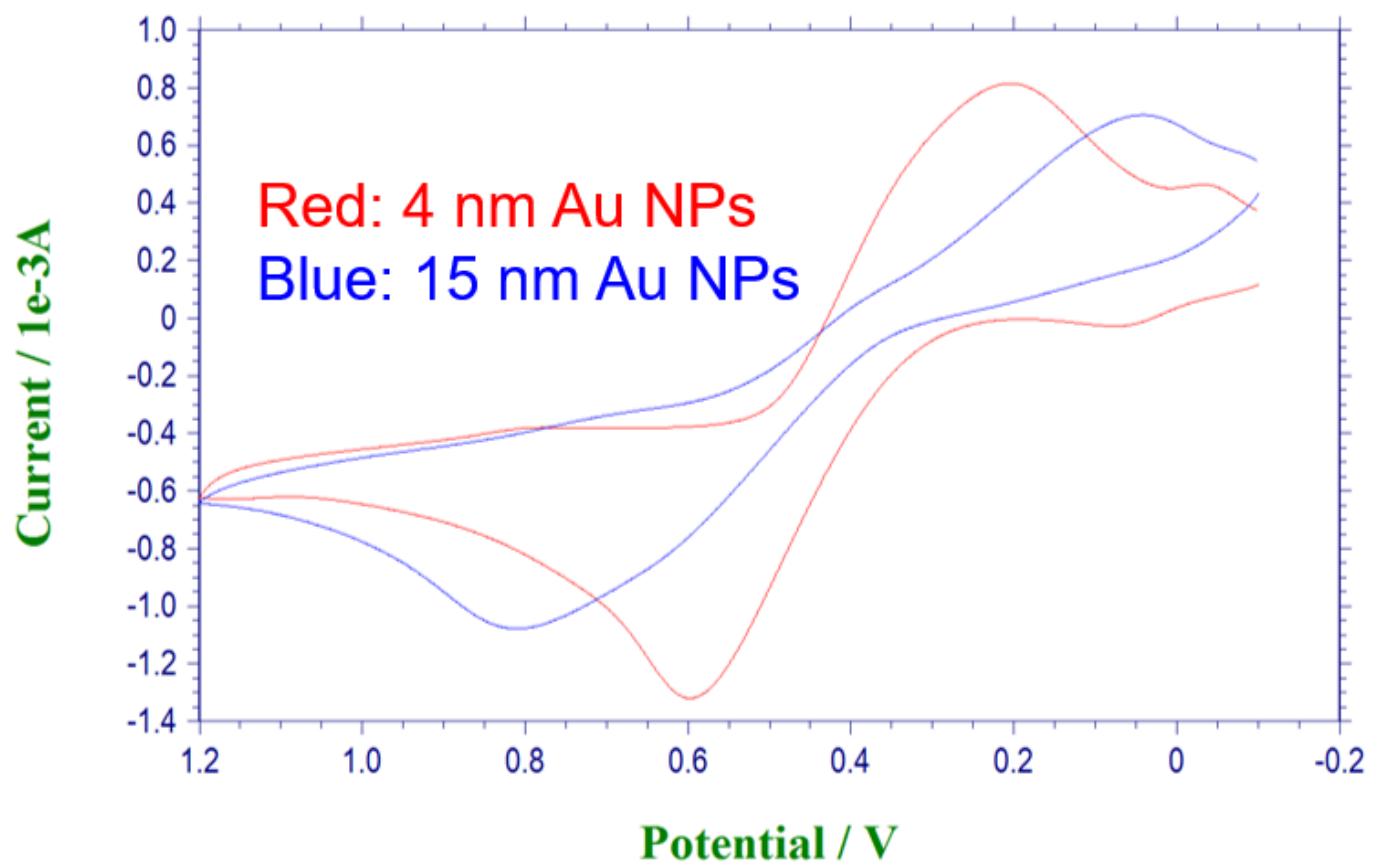

Figure 4.2. HQ voltammetry with $4 \mathrm{~nm}$ and $15 \mathrm{~nm}$ Au NPs on glass/ITO. CVs of glass/ITO/APTES/Au NPs ( $4 \mathrm{~nm}$ or $15 \mathrm{~nm}$ ) in $0.005 \mathrm{M}$ HQ plus $0.1 \mathrm{M} \mathrm{KClO}_{4}$ scanned from $-0.1 \mathrm{~V}$ to $1.2 \mathrm{~V}$ and back. 
NPs at $0.8 \mathrm{~V}$ for 5 minutes. We did the same experiment again, but this time held the 4 $\mathrm{nm} \mathrm{Au} \mathrm{NPs} \mathrm{at} 0.8 \mathrm{~V}$ for 15 seconds and the $15 \mathrm{~nm} \mathrm{Au} \mathrm{NPs} \mathrm{at} 0.8 \mathrm{~V}$ for 5 minutes. The purpose was to see if holding the $4 \mathrm{~nm}$ Au NPs for a longer EPD time would result in an increase of deposition for the $15 \mathrm{~nm}$ Au NPs. All ASVs were ran in $10 \mathrm{mM} \mathrm{KBr}$ and 0.1 $\mathrm{M} \mathrm{KClO}_{4}$ solution from $-0.2 \mathrm{~V}$ to $1.2 \mathrm{~V}$ at a scan rate of $0.01 \mathrm{~V} / \mathrm{s}$.

After performing the experiment in two separate EPD steps, we wanted to consolidate the experiment into only one EPD step. This meant combining the two different sizes in the same EPD solution to see if we could still increase the amount of 15 $\mathrm{nm}$ Au NP deposited while not having a huge oxidation peak for the $4 \mathrm{~nm}$ Au NPs. We would accomplish this by decreasing the amount of $4 \mathrm{~nm} \mathrm{Au} \mathrm{NPs} \mathrm{in} \mathrm{the} \mathrm{EPD} \mathrm{solution,} \mathrm{so}$ it contained either $250 \mu \mathrm{L}$ of $4 \mathrm{~nm}$ Au NPs and $4.75 \mathrm{~mL}$ of $15 \mathrm{~nm} \mathrm{Au} \mathrm{NPs}$, or it had 500 $\mu \mathrm{L}$ of $4 \mathrm{~nm}$ Au NPs and $4.5 \mathrm{~mL}$ of $15 \mathrm{~nm}$ Au NPs. Either way there was a total of $5 \mathrm{~mL}$ of $\mathrm{Au}$ NPs in the EPD solution along with $20 \mathrm{~mL}$ nanopore water and $5 \mathrm{~mL} 0.1 \mathrm{M} \mathrm{HQ}$. The EPD was held even lower at $0.4 \mathrm{~V}$ and $0.6 \mathrm{~V}$ but the time remained the same at 5 minutes.

\subsubsection{Pd NPs}

The Pd NP experiment was set-up in a similar way to the $15 \mathrm{~nm}$ Au NPs. W first ran CVs of the separate NPs in a solution of $0.005 \mathrm{M} \mathrm{HQ}$ plus $0.1 \mathrm{M} \mathrm{KClO}_{4}$ in order to determine the potential at which the two different metals oxidize HQ. Then once those potentials were determined, we performed EPD on a mixture of the two metals. We selected potentials lower than the one established by the CV to show that the $4 \mathrm{~nm} \mathrm{Au}$ NPs were assisting in the deposition of the Pd NPs. The EPD solution contained $20 \mathrm{~mL}$ nanopore water plus $2.5 \mathrm{~mL} 4 \mathrm{~nm}$ Au NPs plus $2.5 \mathrm{~mL}$ Pd NPs plus $5 \mathrm{~mL} \mathrm{0.1} \mathrm{M} \mathrm{HQ} \mathrm{for}$ 
the first part and $20 \mathrm{~mL}$ nanopore water, $4 \mathrm{~mL}$ Pd NPs, $1 \mathrm{~mL} 4 \mathrm{~nm}$ Au NPs, and $5 \mathrm{~mL} 0.1$ M HQ for the second part. EPD potentials ranged from $0.23 \mathrm{~V}$ to $1.0 \mathrm{~V}$ and the EPD times were typically 60 seconds but ranged from 1 minute to 10 minutes. After EPD, the ASVs were performed in $10 \mathrm{mM} \mathrm{KBr}$ and $0.1 \mathrm{M} \mathrm{HClO}_{4}$ solution from $-0.2 \mathrm{~V}$ to $1.2 \mathrm{~V}$ at a scan rate of $0.01 \mathrm{~V} / \mathrm{s}$.

\subsection{3. $\mathrm{TiO}_{2} \mathrm{NPs}$}

The third part of the NP-assisted EPD processes involved using $10 \mathrm{~nm} \mathrm{TiO}_{2}$ NPs to attach to the electrode surface for purposes of semiconductor fabrication. We used UV-vis spectroscopy to analyze the deposition of $\mathrm{TiO}_{2} \mathrm{NPs}$ onto the glass/ITO electrode and scanned from $900 \mathrm{~nm}$ to $300 \mathrm{~nm}$. First, we performed EPD on $\mathrm{TiO}_{2} \mathrm{NPs}$ by themselves (without the $4 \mathrm{~nm}$ Au NPs in the EPD solution) to observe if they would deposit on their own. Then we added the $4 \mathrm{~nm}$ Au NPs into the EPD solution along with the $\mathrm{TiO}_{2}$ NPs and repeated the EPD under the same conditions. The EPD solution contained $20 \mathrm{~mL}$ of nanopore water, $4 \mathrm{~mL}$ TiO2 NPs, $1 \mathrm{~mL}$ of $4 \mathrm{~nm} \mathrm{Au} \mathrm{NPs}$, and $5 \mathrm{~mL}$ 0.1 M HQ. The EPD was held at either $0.3,0.35$, or $0.4 \mathrm{~V}$ for 60 seconds, then the slide was rinsed with nanopore water, held under a gentle stream of $\mathrm{N}_{2}$ for drying, and then the UV-vis spectrum was taken. This cycle was repeated five times on the same slide to see if a thin film of $\mathrm{TiO}_{2}$ could be obtained.

\subsection{Results and Discussion}

\subsection{1. $15 \mathrm{~nm}$ Au NPs}

Figure 4.2 shows CVs of glass/ITO/APTES/Au NPs (4 nm or $15 \mathrm{~nm}$ ) in $0.005 \mathrm{M}$ HQ plus $0.1 \mathrm{M} \mathrm{KClO}_{4}$ scanned from $-0.1 \mathrm{~V}$ to $1.2 \mathrm{~V}$ and back. The set of peaks is due to the oxidation and reduction of HQ. The $4 \mathrm{~nm}$ Au NPs catalyze the HQ 
oxidation/reduction better than the $15 \mathrm{~nm}$ Au NPs, which is indicated by the oxidation peak being more negative by about $200 \mathrm{mV}$ and the reduction peak being more positive and the peak separation being smaller.

Due to the difference in oxidation potential for each of these size NPs, we were able to use the smaller size NP to attach the larger size NP under conditions that would normally not result in deposition or increase the amount of $15 \mathrm{~nm} \mathrm{Au} \mathrm{NPs} \mathrm{that} \mathrm{deposit}$ onto the electrode surface. Figure 4.3 shows three ASVs: one is with $15 \mathrm{~nm}$ Au NPs alone in the EPD solution (orange plot), the second one is with $4 \mathrm{~nm}$ Au NPs attached first for only 5 seconds (blue plot), and the third is with the $4 \mathrm{~nm}$ Au NPs attached first for 15 seconds (red plot). When the $15 \mathrm{~nm}$ Au NPs are alone in the EPD solution, there is very little coverage. However, once the $4 \mathrm{~nm}$ Au NPs are attached first, the coverage of $15 \mathrm{~nm} \mathrm{Au} \mathrm{NPs} \mathrm{increases} \mathrm{significantly,} \mathrm{and} \mathrm{it} \mathrm{increases} \mathrm{even} \mathrm{more} \mathrm{when} \mathrm{the} 4 \mathrm{~nm} \mathrm{Au}$ NPs are attached for 15 seconds. This data shows that attaching the $4 \mathrm{~nm}$ Au NPs to the electrode surface first greatly increases the amount of $15 \mathrm{~nm}$ Au NPs that are collected. This two-step EPD process is illustrated in Figure 4.4.

The second part of this experiment involved performing the EPD in just one step by combining the two different sizes in the same EPD solution. Figure 4.5 shows four ASVs with the different amounts of $4 \mathrm{~nm}$ Au NPs assisting in the deposition, but the total volume of Au NPs is always $5 \mathrm{~mL}$. The pink plot is a control of just the $15 \mathrm{~nm}$ Au NPs held at $0.6 \mathrm{~V}$ for 5 minutes. There is no peak for the $15 \mathrm{~nm}$ Au NPs which correlates well to the $\mathrm{CV}$ in Figure 4.2 which shows the oxidation of HQ by the $15 \mathrm{~nm}$ Au NPs just above $0.8 \mathrm{~V}$. Based on that CV and the pink plot in Figure 4.5, we know that the $15 \mathrm{~nm}$ Au NPs do not deposit on their own at $0.6 \mathrm{~V}$. However, once we add the $4 \mathrm{~nm}$ Au NPs to 


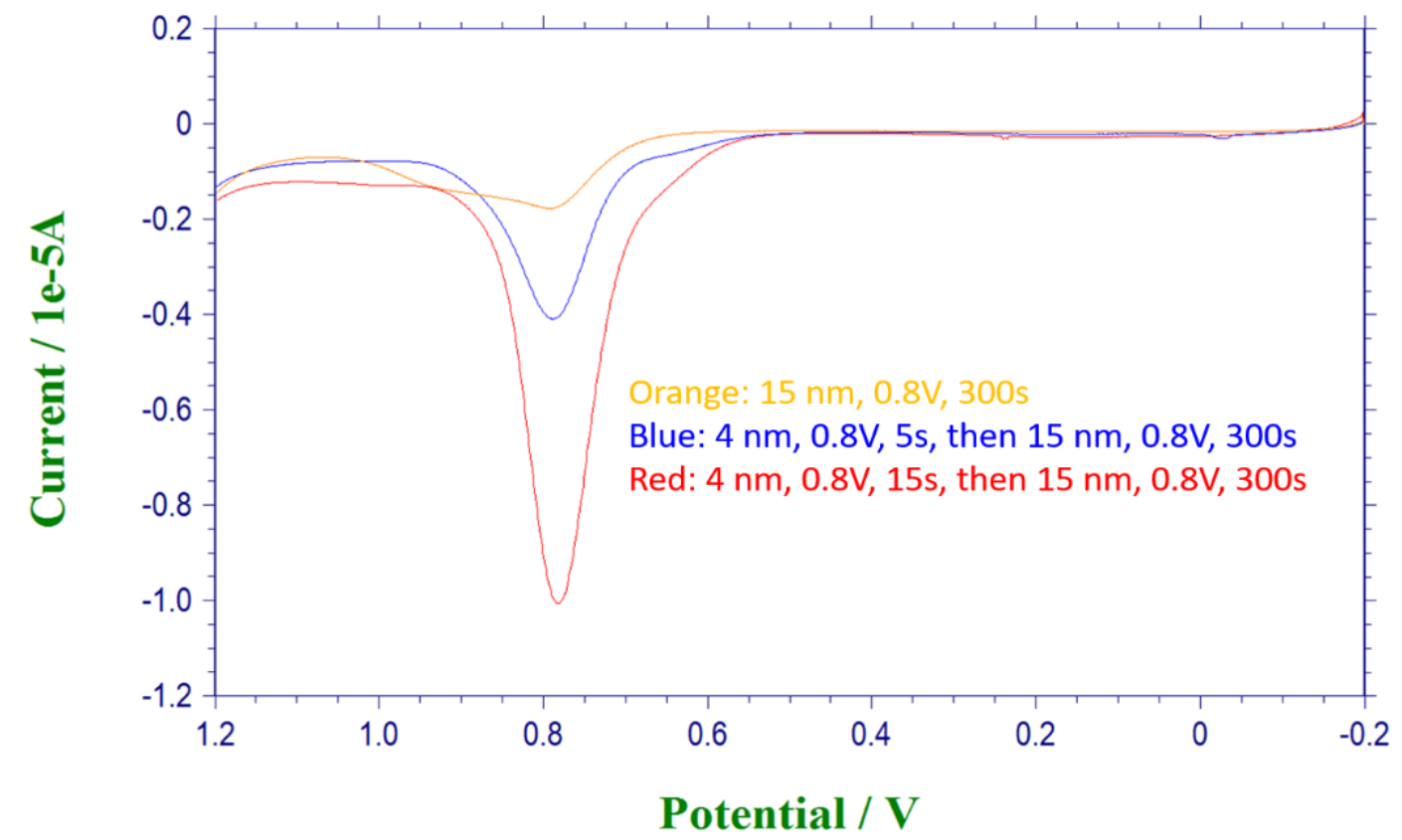

Figure 4.3. ASVs of the $15 \mathrm{~nm}$ Au NPs alone at $0.8 \mathrm{~V}$ for 5 minutes (orange), $4 \mathrm{~nm} \mathrm{Au} \mathrm{NPs} \mathrm{attached}$ first for 5 seconds at $0.8 \mathrm{~V}$ and then $15 \mathrm{~nm}$ Au NPs at $0.8 \mathrm{~V}$ for 5 minutes (blue), and $4 \mathrm{~nm} \mathrm{Au} \mathrm{NPs}$ attached first for 15 seconds at $0.8 \mathrm{~V}$ and then $15 \mathrm{~nm}$ Au NPs at $0.8 \mathrm{~V}$ for 5 minutes (red). Scans were run in $10 \mathrm{mM} \mathrm{KBr}$ and $0.1 \mathrm{M} \mathrm{KClO}_{4}$ at a scan rate of $0.01 \mathrm{~V} / \mathrm{s}$ on glass/ITO slides. 
Two-Step EPD Process.

1) $4 \mathrm{~nm}$ Au NPs only in EPD solution - attach smaller size to WE first

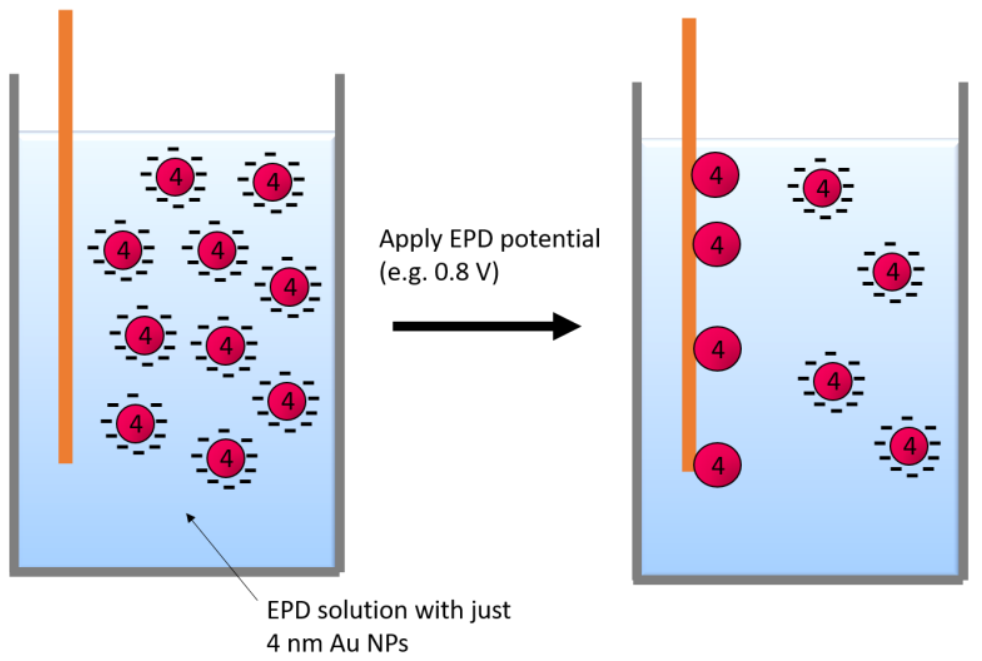

\section{2) $15 \mathrm{~nm}$ Au NPs in EPD solution}

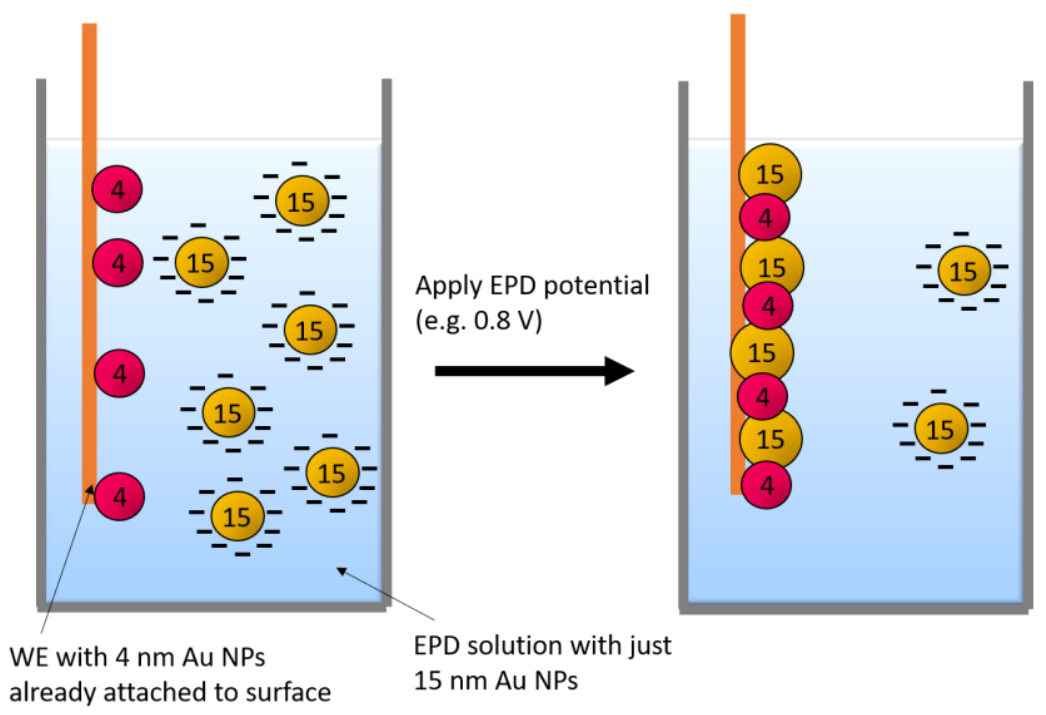

Figure 4.4. Two-step EPD process. First step involves attaching the $4 \mathrm{~nm}$ Au NPs to the WE. The second step involves placing the WE with $4 \mathrm{~nm}$ Au NPs into an EPD solution with $15 \mathrm{~nm} \mathrm{Au}$ NPs to get the larger size NPs to attach under conditions that would normally not result in deposition. 


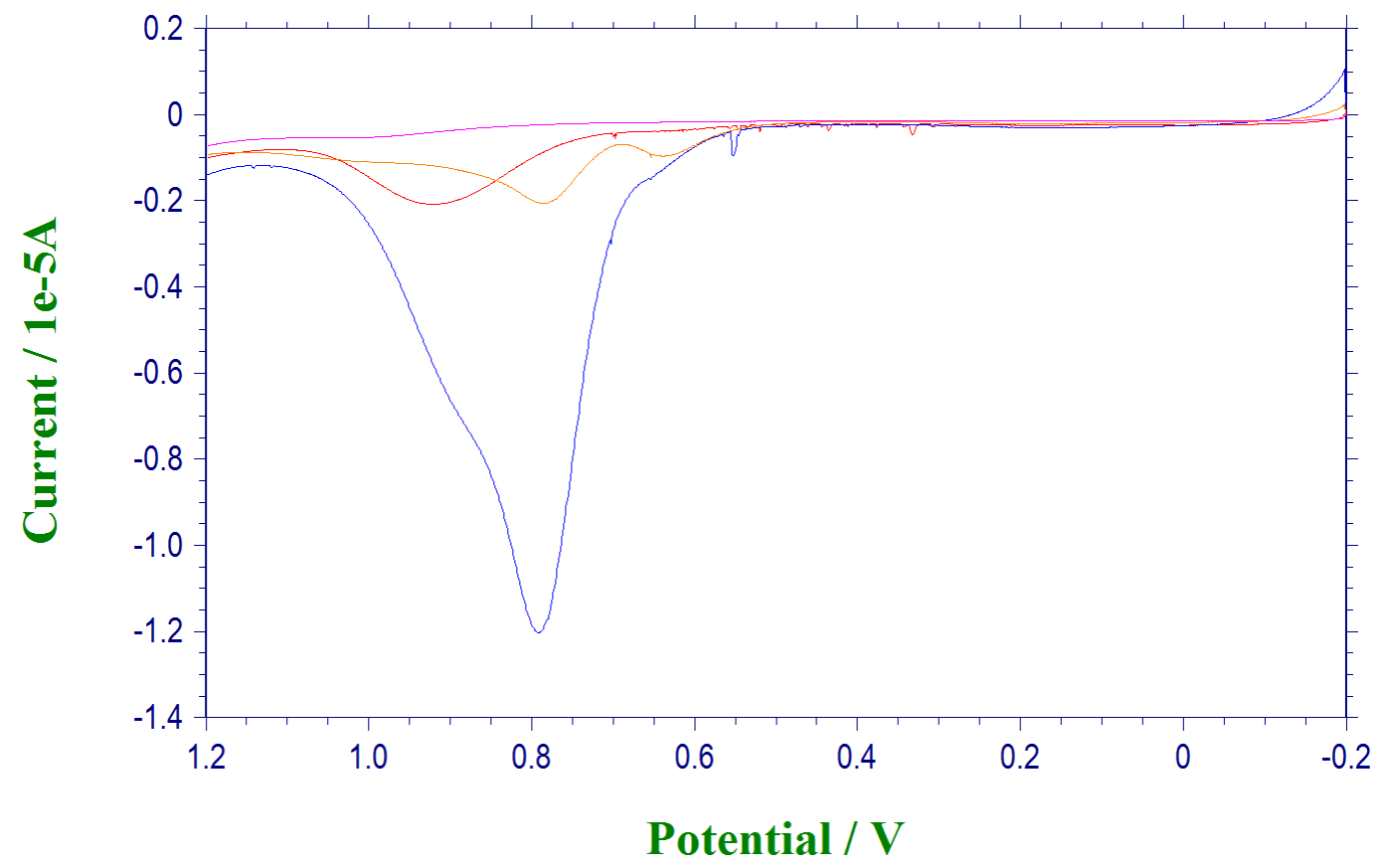

Figure 4.5. ASVs of $15 \mathrm{~nm}$ alone at $0.6 \mathrm{~V}$ for 5 minutes (pink), $250 \mu \mathrm{L}$ of $4 \mathrm{~nm}$ Au NPs and 4.75 $\mathrm{mL}$ of $15 \mathrm{~nm}$ Au NPs at $0.6 \mathrm{~V}$ for 5 minutes (red), $500 \mu \mathrm{L}$ of $4 \mathrm{~nm}$ Au NPs and $4.5 \mathrm{~mL}$ of $15 \mathrm{~nm} \mathrm{Au}$ NPs at $0.4 \mathrm{~V}$ for 5 minutes (orange), and $500 \mu \mathrm{L}$ of $4 \mathrm{~nm}$ Au NPs and $4.5 \mathrm{~mL}$ of $15 \mathrm{~nm}$ Au NPs at $0.6 \mathrm{~V}$ for 5 minutes (blue). All scans were run in $10 \mathrm{mM} \mathrm{KBr}$ and $0.1 \mathrm{M} \mathrm{KClO}_{4}$ at a scan rate of $0.01 \mathrm{~V} / \mathrm{s}$ on glass/ITO slides. 
the EPD solution, we start to see coverage for the $15 \mathrm{~nm}$ Au NPs as demonstrated by the red, orange, and blue plots in Figure 4.5. The red plot is of $250 \mu \mathrm{L}$ of the $4 \mathrm{~nm}$ Au NPs (and $4.75 \mathrm{~mL} 15 \mathrm{~nm} \mathrm{Au} \mathrm{NPs)} \mathrm{in} \mathrm{the} \mathrm{EPD} \mathrm{solution} \mathrm{at} 0.6 \mathrm{~V}$, the orange plot is with 500 $\mu \mathrm{L}$ of $4 \mathrm{~nm}$ Au NPs (and $4.5 \mathrm{~mL} 15 \mathrm{~nm}$ Au NPs) at $0.4 \mathrm{~V}$, and the blue plot is with 500 $\mu \mathrm{L}$ of the $4 \mathrm{~nm} \mathrm{Au} \mathrm{NPs} \mathrm{(and} 4.5 \mathrm{~mL} 15 \mathrm{~nm} \mathrm{Au} \mathrm{NPs}$ ) at $0.6 \mathrm{~V}$, and all trials were held for 5 minutes. The red plot shows an oxidation peak for the $15 \mathrm{~nm}$ Au NPs with a coverage of approximately $0.2 \times 10^{-5} \mathrm{~A}$. But once we increase the amount of $4 \mathrm{~nm}$ Au NPs to 500 $\mu \mathrm{L}$ (with $4.5 \mathrm{~mL}$ of $15 \mathrm{~nm} \mathrm{Au} \mathrm{NPs),} \mathrm{the} \mathrm{coverage} \mathrm{for} \mathrm{the} 15 \mathrm{~nm}$ Au NPs increase to over $1.2 \times 10^{-5} \mathrm{~A}$. The blue plot tells us that we can hold the potential at $0.6 \mathrm{~V}$ for 5 minutes and get a significant amount of $15 \mathrm{~nm}$ Au NPs attached to electrode surface just by adding $500 \mu \mathrm{L}$ of $4 \mathrm{~nm}$ Au NPs to the EPD solution when normally it would not deposit (pink plot).

\subsubsection{Pd NPs}

The second example of the NP-assisted EPD involved mixing the $4 \mathrm{~nm}$ Au NPs with Pd NPs in the EPD solution. First, we ran CVs of the separate metal NPs in 0.005 M HQ plus $0.1 \mathrm{M} \mathrm{KClO}_{4}$ which were scanned from $-0.1 \mathrm{~V}$ to $1.2 \mathrm{~V}$ and back. Figure 4.6 is on overlay of the two CVs which show that the $4 \mathrm{~nm}$ Au NPs oxidize HQ around 475 $\mathrm{mV}$ and the Pd NPs oxidize HQ around $675 \mathrm{mV}$. After this preliminary scan, we ran the EPD with $2.5 \mathrm{~mL}$ of the $4 \mathrm{~nm}$ Au NPs and $2.5 \mathrm{~mL}$ of the Pd NPs in the same solution with the potential ranging from $0.23 \mathrm{~V}$ to $0.3 \mathrm{~V}$ for 60 seconds. Figure 4.7 shows all the ASVs from this experiment. The green plot is a control of just the $4 \mathrm{~nm}$ Au NPs at $0.3 \mathrm{~V}$ for 60 seconds. There is only one peak around $650 \mathrm{mV}$ indicating the presence of the 4 nm Au NPs. Once the Pd NPs were added to the EPD solution, a shouldering peak is 


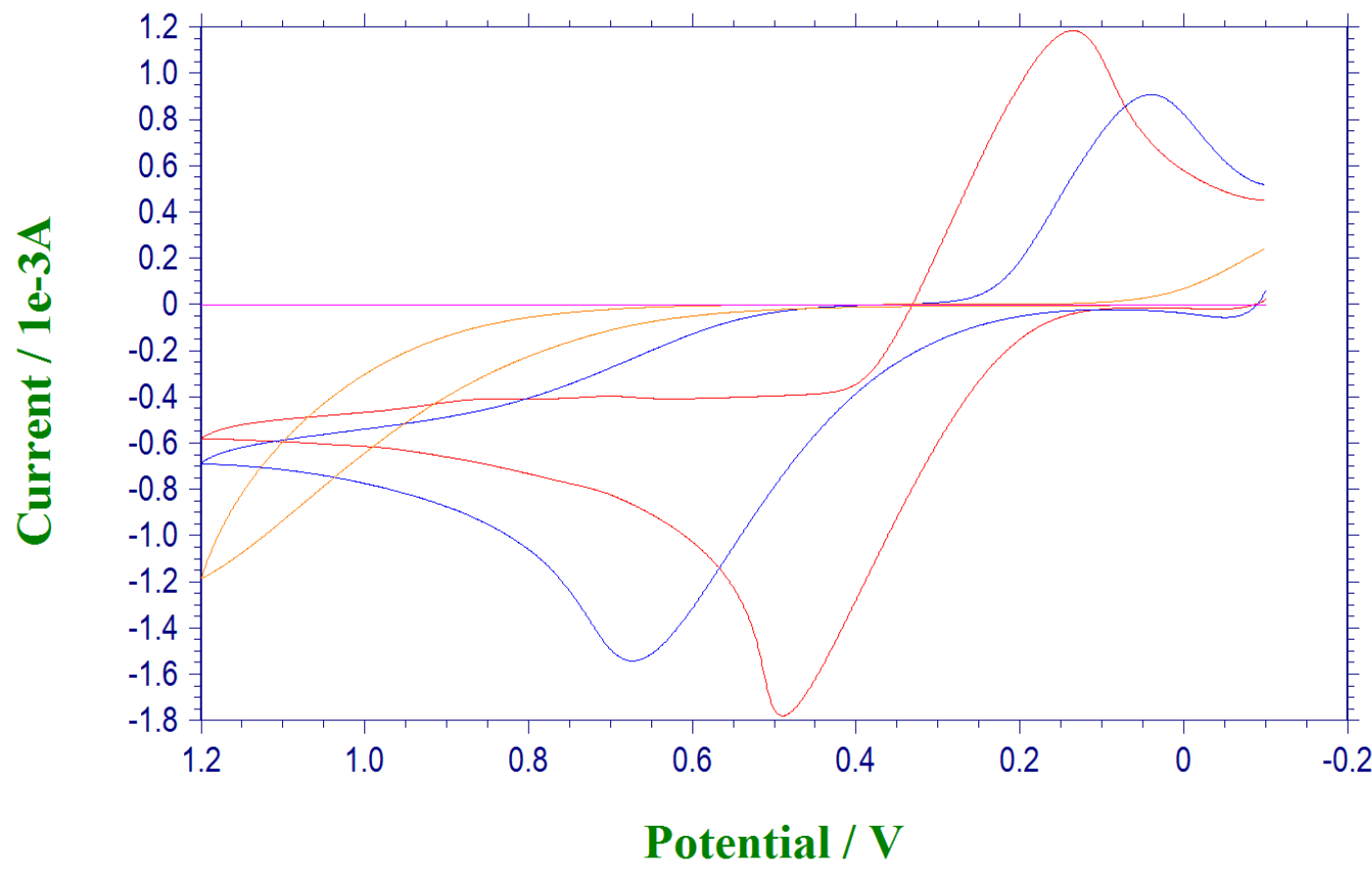

Figure 4.6. CVs of glass/ITO/APTES/4nmAuNPs (red) and glass/ITO/APTES/PdNPs in 0.005 M HQ plus $0.1 \mathrm{M} \mathrm{KClO}_{4}$ scanned from $-0.1 \mathrm{~V}$ to $1.2 \mathrm{~V}$ and back. Controls were run with glass/ITO/APTES (orange) and glass/ITO (pink). 


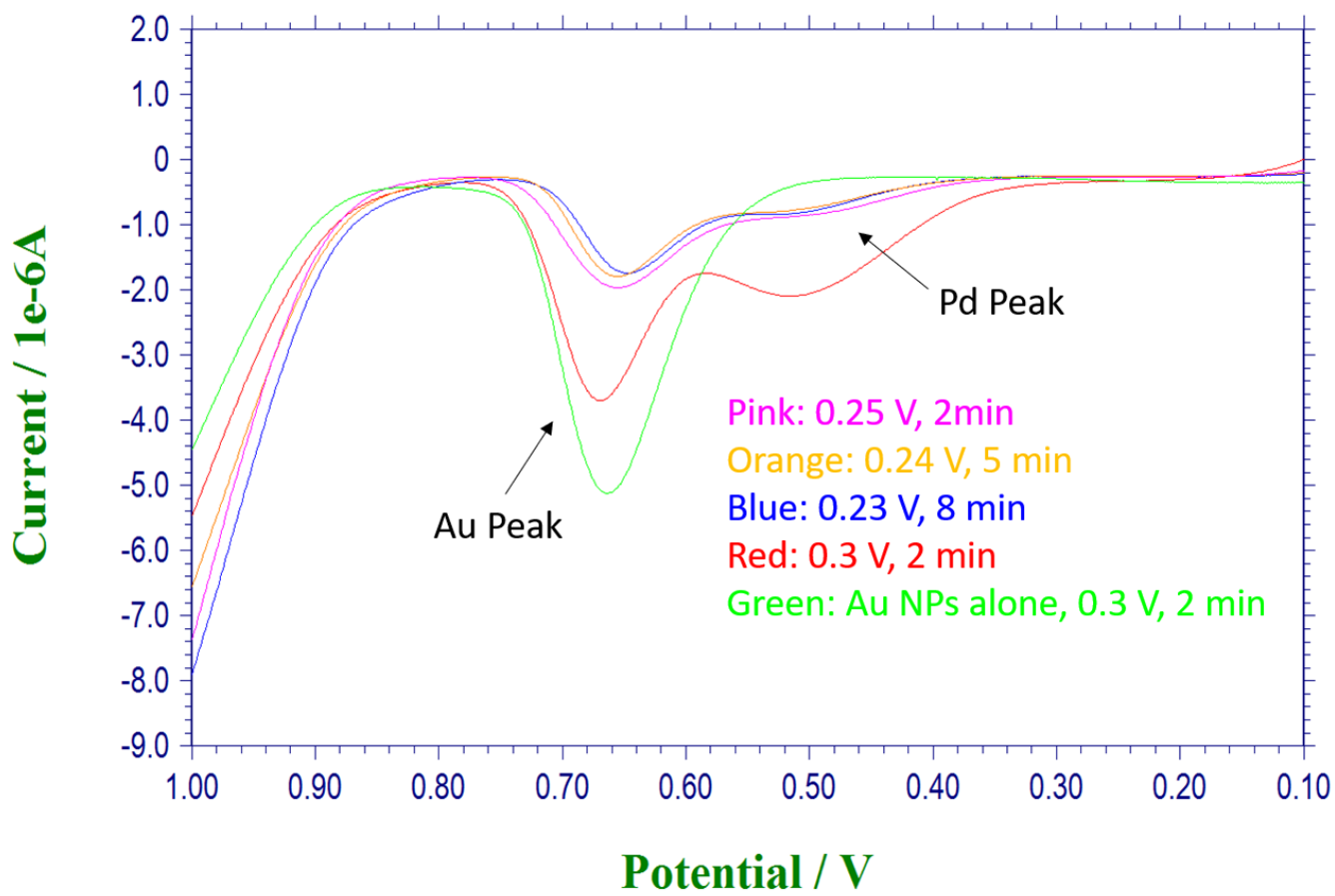

Figure 4.7. ASVs of $4 \mathrm{~nm}$ Au NPs alone at $0.3 \mathrm{~V}$ for 2 minutes (green), and equal amounts of $4 \mathrm{~nm}$ $\mathrm{Au}$ NPs and Pd NPs at $0.25 \mathrm{~V}$ for 2 minutes (pink), $0.24 \mathrm{~V}$ for 5 minutes (orange), $0.23 \mathrm{~V}$ for 8 minutes (blue), and $0.3 \mathrm{~V}$ for 2 minutes (red). All scans were run in $10 \mathrm{mM} \mathrm{KBr}$ and $0.1 \mathrm{M} \mathrm{HClO}_{4}$ at a scan rate of $0.01 \mathrm{~V} / \mathrm{s}$ on glass $/ \mathrm{ITO}$ slides. 
observed even at potentials as low $0.23 \mathrm{~V}$. According to the Pd CV in Figure 4.6, Pd does not oxidize HQ until a potential of $0.675 \mathrm{~V}$ is reached. Therefore, we should not observe an oxidation peak for Pd until applying an EPD potential of $0.675 \mathrm{~V}$ or higher. The red plot in Figure 4.7 shows the ASV of $4 \mathrm{~nm} \mathrm{Au} \mathrm{NPs} \mathrm{and} \mathrm{Pd} \mathrm{NPs} \mathrm{at} 0.3 \mathrm{~V}$ for 2 minutes. There is a significant oxidation peak for $\mathrm{Pd}$ under these conditions. Even at $0.25 \mathrm{~V}$ for 2 minutes (pink plot), $0.24 \mathrm{~V}$ for 5 minutes (orange plot), and $0.23 \mathrm{~V}$ for 8 minutes (blue plot), there is coverage for the Pd NPs.

The second part of the Pd experiment involved using a lesser amount of the $4 \mathrm{~nm}$ $\mathrm{Au}$ NPs in the EPD solution. Instead of equal amounts of $\mathrm{Au}$ to $\mathrm{Pd}$, we decreased the amount of $4 \mathrm{~nm} \mathrm{Au}$ NPs to $1 \mathrm{~mL}$ and increased the amount of Pd to $4 \mathrm{~mL}$ (total NP volume of $5 \mathrm{~mL}$ stayed the same). Figures 4.8-4.10 show the ASVs with the reduced amount of $4 \mathrm{~nm} \mathrm{Au} \mathrm{NPs} \mathrm{in} \mathrm{solution.} \mathrm{They} \mathrm{were} \mathrm{all} \mathrm{held} \mathrm{at} 0.3 \mathrm{~V}$ but for varying times. Figure 4.8 was held for 1 minute, Figure 4.9 was held for 5 minutes, and Figure 4.10 was held for 10 minutes. The red plot in all the ASVs are the control with just the Pd NPs (no Au in the EPD solution). This shows that by themselves, the Pd NPs do not deposit under those EPD parameters. However, once the $4 \mathrm{~nm} \mathrm{Au} \mathrm{NPs} \mathrm{are} \mathrm{added} \mathrm{to} \mathrm{the} \mathrm{solution,}$ deposition of Pd NPs starts to occur. Once again, these results show the catalytic activity of the smaller size Au NPs in assisting other NPs to deposit when they otherwise wouldn't.

\subsection{3. $\mathrm{TiO}_{2} \mathrm{NPs}$}

The final type of NP analyzed in this project is the $\mathrm{TiO}_{2} \mathrm{NP}$. As mentioned previously, we used UV-vis spectroscopy to analyze the results of the NP-assisted EPD and Figure 4.11 shows the results. The green and black plots are the control trials with 


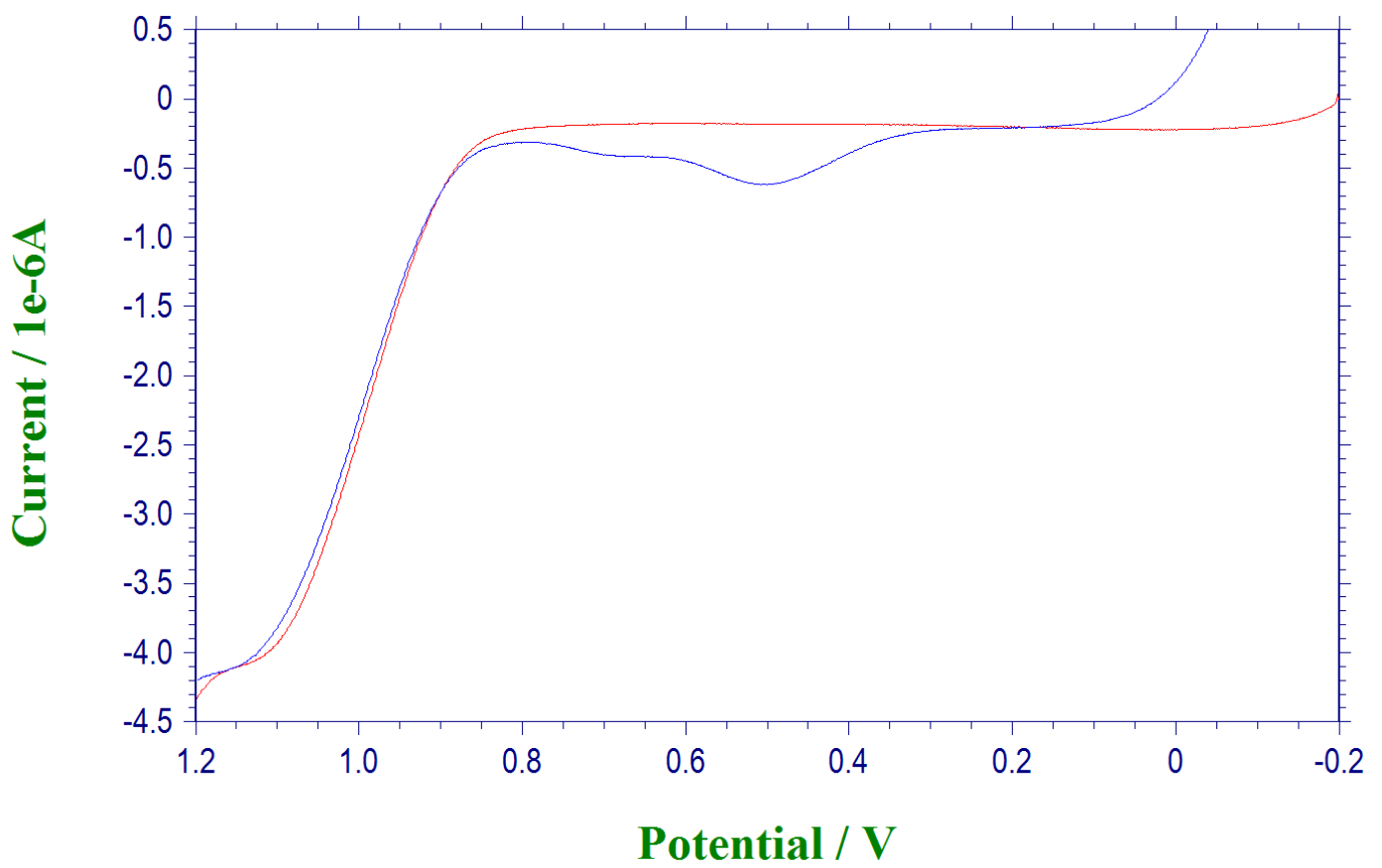

Figure 4.8. ASVs taken after EPD at $0.3 \mathrm{~V}$ for 1 minute with Pd NPs (red plot) and Pd NPs plus $4 \mathrm{~nm}$ Au NPs (blue plot). Scans were run in $10 \mathrm{mM} \mathrm{KBr}$ and $0.1 \mathrm{M} \mathrm{HClO}_{4}$ at a scan rate of $0.01 \mathrm{~V} / \mathrm{s}$ on glass/ITO slides. 


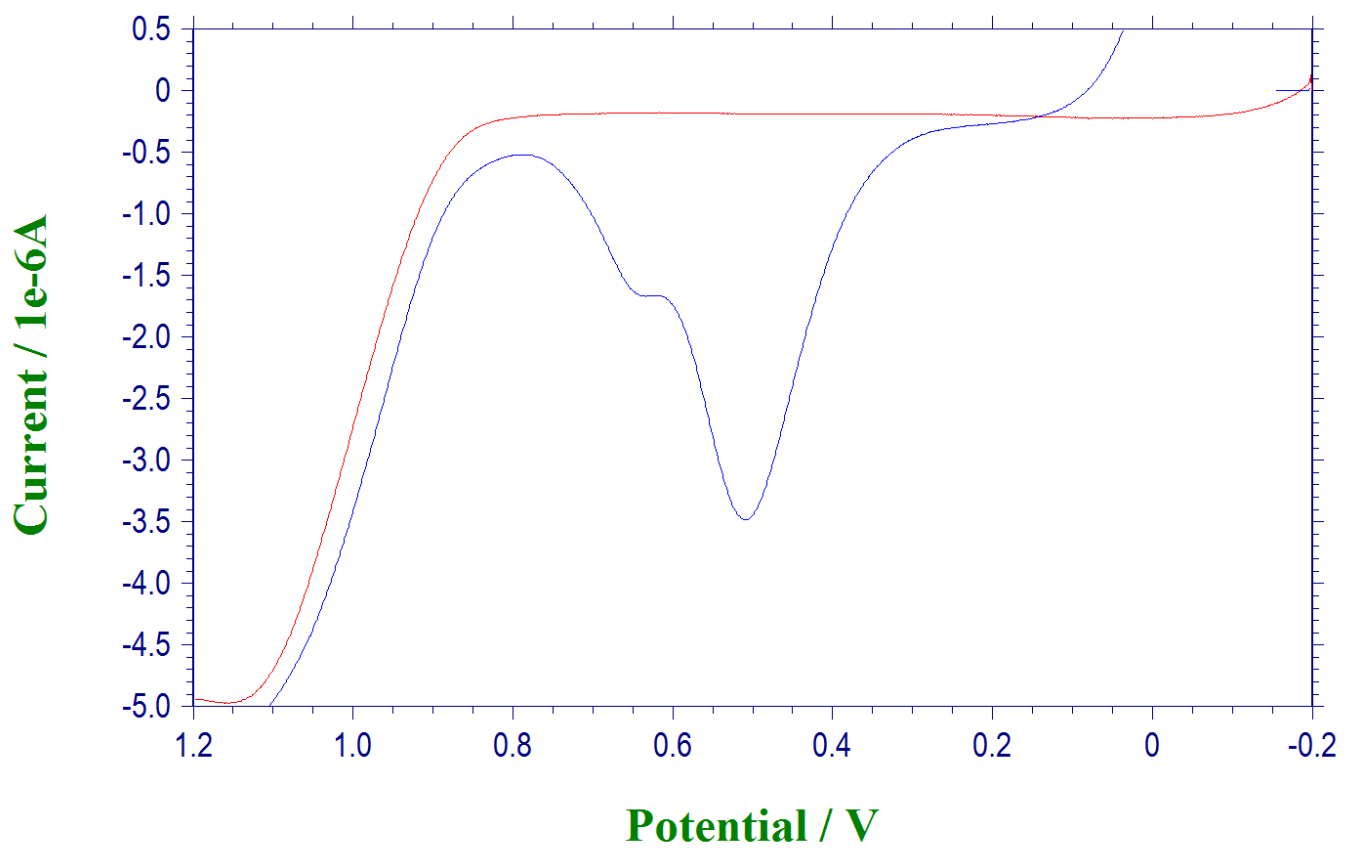

Figure 4.9. ASVs taken after EPD at $0.3 \mathrm{~V}$ for 5 minutes with Pd NPs (red plot) and Pd NPs plus $4 \mathrm{~nm} \mathrm{Au} \mathrm{NPs} \mathrm{(blue} \mathrm{plot).} \mathrm{Scans} \mathrm{were} \mathrm{run} \mathrm{in} 10 \mathrm{mM} \mathrm{KBr}$ and $0.1 \mathrm{M} \mathrm{HClO}_{4}$ at a scan rate of 0.01 $\mathrm{V} / \mathrm{s}$ on glass/ITO slides. 


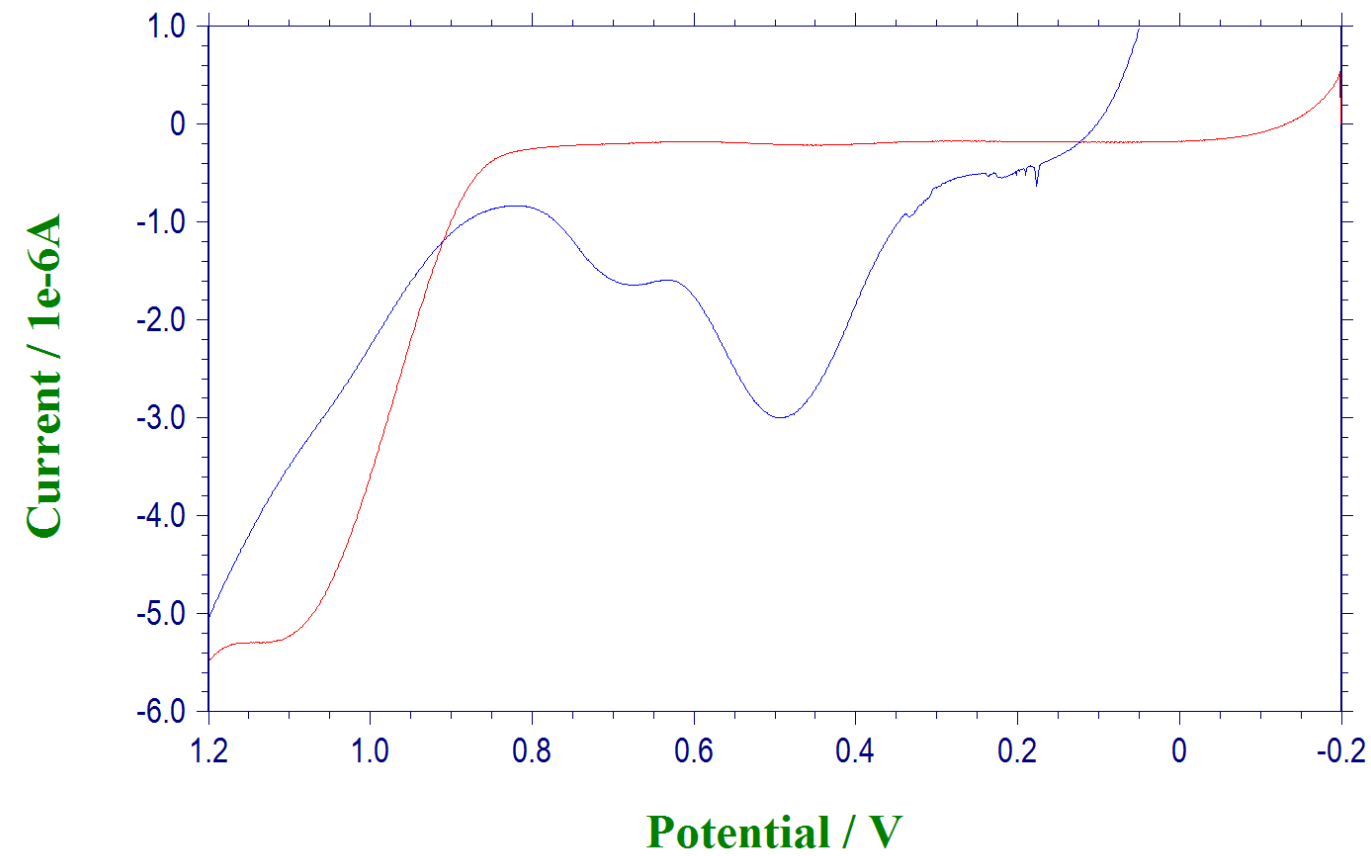

Figure 4.10. ASVs taken after EPD at $0.3 \mathrm{~V}$ for 10 minutes with Pd NPs (red plot) and Pd NPs plus $4 \mathrm{~nm} \mathrm{Au} \mathrm{NPs} \mathrm{(blue} \mathrm{plot).} \mathrm{Scans} \mathrm{were} \mathrm{run} \mathrm{in} 10 \mathrm{mM} \mathrm{KBr}$ and $0.1 \mathrm{M} \mathrm{HClO}_{4}$ at a scan rate of $0.01 \mathrm{~V} / \mathrm{s}$ on glass/ITO slides. 


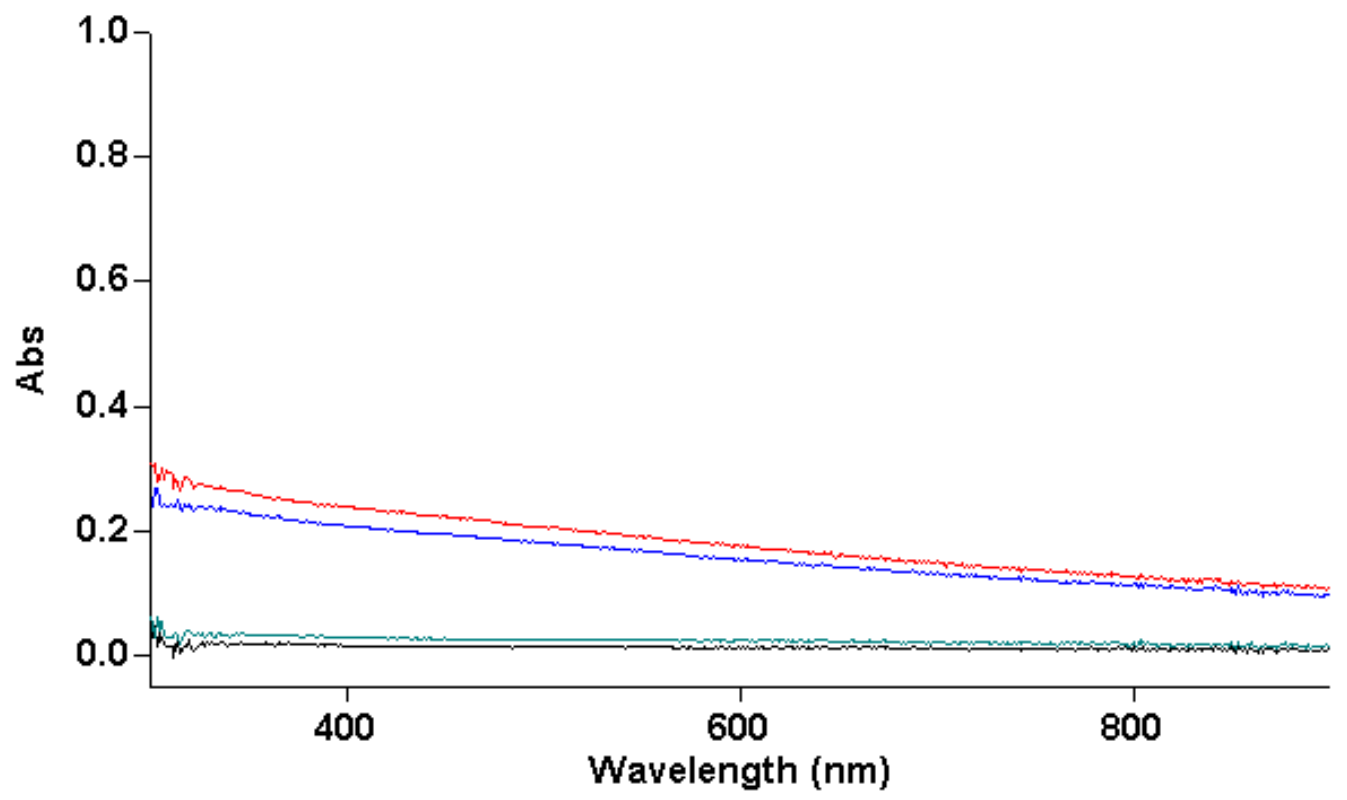

Figure 4.11. UV-vis spectra of Pd NPs (black and green plots) and Pd NPs plus $4 \mathrm{~nm}$ Au NPs in the EPD solution (red and blue plots) after 60 seconds at $0.4 \mathrm{~V}$. 
just $\mathrm{TiO}_{2} \mathrm{NPs}$ in the EPD solution and no Au. The red and blue plots have $1 \mathrm{~mL}$ of the 4 nm Au NPs in EPD solution (and $4 \mathrm{~mL}$ of $\mathrm{TiO}_{2} \mathrm{NPs}$ ). $\mathrm{TiO}_{2} \mathrm{NPs}$ alone have negligible absorbance around $300 \mathrm{~nm}$, however, after the addition of the $4 \mathrm{~nm}$ Au NPs in the EPD solution, the absorbance band around $300 \mathrm{~nm}$ increases to around 0.3 . Adding a more catalytic NP into the EPD solution proves to be an efficient way to fabricate thin films. A very noticeable thin film developed on the glass/ITO substrate surface with the $4 \mathrm{~nm} \mathrm{Au}$ NPs in solution as compared to their absence.

\subsection{Conclusions}

All three NPs (15 nm Au, Pd NPs, and $\left.\mathrm{TiO}_{2} \mathrm{NPs}\right)$ tested in this project showed an increase in deposition once the $4 \mathrm{~nm}$ Au NPs were added to the EPD solution. Little to no deposition occurred with the $15 \mathrm{~nm}$ Au NPs, Pd NPs, and TiO2 NPs under the EPD parameters in the absence of the $4 \mathrm{~nm}$ Au NPs. Once the $4 \mathrm{~nm}$ Au NPs were added to the EPD solution and the same parameters applied, there was a significant increase in coverage for all three types of NPs as indicated by the ASV, thus highlighting the catalytic activity of the $4 \mathrm{~nm}$ Au NPs. The $4 \mathrm{~nm}$ Au NPs are assisting in the deposition of the other NPs by facilitating the oxidation of HQ at a lower potential than the other NPs would on their own. For instance, the Pd NPs oxidize HQ around $675 \mathrm{mV}$, but the presence of $4 \mathrm{~nm}$ Au NPs in the EPD solution allows for HQ to be oxidized at a lower potential than $675 \mathrm{mV}$. Since the $4 \mathrm{~nm}$ Au NPs oxidize HQ at a lower potential, having them in the same EPD solution allows for the Pd NPs to deposit onto the electrode surface below $675 \mathrm{mV}$. This concept applies for all three types of NPs analyzed. 


\section{CHAPTER 5}

SIZE-SELECTIVE ELECTROPHORETIC DEPOSITION BY FUNCTIONALIZATION

OF THE WORKING ELECTRODE WITH SILANE FILTERS ON GLASS/ITO

\section{SUBSTRATES}

\subsection{Introduction}

In this project we studied the different processes involved in selectively depositing NPs of a particular size by EPD. We tested different silane filters for separating NPs in a mixture with the goal of being able to control which size gets deposited onto the electrode. This set of experiments is the first time NP size selection is achieved by chemical electrode modification.

\subsection{Experimental}

The overall scheme for the experimental design is shown in Figure 5.1. The first step is the synthesis of NPs of varying sizes. Simultaneously, the glass/ITO substrate surface is functionalized with an organosilane monolayer or polymer. Next, we attach the NPs to the functionalized electrode by EPD with the expectation that the silane or polymer layers will act as NP filters to select a specific size of NPs. Lastly, we run an ASV to determine which size NPs deposited and how much.

\subsubsection{Chemical Surface Modifications}

By altering the surface of the glass/ITO slide, our goal was to isolate specific size NPs from a mixture of sizes. We are trying to size-selectively deposit the small Au NPs by physically blocking or filtering out the larger sizes. The first modification made to the 


\section{Step 1: NP Synthesis}

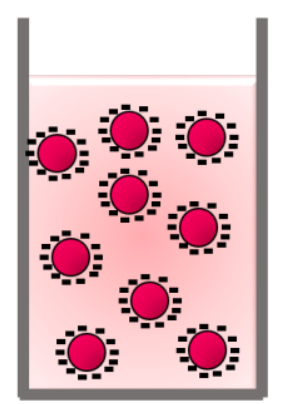

$4 \mathrm{~nm}$ Au NP

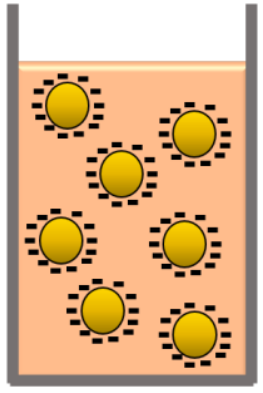

$15 \mathrm{~nm}$ Au NP

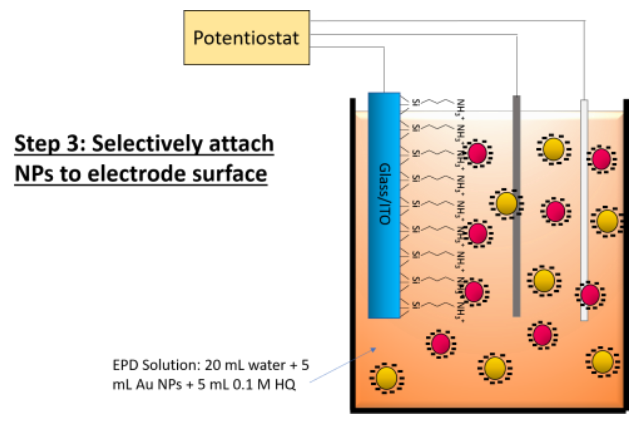

Step 5: Analysis of ASV

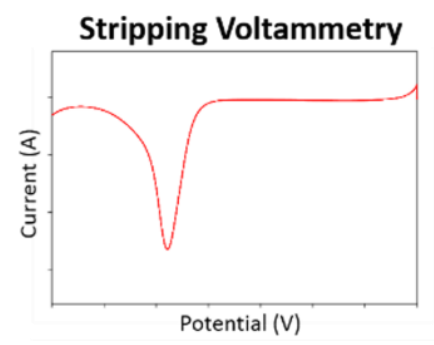

Step 2: Glass/ITO

\section{Functionalization}

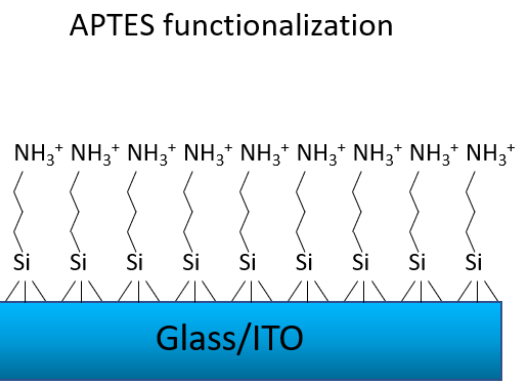

Step 4: Performing ASV

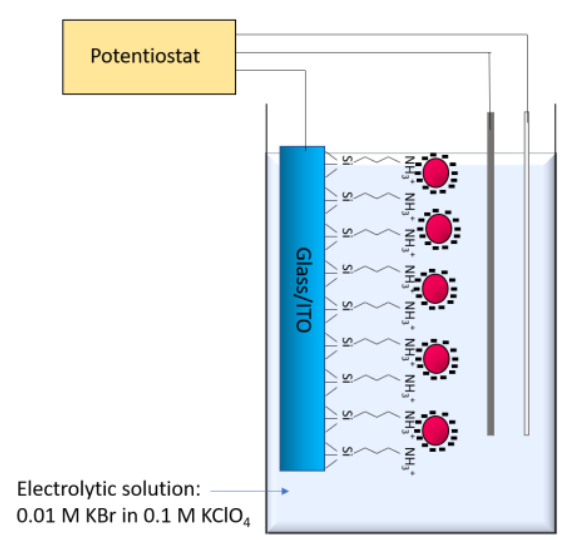

Figure 5.1. Scheme of experimental design for size-selection by functionalization of the WE. The first step is the synthesis of NPs of varying sizes. Simultaneously, the glass/ITO substrate surface is functionalized with an organic molecule. Next, we attach the NPs to the functionalized electrode with the objective of selecting a specific size, and then, lastly, run an $\mathrm{ASV}$ or $\mathrm{CV}$ to correlate the oxidation peak to the specific size NP. 
glass/ITO slides involved functionalization with APTES and mercaptopropyltrimethoxysilane (MPTMS). Figure 5.2A is a scheme illustrating the difference between APTES and MPTMS monolayer films on glass/ITO. The former has an amine group with a positive charge and the latter a thiol with a neutral charge. Other molecules that were attached to the glass/ITO substrate include mercaptopropyl-triethoxysilane (MPTES), 3,3,3-trifluoropropyl-trimethoxysilane (TFPTMS) and propyltrimethoxysilane (PTMS). The differences in all these molecules is shown in Figure 5.2B. MPTES has a $-\mathrm{CH}_{2}$ group between the substrate and oxygen molecule, thus giving the linker a longer spacer between the ITO and SH group as compared to the MPTMS. PTMS has a terminal methyl group and TFPTMS has a similar structure as PTMS except that instead of a terminal $-\mathrm{CH}_{3}$ group, it has a $-\mathrm{CF}_{3}$ group at the end.

Functionalization of the electrode consisted of soaking a bare glass/ITO slide in a solution of $10 \mathrm{~mL}$ isopropanol (IPA), a few drops of nanopore water, and $100 \mu \mathrm{L}$ of the organic linker (APTES, MPTMS, PTMS, or TFPTMS). The vials were placed on a hot plate at $85^{\circ} \mathrm{C}$ and after thirty minutes the slides were removed from the vial, rinsed with IPA, and dried under $\mathrm{N}_{2}$.

\subsubsection{Selective Attachment of NPs to the Electrode Surface}

When trying to select a specific size NP, equal amounts of each size NP were placed into the EPD solution. The EPD solution contained $20 \mathrm{~mL}$ water, $5 \mathrm{~mL} 0.1 \mathrm{M}$ HQ, $2.5 \mathrm{~mL} 4 \mathrm{~nm}$ Au NPs, and $2.5 \mathrm{~mL} 15 \mathrm{~nm}$ Au NPs. Varying EPD potentials and times were applied, the most common being $1.0 \mathrm{~V}$ for 60 seconds. After EPD, the functionalized glass/ITO/AuNP slide was removed from solution, rinsed with nanopure 
APTES functionalization

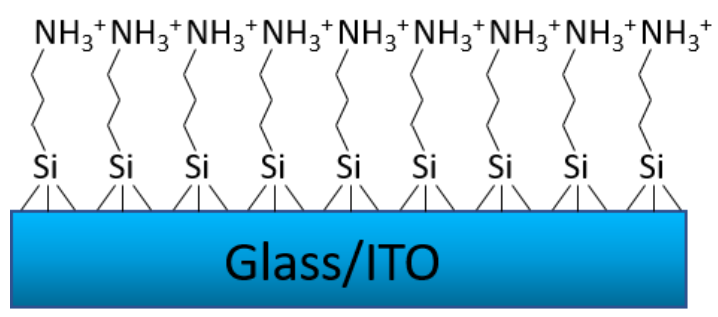

MPTMS functionalization

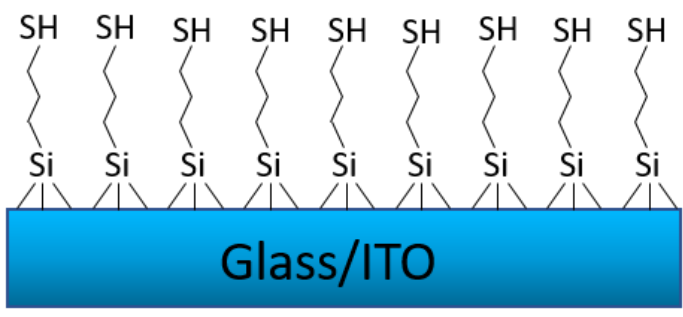

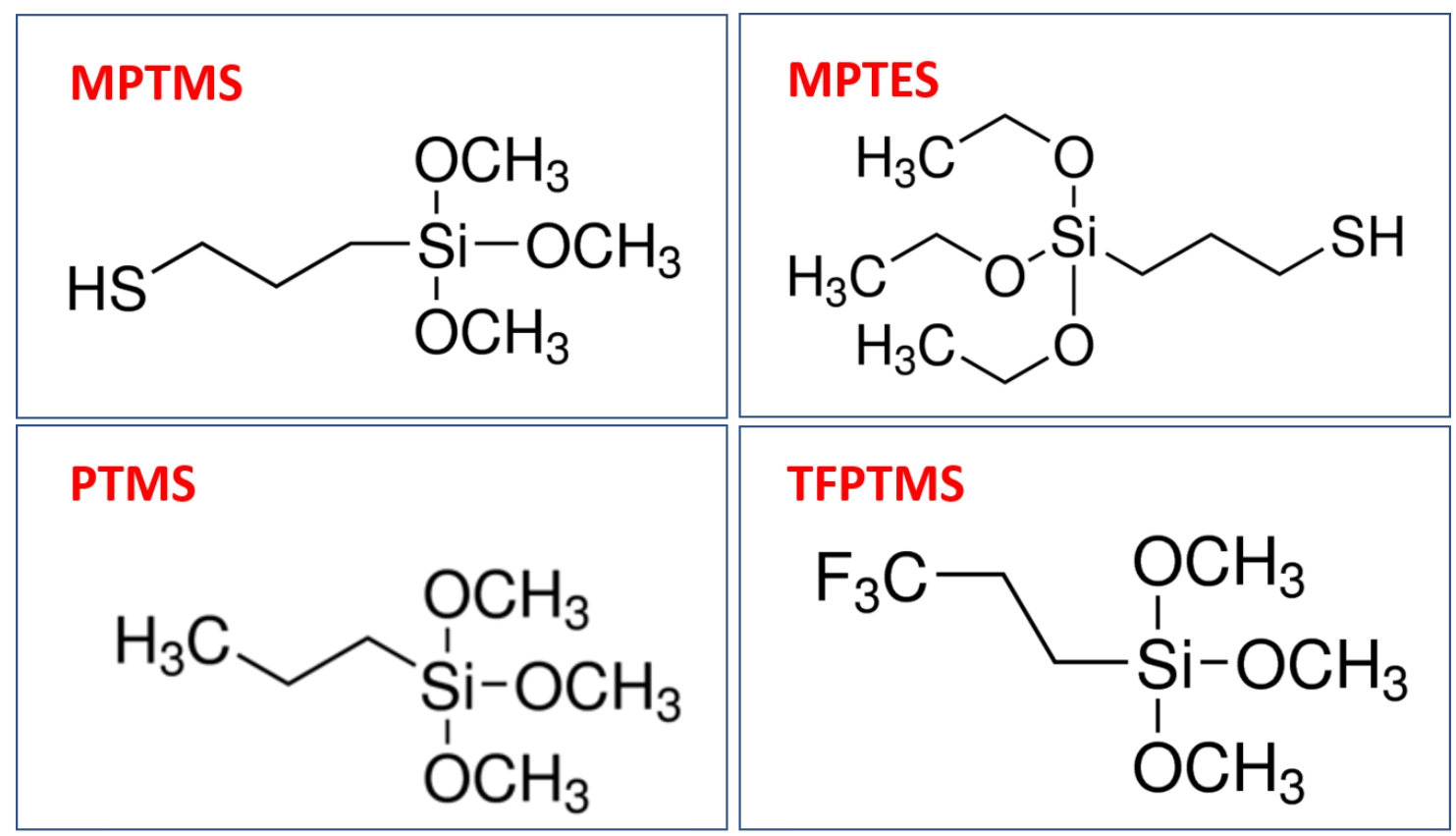

Figure 5.2. (A) APTES versus MPTMS functionalization on glass/ITO substrate. (B) Skeletal structural formulas of different organic compounds used as linkers on the glass/ITO substrate. 
water, and then dried with $\mathrm{N}_{2}$ before being analyzed by ASV. All ASVs were ran in 10 $\mathrm{mM} \mathrm{KBr}$ and $0.1 \mathrm{M} \mathrm{KClO}_{4}$ solution from $-0.2 \mathrm{~V}$ to $1.2 \mathrm{~V}$ at a scan rate of $0.01 \mathrm{~V} / \mathrm{s}$.

\subsection{Results and Discussion}

Figure 5.3 shows the ASVs providing the Au NP stripping analysis after EPD in a solution of a mixture of $4 \mathrm{~nm}$ and $15 \mathrm{~nm}$ Au NPs held at a potential of $1.0 \mathrm{~V}$ for 60 seconds on three different surfaces: bare glass/ITO (red), glass/ITO/APTES (blue), and glass/ITO/MPTMS (orange). The bare glass/ITO captured both $4 \mathrm{~nm}$ and $15 \mathrm{~nm} \mathrm{Au} \mathrm{NPs}$ as indicated by the peaks at approximately $650 \mathrm{mV}$ and $775 \mathrm{mV}$, respectively. The glass/ITO/MPTMS is clearly selective for the $4 \mathrm{~nm}$ Au NPs only, since there is only one peak mainly at $650 \mathrm{mV}$ (4 $\mathrm{nm}$ Au NPs), and the glass/ITO/APTES did not capture a significant amount of either size NPs. Based on these results, we can observe that there is something about the MPTMS surface that is not conducive for capturing $15 \mathrm{~nm}$ Au NPs and something about the APTES layer that blocks EPD of both size NPs. Clearly, the MPTMS is successful at filtering out the $15 \mathrm{~nm}$ Au NPs from depositing by EPD.

After noticing the filtering effect of MPTMS, we switched out the terminal group from a thiol to other moieties like methyl and fluorinated silanes. Figure 5.4 shows the results of EPD performed with $4 \mathrm{~nm}$ and $15 \mathrm{~nm}$ Au NPs on glass/ITO slides functionalized with MPTMS (pink plot), MPTES (orange plot), TFPTMS (blue), and PTMS (red) at $1.0 \mathrm{~V}$ for 60 seconds. The green plot is bare glass/ITO. All variations have similar coverage for the $4 \mathrm{~nm}$ Au NPs, but as it pertains to the $15 \mathrm{~nm}$ Au NPs, the MPTMS has no coverage, MPTES has half as much as the bare glass/ITO, TFPTMS has similar coverage to the bare, and PTMS has slightly more coverage as compared to the bare. In summary, the MPTMS has the least amount of $15 \mathrm{~nm}$ Au NPs collected and the 


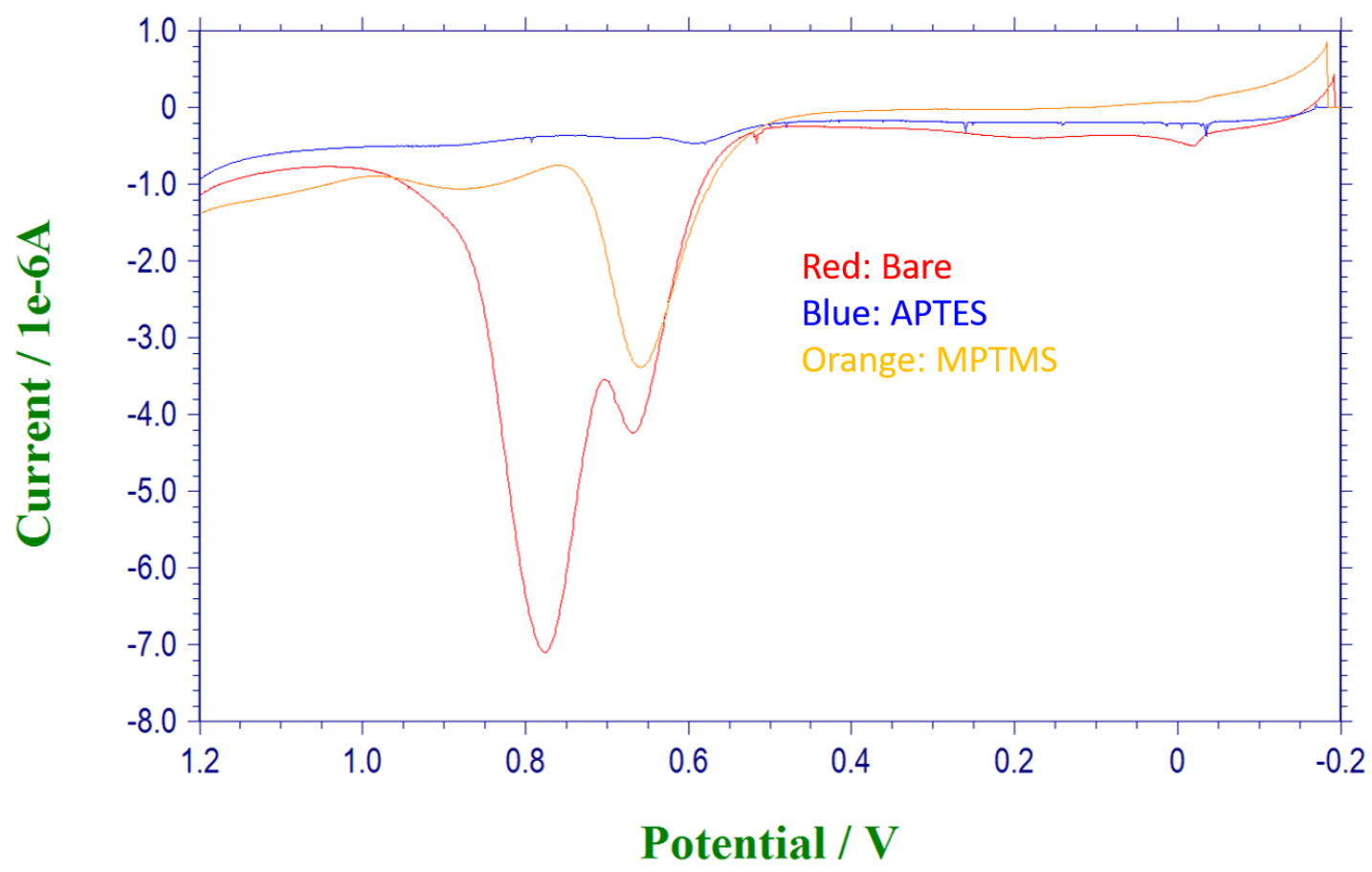

Figure 5.3. $4 \mathrm{~nm}$ and $15 \mathrm{~nm}$ Au NPs held at $1.0 \mathrm{~V}$ for 60 seconds on bare (red), APTES (blue), and MPTMS (orange). 


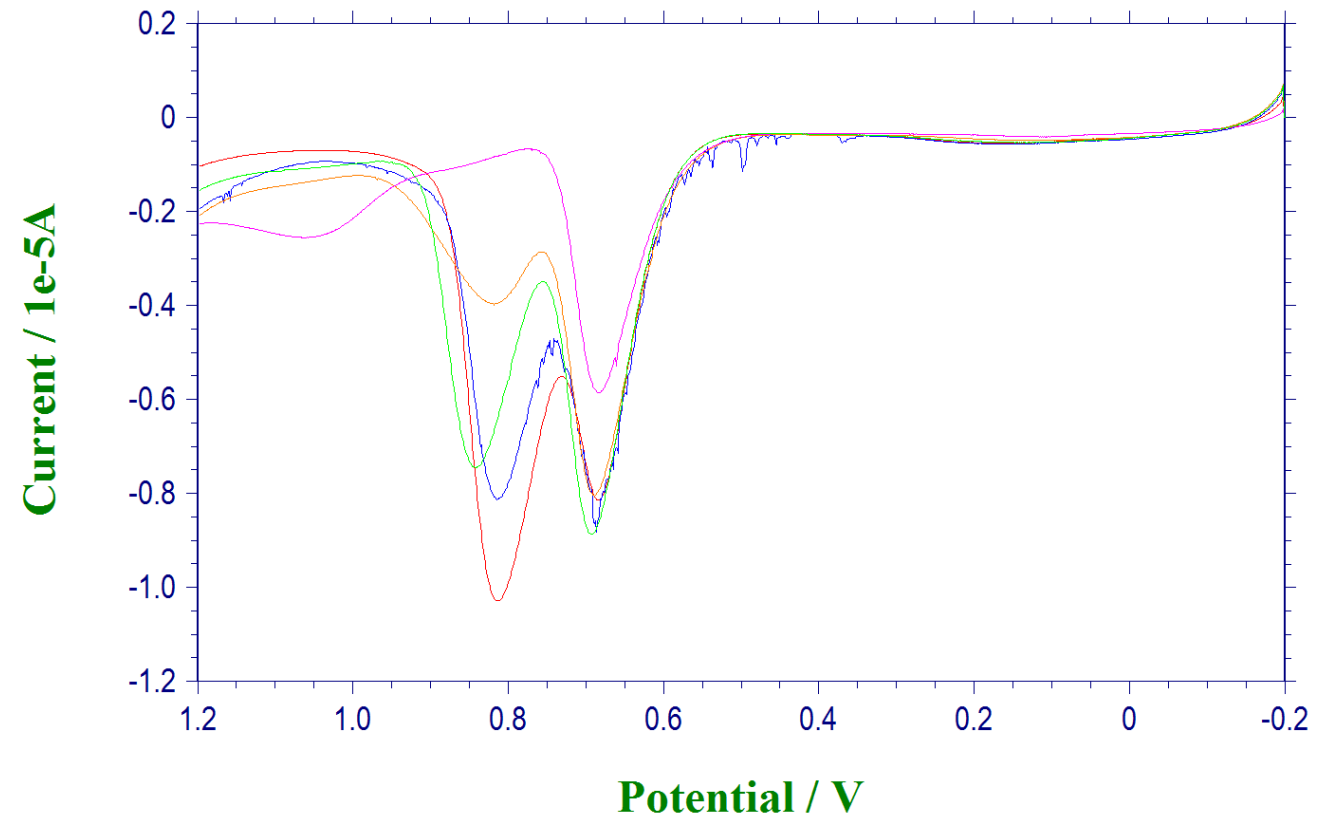

Figure 5.4. ASVs of $4 \mathrm{~nm}$ and $15 \mathrm{~nm}$ Au NPs at $1.0 \mathrm{~V}$ for 60 seconds with bare glass/ITO (green), glass/ITO functionalized with MPTMS (pink), MPTES (orange), 3,3,3-Trifluoropropyltrimethoxysilane (blue), and propyltrimethoxysilane (red). 
PTMS had the most. The difference between those two compounds is the addition of the thiol group on the end for the MPTMS. Since MPTMS and MPTES had the least amount of $15 \mathrm{~nm} \mathrm{Au} \mathrm{NPs} \mathrm{deposition,} \mathrm{then} \mathrm{we} \mathrm{can} \mathrm{infer} \mathrm{that} \mathrm{the} \mathrm{thiol} \mathrm{group} \mathrm{is} \mathrm{responsible} \mathrm{for}$ deterring the deposition of the larger size NPs. Although several possible explanations exist, we know there is something about the MPTMS that is a good blocker for the $15 \mathrm{~nm}$ Au NPs. One possible reason for the lack of deposition for the $15 \mathrm{~nm}$ Au NPs with the MPTMS and MPTES relates to the nature of the carbon-sulfur bond. Since sulfur is a larger element than the other terminal elements, the bond length is longer between the carbon and sulfur. For example, the $\mathrm{C}-\mathrm{S}$ bond is about 40 picometers longer than a $\mathrm{C}-\mathrm{O}$ bond. Also, C-S-H bonds approach $90^{\circ}$ whereas the other terminal group's bonds to carbon are more obtuse. ${ }^{113}$ These are two possibilities as to why the MPTMS and MPTES do not collect as much of the $15 \mathrm{~nm}$ Au NPs as the other functional groups, but it also could have to do with the Au-S binding since both thiol containing layers blocked the larger NPs the best. They all collect the smaller size $4 \mathrm{~nm} \mathrm{Au} \mathrm{NPs,} \mathrm{but} \mathrm{the} 15 \mathrm{~nm} \mathrm{Au}$ NPs might have a harder time getting past the longer bonds that are also positioned at 90 degrees, thus blocking the larger size NPs from reaching the electrode surface. 


\section{CHAPTER 6}

\section{AGGREGATION-DEPENDENT OXIDATION OF METAL NANOPARTICLES}

\subsection{Introduction}

Here we describe the effect of aggregation on the oxidation of citrate-stabilized Au nanoparticles (NPs) attached electrostatically to amine-functionalized glass/ITO electrodes. When the Au NPs are attached to the electrode from a solution with $\mathrm{pH}$ greater than $\sim 3.0$, they are well-separated on the electrode and oxidize in bromidecontaining electrolyte at $0.698 \mathrm{~V}, 0.757 \mathrm{~V}$, and $0.943 \mathrm{~V}$ (vs. $\mathrm{Ag} / \mathrm{AgCl}$ ) for $4 \mathrm{~nm}, 15 \mathrm{~nm}$, and $50 \mathrm{~nm}$ diameter Au NPs, respectively, in line with their size-dependent oxidation behavior. In solutions below $\mathrm{pH}$ 3.0, the Au NPs aggregate in solution and attach to the electrode in the aggregated form. The solution UV-vis spectra and scanning electron microscopy (SEM) images of the electrodes show clear evidence of aggregation. The oxidation potential for aggregated $4 \mathrm{~nm}$ and $15 \mathrm{~nm}$ diameter Au NPs shifts positive by a maximum of $230 \mathrm{mV}$ and $180 \mathrm{mV}$, respectively. The magnitude of the shift depends on the extent of aggregation, which was controlled by the solution $\mathrm{pH}$ and time. NP aggregation leads to a significant reduction in the surface area-to-volume ratio, which is likely responsible for the positive shift in the oxidation potential. The oxidation potential does not shift at all for aggregated $50 \mathrm{~nm}$ diameter Au NPs.

The size-dependent oxidation potential of metal nanoparticles (NPs) is an important property for understanding metal stability, ${ }^{114-115}$ toxicity, ${ }^{116}$ and reactivity. ${ }^{100}$,

117 It may also be useful for NP size analysis. ${ }^{9}$ Henglein $^{118}$ and Plieth $^{119}$ provided early 
predictions of size-dependent oxidation potentials for metal NPs based on sublimation energies (along with indirect reactivity) and changes in surface free energy, respectively. Later, several groups used electrochemical scanning tunneling microscopy to image oxidizing metal NPs. ${ }^{114-115}$ Our group showed the use of linear sweep stripping voltammetry (LSSV) to measure the size-dependent oxidation of $\mathrm{Ag}^{9,120}$ and $\mathrm{Au}^{120-123}$ NPs electrochemically. Others also used voltammetry to study the size-dependent oxidation of Au, ${ }^{124} \mathrm{Ag},{ }^{125}$ and Pd NPs. ${ }^{100}$ The metals can be studied as an array of NPs on an electrode, ${ }^{120}$ a single metal NP on an electrode, ${ }^{126}$ and single metal NP collisions with a microelectrode in solution. ${ }^{127}$ It is pretty well recognized that the standard potential shifts negative as the size of the metal NP decreases and the shift is often proportional to 1/radius as predicted by Plieth. ${ }^{119}$ Some recent theory extended Plieth's theory in more detail along with diffusion considerations. ${ }^{3,99,124}$

Here we focus on the oxidation of aggregated NPs as compared to individual, isolated NPs. This is important for several reasons. First, there have been some reports showing no change in the oxidation potential of metal NPs with size, but it was later clear that NP aggregation likely affected the results. ${ }^{3,123,125}$ We hypothesized that aggregation was an important factor for metal NP oxidation in earlier work, ${ }^{9}$ but there have not been any well-controlled studies up to this point, leaving it an unexplored variable. Second, some experiments with metal NPs (catalysis, sensing, optics, nanoelectronics) might involve aggregated NPs, rather than individual, isolated NPs. It is therefore important to understand how their reactivity might be different. Third, in NP collision studies at microelectrodes, it is not always well-understood if the NPs are colliding as isolated NPs or aggregates. ${ }^{3,128-129}$ If NP oxidation is acting as the signal, the standard potential 
change is important to know. Fourth, the detection of NP aggregation by LSSV could be a very useful alternative to the detection of aggregation by several optical-based methods used in biosensing assays. ${ }^{130-131}$

While there is a great deal of work on the optical plasmonic properties of metal NPs in isolated and aggregated form, ${ }^{132}$ there is very little work on the oxidation (or other electrochemical properties) of metal NPs as a function of controlled aggregation state. Recently, Compton and co-workers used anodic particle coulometry to observe and monitor the aggregation of $\mathrm{Ag}$ NPs and quantitatively measure aggregates up to $150 \mathrm{~nm}$ in diameter. ${ }^{35}$ They also used chronoamperometry to estimate the degree of aggregation that occurred while immobilizing NPs onto an electrode surface. ${ }^{36}$ The Compton group also showed a decrease in the stripping peak area for dopamine-capped Ag NPs that were aggregated in the presence of melamine, which they attributed to incomplete stripping or an inactivation mechanism. ${ }^{37}$ A recent reports studied the kinetics of dissolution of isolated versus aggregated nanoparticles, showing that aggregated nanoparticles dissolved more slowly. ${ }^{117}$ These studies measured the current or rate of dissolution during oxidation of aggregated NPs. Our work reported here focuses on the change in oxidation potential of aggregated versus individual Au NPs as measured by LSSV.

\subsection{Experimental}

6.2.1. Preparation of the Working Electrode. The glass/ITO/APTES electrode was placed in a vial with $10.0 \mathrm{~mL}$ of the appropriate non-aggregated or aggregated $\mathrm{Au}$ NP solution with the conductive side facing up. The soaking times were varied for the different sizes and $\mathrm{pH}$ values in order to obtain a similar coverage on the linear sweep 
voltammograms. After soaking, the slides were rinsed with nanopure water and dried with nitrogen before the electrochemical measurement.

\subsection{Results and Discussion}

Figure 6.1 shows the general experimental procedure involved with this work. Step 1 is the synthesis of citrate-coated Au NPs of different sizes in aqueous solution. We synthesized $4 \mathrm{~nm}, 15 \mathrm{~nm}$ and $50 \mathrm{~nm}$ diameter Au NPs, ${ }^{122}$ which were all stable and exhibited an initial solution $\mathrm{pH}$ of about 9.0, 5.8, and 3.6, respectively. In step 1a, we lowered the solution $\mathrm{pH}$ to below 3 by adding $10 \mu \mathrm{L}$ of varying concentration of perchloric acid (2 $\mathrm{M}$ to $6 \mathrm{M}$ ) in order to induce NP aggregation via protonation of the carboxylate groups of citrate, which presumably led to less electrostatic repulsion between the Au NPs. ${ }^{122}$ The aggregation was indicated by the change in solution color from red to purple/blue. Step 2 involved attaching the individual, isolated Au NPs or aggregated Au NPs (Step 2a) to aminopropyltriethoxysilane - functionalized glass/ITO

electrodes (glass/ITO/APTES) ${ }^{122}$ by simply soaking the functionalized electrodes in the Au NP solution for a certain amount of time to get a similar overall Au NP coverage (soak times from 60 seconds to 9 minutes). Step 3 (and 3a) for both samples utilized electrochemical characterization by LSSV to determine the peak potential $\left(\mathrm{E}_{\mathrm{p}}\right)$ for oxidation, which is related to the $\mathrm{E}^{0}$, of the reaction. We also performed scanning electron microscopy (SEM) on separate samples and UV-vis spectroscopy of the solutions before attaching the NPs to the glass/ITO/APTES electrode.

Figure 6.2 shows the LSSV, UV-vis, and SEM images for $4 \mathrm{~nm}$ Au NPs at varying $\mathrm{pH}$ value, where the UV-vis was performed directly in solution and the LSSV and SEM were obtained after attachment to glass/ITO/APTES from the solution. Figure 


\section{Step 1:}

\section{Au NP Synthesis}
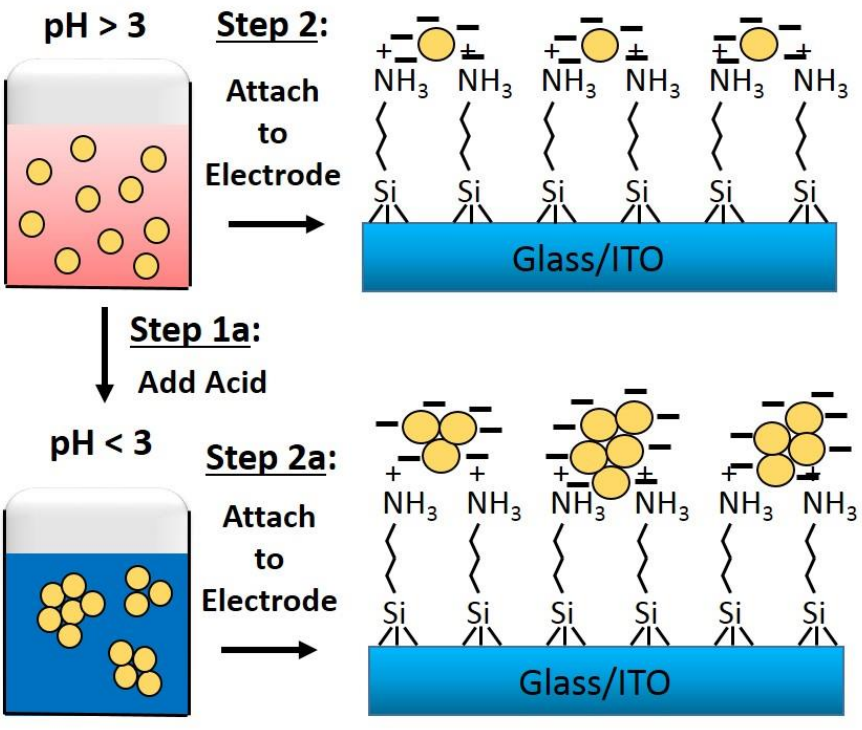

Step 3 and 3a:

Characterize by LSSV

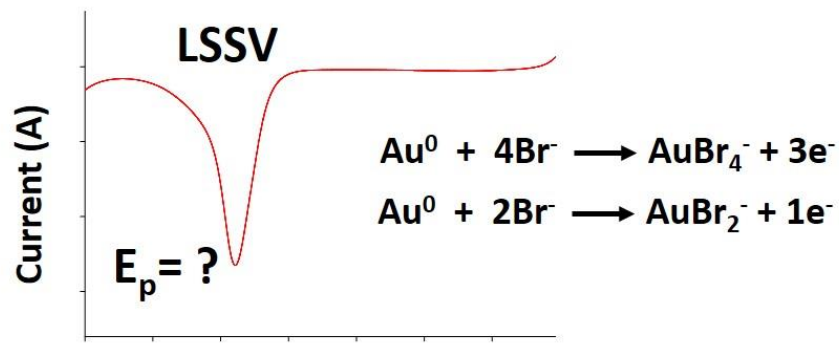

\section{Potential (V)}

Figure 6.1. General aggregation scheme showing the addition of acid which causes the NPs to aggregate in solution and on the glass/ITO/APTES electrode. 

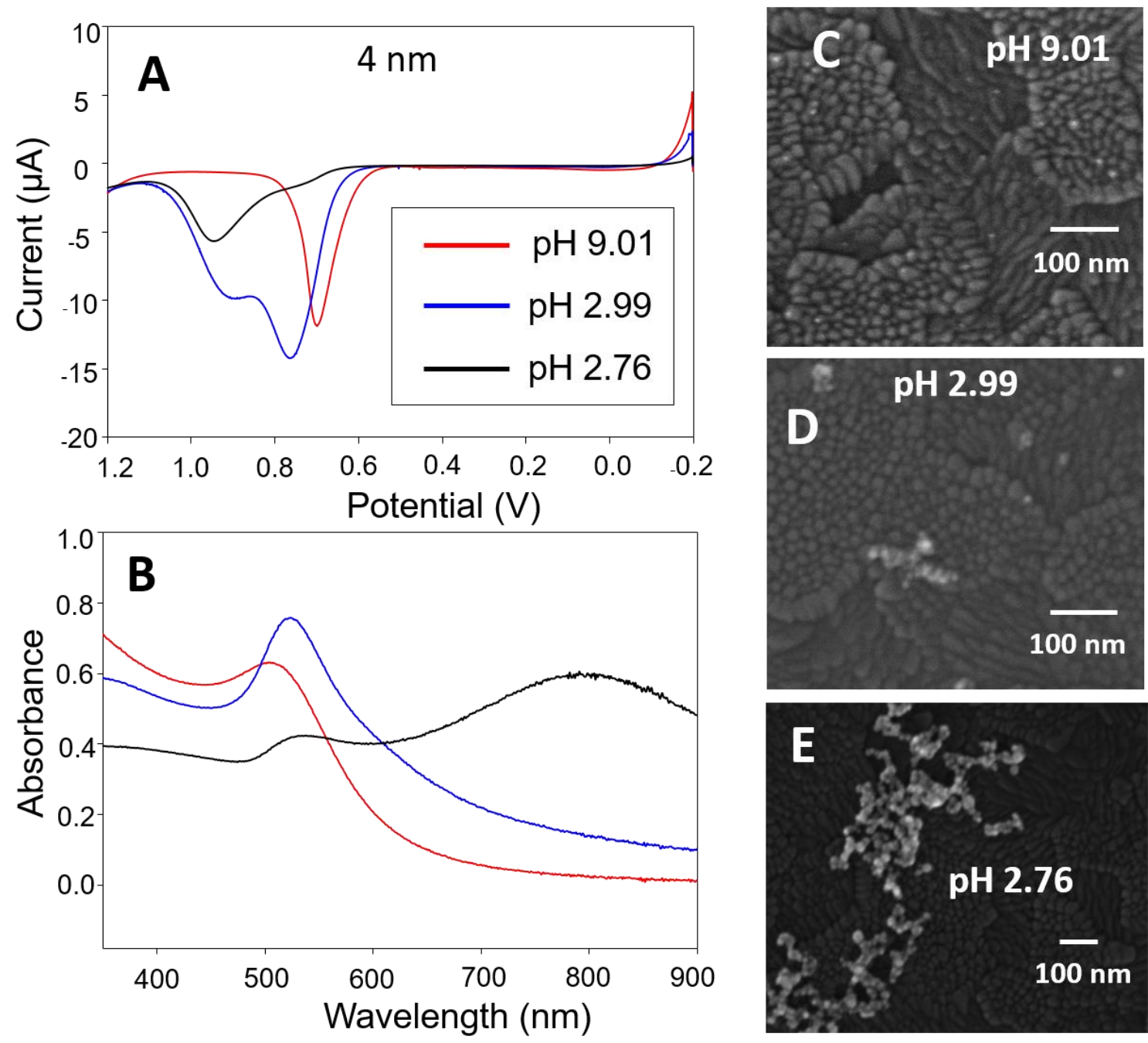

Figure 6.2. (A) LSSV of glass/ITO/APTES electrodes coated with $4 \mathrm{~nm}$ diameter citrate-coated Au NPs attached from solution at pH 9.01 (red), 2.99 (blue), and 2.76 (black). The LSSV was ran in $0.1 \mathrm{M} \mathrm{KClO}_{4}$ $+0.01 \mathrm{M} \mathrm{KBr}$ from -0.2 to $1.2 \mathrm{~V}$ at a scan rate of $0.01 \mathrm{~V} / \mathrm{s}$. (B) UV-vis spectra of $4 \mathrm{~nm}$ diameter Au NP solutions at pH 9.01 (red), 2.99 (blue), and 2.76 (black). (C-E) SEM images of the glass/ITO/APTES electrode after being immersed in the Au NP solutions with the indicated $\mathrm{pH}$. For the $4 \mathrm{~nm}$ diameter Au NPs the unaltered solution had a $\mathrm{pH}$ of 9.01 and the $\mathrm{pH} 2.99$ and $\mathrm{pH} 2.76$ solutions were prepared by adding 10 $\mu \mathrm{L}$ of $4 \mathrm{M}$ and $5 \mathrm{M} \mathrm{HClO}_{4}$ to the as prepared NPs, respectively. The soak times for the LSSV and SEM data were 80 seconds, 6 minutes, and 6 minutes for the 9.01, 2.99, and $2.76 \mathrm{pH}$ solutions, respectively. 
6.2A shows the LSSV of the $4 \mathrm{~nm}$ Au NPs attached from solutions of $\mathrm{pH} 9.01$ (as synthesized), 2.99, and 2.76. The $4 \mathrm{~nm} \mathrm{Au} \mathrm{NPs} \mathrm{at} \mathrm{pH} 9.01$ oxidized at $0.698 \mathrm{~V}$, which is consistent with what we have seen on well-isolated $4 \mathrm{~nm}$ diameter Au NPs in previous work. $^{120-123}$ Those attached from a solution of $\mathrm{pH} 2.99$ exhibited two oxidation peaks, one at $0.762 \mathrm{~V}$ and a second smaller peak at $0.890 \mathrm{~V}$. At $\mathrm{pH} 2.76$, there was a small peak at $0.824 \mathrm{~V}$ and main peak at $0.927 \mathrm{~V}$ in the LSSV.

The UV-vis of the Au NP solution in Figure 6.2B at the same $\mathrm{pH}$ values shows that the $\mathrm{pH} 9.01$ solution is comprised of well-isolated, individual Au NPs, based on the single localized surface plasmon resonance (LSPR) band at about $510 \mathrm{~nm}$ and very low absorbance in the $600-900 \mathrm{~nm}$ range. The UV-vis at $\mathrm{pH} 2.99$ and 2.76 show clear signs of Au NP aggregation, where the absorbance of the LSPR band increased and shifted to a higher wavelength and the baseline absorbance from $600-900 \mathrm{~nm}$ increased. ${ }^{133}$ At the lowest $\mathrm{pH}$, there is a broad peak at $800 \mathrm{~nm}$, indicating a high degree of aggregation in that sample relative to the $\mathrm{pH} 2.99$ solution. ${ }^{133}$ The SEM images (Figure 6.2C-6.2E) at varying $\mathrm{pH}$ agree very well with the UV-vis data. At $\mathrm{pH} 9.01$, the Au NPs are attached as well-isolated NPs, although they are very hard to see because that is approaching the resolution of our SEM. There are small aggregates of Au NPs on the surface at $\mathrm{pH} 2.99$ and larger, more extended aggregates at $\mathrm{pH} 2.76$.

The LSSV data perfectly reflect what the UV-vis and SEM data show. At $\mathrm{pH}$ 9.01, the one peak in the LSSV is for the oxidation of well isolated Au NPs. At pH 2.99, the two peaks (both shifted positive relative to $\mathrm{pH} 9.01$ ) correspond to the oxidation of small and large aggregates of $4 \mathrm{~nm}$ Au NPs on the electrode. Finally, at $\mathrm{pH} 2.76$, the most positive peak is due to oxidation of the larger aggregates on the surface, while the 
small peak indicates some small aggregates on the electrode as well. These results show very clearly that the oxidation potential of metal NPs is not only highly sensitive to aggregation but can also differentiate between different sized aggregates. The maximum shift in oxidation potential from isolated Au NPs to the largest aggregates was $+0.229 \mathrm{~V}$.

Figure 6.3 shows the LSSV, UV-vis, and SEM images for $15 \mathrm{~nm}$ Au NPs at varying $\mathrm{pH}$ value. The results are very similar to those for the $4 \mathrm{~nm}$ diameter Au NPs. At pH 5.80, the LSSV (Figure 6.3A) shows one main peak at $0.757 \mathrm{~V}$, that is consistent with the oxidation of isolated $15 \mathrm{~nm}$ Au NPs as observed previously. ${ }^{120,122-123}$ The UVvis spectrum accordingly shows one, fairly sharp LSPR band at about $518 \mathrm{~nm}$ and the SEM image shows individual, isolated $15 \mathrm{~nm}$ diameter Au NPs on the glass/ITO/APTES electrode surface. At pH 2.92 there are two clear oxidation peaks, one at $0.768 \mathrm{~V}$ and another at $0.930 \mathrm{~V}$. Based on the $4 \mathrm{~nm}$ Au NPs, this indicates the presence of isolated NPs, small aggregates, and large aggregates on the surface. The UV-vis spectrum, however, only shows a very small shift in the main LSPR band to $523 \mathrm{~nm}$ and slight increase in baseline absorbance. While this also indicates aggregation, the LSSV is much more sensitive to it. The corresponding SEM shows there are indeed small and large aggregates and individual $15 \mathrm{~nm}$ Au NPs on the surface at this $\mathrm{pH}$. At $\mathrm{pH} 2.71$ and 2.69, the LSSV still shows two peaks. One is a decreasing shoulder peak at $0.780 \mathrm{~V}$ and 0.764 $\mathrm{V}$, respectively, and the second is a major peak at $0.938 \mathrm{~V}$. The former corresponds to the oxidation of isolated $15 \mathrm{~nm}$ Au NPs or very small aggregates while the latter peak corresponds to the oxidation of large aggregates. The $\mathrm{UV}$-vis spectra at $\mathrm{pH} 2.71$ shows a larger shift in the main LSPR band to $530 \mathrm{~nm}$ and even higher baseline absorbance at $600-900 \mathrm{~nm}$ and at $\mathrm{pH} 2.69$, there is the emergence of a broad LSPR peak at $800 \mathrm{~nm}$, 

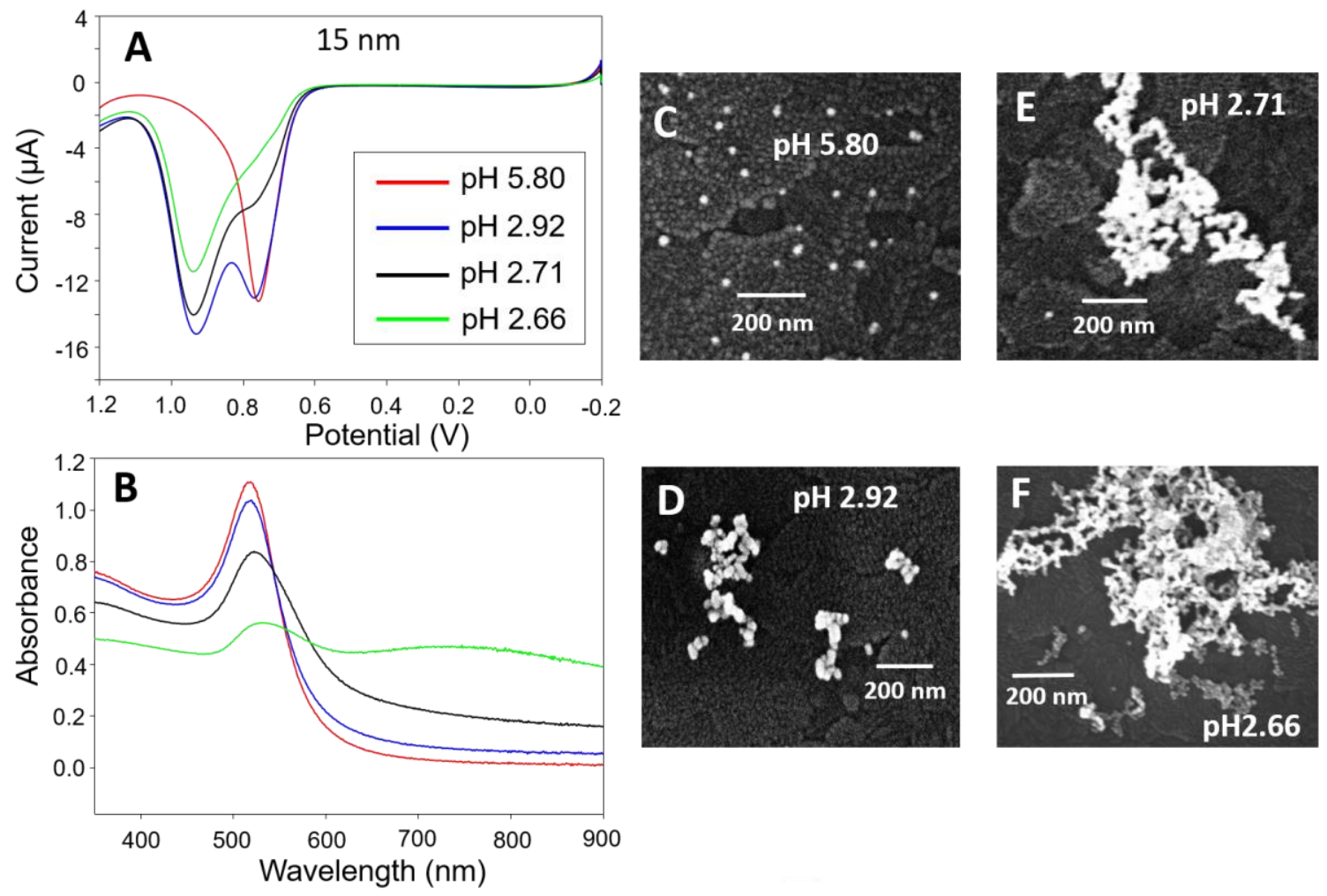

Figure 6.3. (A) LSSV of glass/ITO/APTES electrodes coated with $15 \mathrm{~nm}$ diameter Au NPs attached from solution at pH 5.80 (red), 2.92 (blue), 2.71 (black), and 2.65 (green). The LSSV was ran in $0.1 \mathrm{M} \mathrm{KClO}_{4}+$ $0.01 \mathrm{M} \mathrm{KBr}$ from -0.2 to $1.2 \mathrm{~V}$ at a scan rate of $0.01 \mathrm{~V} / \mathrm{s}$. (B) UV-vis spectra of $15 \mathrm{~nm}$ diameter Au NP solutions at $\mathrm{pH} 5.80$ (red), 2.92 (blue), 2.71 (black), and 2.65 (green). (C-F) SEM images of glass/ITO/APTES electrodes after being immersed in the $15 \mathrm{~nm}$ diameter Au NPs at the indicated $\mathrm{pH}$. The unaltered solution had a $\mathrm{pH}$ of 5.80 and the $\mathrm{pH} 2.92,2.71$, and 2.66 solutions were obtained by adding $10 \mu \mathrm{L}$ of $4 \mathrm{M}, 5 \mathrm{M}$, and $6 \mathrm{M} \mathrm{HClO}_{4}$ to the unaltered solution, respectively. The soak times for the LSSV and SEM data were 60 seconds, 6 minutes, 6.5 minutes, and 7.5 minutes for the 5.80, 2.92, 2.71, and 2.66 pH solutions, respectively. 
again consistent with increasing aggregation as the $\mathrm{pH}$ decreases. This is also reflected in the SEM images of Figure 6.3E-6.3F, where the aggregate size increased with decreasing $\mathrm{pH}$. Even with the very large aggregates at $\mathrm{pH} 2.71$, there is still evidence of very small and isolated $15 \mathrm{~nm}$ diameter Au NPs (Figure 6.3E), which is consistent with the shoulder peak in the LSSV. Again, the LSSV is very sensitive to aggregation and correlates well with the UV-vis and SEM data. The maximum shift in the oxidation potential from isolated $15 \mathrm{~nm}$ Au NPs to large aggregates is $+0.181 \mathrm{~V}$.

Figure 6.4 shows the LSSV, UV-vis, and SEM images for the $50 \mathrm{~nm}$ Au NPs at varying $\mathrm{pH}$ values. For this size Au NPs, the LSSVs in Figure 6.4A are indistinguishable at $\mathrm{pH} 3.63,2.10$, and 1.89 . They show one main peak near $0.945 \mathrm{~V}$ and a small shoulder peak in the 0.720 to $0.750 \mathrm{~V}$ range. The UV-vis spectra in Figure 6.4B show one main LSPR band at $538 \mathrm{~nm}$ at $\mathrm{pH} 3.63$ and a decrease in the $538 \mathrm{~nm}$ peak and emergence of a peak at $800 \mathrm{~nm}$ at $\mathrm{pH} 2.10$. At $\mathrm{pH} 1.89$, the $538 \mathrm{~nm}$ peak shifts and decreases more, a new broad peak appears at $650 \mathrm{~nm}$, and the $800 \mathrm{~nm}$ peak shifts and grows larger. These spectra correlate well with the SEM images in Figure 6.4C-6.4E, which show well-isolated $50 \mathrm{~nm}$ diameter Au NPs at $\mathrm{pH} 3.63$, small aggregates at $\mathrm{pH}$ 2.10, and large and small aggregates at $\mathrm{pH} 1.89$. The data interestingly reveals that the oxidation potential is not at all sensitive to aggregation for this large NP size.

\subsection{Conclusions}

Our results indicate that there is excellent correlation between the oxidation potential and aggregation state of Au NPs, depending on their size. The sensitivity to aggregation increased as the size of the Au NPs decreased. This can be explained by the size-dependent oxidation potential of metal NPs, which has been described theoretically 

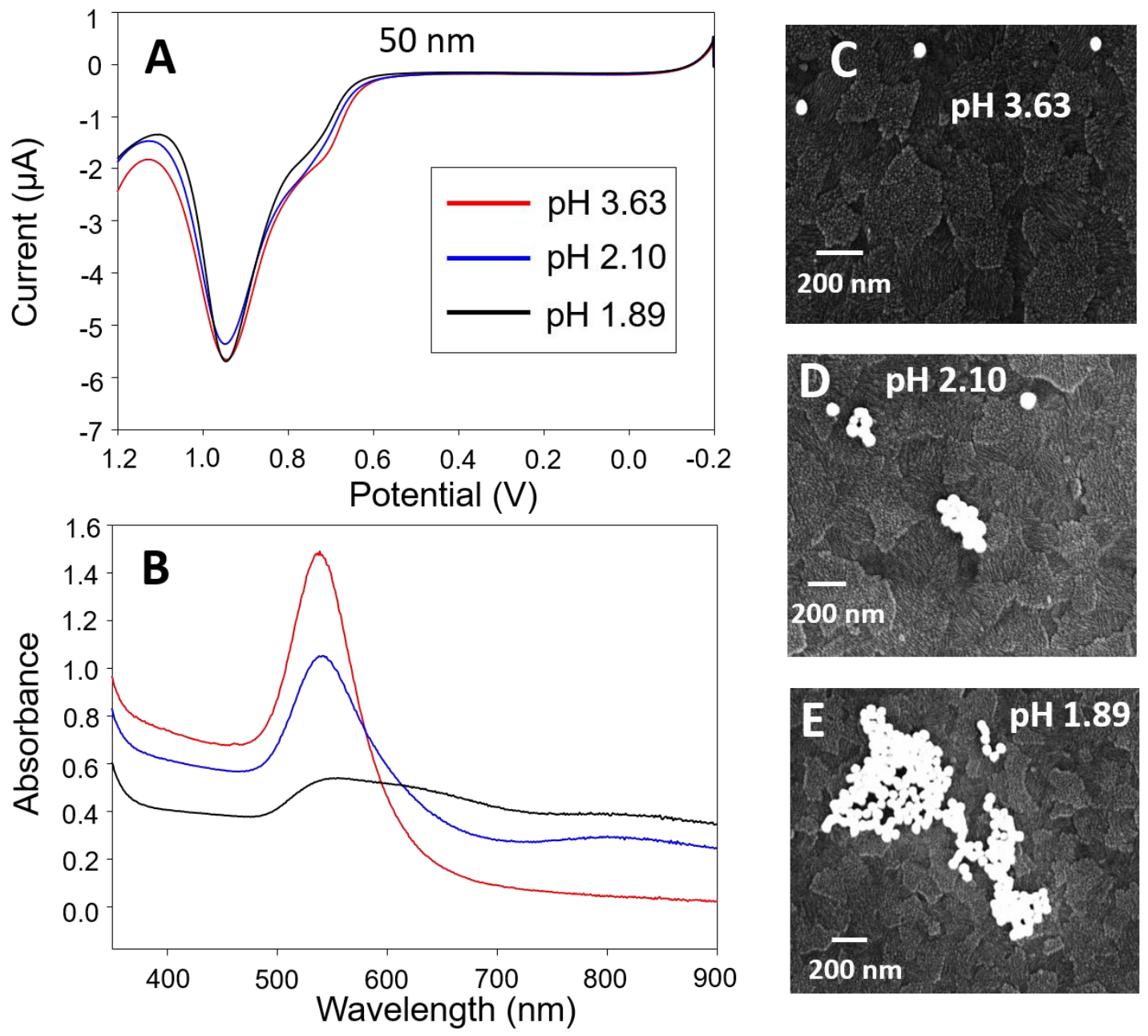

Figure 6.4. (A) LSSV of glass/ITO/APTES electrodes coated with $50 \mathrm{~nm}$ diameter Au NPs attached from solution at $\mathrm{pH} 3.63$ (red), 2.10 (blue), and 1.89 (black). The LSSV was ran in $0.1 \mathrm{M} \mathrm{KClO}_{4}+0.01$ $\mathrm{M} \mathrm{KBr}$ from -0.2 to $1.2 \mathrm{~V}$ at a scan rate of $0.01 \mathrm{~V} / \mathrm{s}$. (B) $\mathrm{UV}$-vis spectra of $50 \mathrm{~nm}$ diameter citrate-coated $\mathrm{Au}$ NP solutions at $\mathrm{pH} 3.63$ (red), 2.10 (blue), and 1.89 (black). (C-E) SEM images of the glass/ITO/APTES electrodes after being immersed in the $50 \mathrm{~nm}$ diameter $\mathrm{Au}$ NPs at the indicated $\mathrm{pH}$. The unaltered solution had a $\mathrm{pH}$ of 3.63 and the $\mathrm{pH} 2.10$ and 1.89 solutions were obtained by adding 10 $\mu \mathrm{L}$ of $2 \mathrm{M}$ and $3 \mathrm{M} \mathrm{HClO}_{4}$ to the unaltered solution, respectively. The soak times for the LSSV and SEM data were 9 minutes, 6 minutes, and 6 minutes for the 3.63,2.10, and $1.89 \mathrm{pH}$ solutions, respectively. 
by Plieth ${ }^{119}$ and experimentally by us ${ }^{9,120-121,123}$ and others. ${ }^{100,114,124,134}$ Smaller NPs oxidize at more negative potential due to greater exposed surface area relative to larger NPs. When small metal NPs aggregate, which might involve sintering and fusion of NPs ${ }^{133}$ this area is reduced and they oxidize at potentials corresponding to larger NPs. Since the smallest NPs exhibit the greatest decrease in surface area going from small isolated NPs to large aggregates, they exhibit the largest positive shift in oxidation potential. The maximum oxidation potential observed is that of bulk Au oxidation. Since the $50 \mathrm{~nm}$ diameter Au NPs oxidize at bulk Au potentials in the isolated form, they do not show any shift upon aggregation.

We determined that the surface area-to-volume ratio (SA/V) decreased by a factor of 7 and a factor of 2 for $4 \mathrm{~nm}$ and $15 \mathrm{~nm}$ Au NPs upon aggregation, respectively, using an electrochemical method. This is consistent with the shift in oxidation potential being related to a decrease in SA/V. It is possible that plasmonic coupling between the Au NPs has a stabilizing effect on the oxidation potential or the effective surface area, but this was not observed for $50 \mathrm{~nm}$ diameter Au NPs and plasmon coupling leads to the electrons being less confined and more easily excited at lower energy, making this a less likely explanation. Interestingly, UV-vis spectroscopy is more sensitive to Au NP aggregation than LSSV for large size NPs, while LSSV is more sensitive than UV-vis spectroscopy for small sizes. LSSV can importantly detect metal NP aggregation of nonplasmonic metals and very small NPs $(<2 \mathrm{~nm})$ that are too small to exhibit a LSPR band. It can also potentially be used to detect very small aggregates (dimers, trimers, tetramers, etc.). 


\section{CHAPTER 7}

\section{SUMMARY AND FUTURE DIRECTIONS}

\subsection{Summary}

This dissertation covered topics pertaining to the study of size-controlled EPD and aggregation-dependent oxidation properties of metal NPs using ASV. After discussing the background in the field of size-dependent metal NPs oxidation, the use of ASV for metal NP characterization, EPD of metal NPs, and aggregation-based NP assays for sensing applications, we delved into the four main projects. First, we discussed the mechanism of size-selective EPD of Au NPs mediated by HQ oxidation at different potentials. ${ }^{1}$ The second project described the NP-assisted EPD process that allows deposition of nanostructures at potentials where they normally will not deposit. Third, we showed that the oxidation potential of Au depends on their varying degrees of aggregation. ${ }^{2}$ And lastly, the size-selective EPD by functionalization of the working electrode with silane and polymer films, which act as filters.

The main principles of our projects are listed below.

1) Size-Selective Electrophoretic Deposition of Gold Nanoparticles Mediated by the Oxidation of Hydroquinone. We concluded that the proton mechanism is responsible for NP deposition in the presence of $\mathrm{HQ}$.

2) Nanoparticle (NP)-Assisted Electrophoretic Deposition (EPD). The catalytic activity of $4 \mathrm{~nm} \mathrm{Au} \mathrm{NPs} \mathrm{assists} \mathrm{in} \mathrm{the} \mathrm{deposition} \mathrm{of} \mathrm{other} \mathrm{non-catalytic} \mathrm{NPs.}$ 
3) Size-Selective Electrophoretic Deposition by Functionalization of the Working Electrode with Silane Filters on Glass/ITO Substrates. By chemically modifying the surface of the glass/ITO electrode, we were able to perform size selection from a mixture of NPs.

4) Aggregation-Dependent Oxidation of Metal Nanoparticles. The change in oxidation potential is based on NP aggregation state. As the NPs become more aggregated, their oxidation potential shifts more positive.

Our current work has inspired some future studies including the use of aggregation-dependent oxidation of Au NPs for chemical sensing by ASV.

\subsection{Future Directions}

\subsubsection{Sensing of Hazardous Chemicals by Electrochemical Detection of Aggregating Au NPs}

We are currently applying ASV to detect the presence of an analyte by its ability to induce aggregation of Au NPs through hydrogen bonding with the stabilizer molecules surrounding the Au NPs. Hormozi-Nezhad et al. studied the presence of pamidronate disodium in human plasma samples using UV-vis and a colorimetric assay. ${ }^{135}$ Pamidronate disodium (PAM) is a nitrogen-containing diphosphonate used to prevent osteoporosis and treat certain bone diseases so its detection in biological samples is important. Their goal was to establish a method for detection in low concentrations without the lengthy, complicated sample preparation or expensive lab equipment that is typically used for high-performance liquid chromatography (HPLC), gas chromatography, ion pair liquid chromatography, and capillary electrophoresis. Their UV-vis and TEM data shows aggregation of Au NPs in the presence of $100 \mu \mathrm{M}$ PAM 
with aggregation detectable down to $75 \mu \mathrm{M}$ in the UV-vis spectra. ${ }^{135}$ The color of the NP solution remains red at $50 \mu \mathrm{M}$ PAM, which means PAM cannot be detected by UV-vis spectroscopy below this method. To analyze lower concentrations of PAM, we explored the use of ASV to determine if our method was more sensitive to aggregation as compared to optical detection methods.

\subsection{1a. Pamidronate Disodium Detection}

We performed ASV on $4 \mathrm{~nm}$ Au NPs attached to amine-functionalized glass/ITO after exposure to solutions containing 50, 25, 20, 15, and $10 \mu \mathrm{M}$ PAM. Our results show that the color of the Au NP solution at these levels of PAM remains the same and the absorbance band in the UV-vis spectra does not show signs of aggregation. In contrast, the ASV shows a shoulder peak more positive of the normal oxidation peak for $4 \mathrm{~nm} \mathrm{Au}$ NPs. The size of the shoulder peak increases as the concentration of PAM increases, so we are planning to create a calibration curve with the data in order to determine the PAM concentration of unknown samples.

Since the preliminary data with PAM has shown promising results, we are planning to study other analytes in low concentrations, such as pesticides and insecticides. In their paper, Hormozi-Nezhad et al. explained the aggregation mechanism as the result of hydrogen bonding through the carboxyl and amino groups of the PAM molecules. The PAM molecule adsorbed onto the surface of the Au NPs through its oxygen molecule because electron-rich atoms have a high affinity to the surface of $\mathrm{Au}$ NPs. ${ }^{135}$ Due to the structure and composition of the PAM molecules, we believe we can analyze other compounds possessing electron-rich atoms that will bind to the surface of the Au NPs as well as cause hydrogen bonding between the molecules, thus resulting in 
aggregation of the Au NPs and positive shift in their oxidation potential. The

electrochemistry method is more sensitive to aggregation than optical detection methods such as UV-vis and colorimetric analysis. Future plans will include determining the lower limit of detection of the PAM using ASV to determine PAM-induced Au NP aggregation. In addition, another goal is to filter small size $(<4 \mathrm{~nm})$ NPs in a mixture by fine-tuning the chemical surface modifications (MPTMS and polymers) on the electrode surface.

\subsection{1b. Chromium Detection}

Along with PAM, we tested chromium as a possible analyte for NP aggregation.

It was set-up in a similar way as the PAM experiment with $10 \mathrm{~mL}$ of $4 \mathrm{~nm}$ Au NP plus 10 $\mu \mathrm{L}$ of various concentrations of chromium and then took $\mathrm{UV}$-vis spectra of the $\mathrm{NP}+\mathrm{Cr}$ solution and ASVs of the glass/ITO/APTES/AuNP slide. Preliminary ASV data shows no shouldering with the control solution (no $\mathrm{Cr}$ ), a noticeable shoulder in the $5 \mathrm{ppb}$ solution, and a noticeable second peak forming in the $1000 \mathrm{ppb}$ solution. However, the UV-vis spectra do not change dramatically. The 5 ppb solution and the control have identical absorbance bands, and the 1000 ppb solution has just a slight higher absorbance in the $600-900 \mathrm{~nm}$ range. Future plans include performing ASVs on a wider range of $\mathrm{Cr}$ levels, and then calculating the analytical merits such as reproducibility and limit of detection. 


\section{REFERENCES}

1. $\quad$ Allen, S. L.; Zamborini, F. P., Size-Selective Electrophoretic Deposition of Gold Nanoparticles Mediated by Hydroquinone Oxidation. Langmuir 2019, 35 (6), 2137-2145.

2. $\quad$ Allen, S. L. S., J.; Zamborini, F.P., Aggregation-Dependent Oxidation of Metal Nanoparticles. J. Am. Chem. Soc. 2017, 139, 12895-12898.

3. Toh, H. S.; Batchelor-McAuley, C.; Tschulik, K.; Uhlemann, M.; Crossley, A.; Compton, R. G., The Anodic Stripping Voltammetry of Nanoparticles: Electrochemical Evidence for the Surface Agglomeration of Silver Nanoparticles. Nanoscale 2013, 5 (11), 4884-4893.

4. Ivanova, O. S.; Zamborini, F. P., Size-Dependent Electrochemical Oxidation Of Silver Nanoparticles. J. Am. Chem. Soc. 2010, 132, 70-2.

5. $\quad$ Zeng, S.; Yong, K.-T.; Roy, I.; Dinh, X.-Q.; Yu, X.; Luan, F., A Review on Functionalized Gold Nanoparticles for Biosensing Applications. Plasmonics 2011, 6 (3), 491506.

6. Klabunde, K. J., Nanoscale materials in chemistry. Wiley-Interscience: New York, 2001.

7. Roduner, E., Size Matters: Why Nanomaterials are Different. Chem. Soc. Rev. 2006, 35 (7), 583-592.

8. Piella, J.; Bastus, N. G.; Puntes, V., Size-Controlled Synthesis of Sub-10-nanometer Citrate-Stabilized Gold Nanoparticles and Related Optical Properties. Chem. Mater. 2016, 28 (4), 1066-1075.

9. Ivanova, O. S.; Zamborini, F. P., Size-Dependent Electrochemical Oxidation of Silver Nanoparticles. J. Am. Chem. Soc. 2010, 132, 70-72.

10. Masitas, R. A.; Zamborini, F. P., Oxidation of Highly Unstable <4 nm Diameter Gold Nanoparticles $850 \mathrm{mV}$ Negative of the Bulk Oxidation Potential. J. Am. Chem. Soc. 2012, 134, 5014-5017.

11. Allen, S. L.; Sharma, J. N.; Zamborini, F. P., Aggregation-Dependent Oxidation of Metal Nanoparticles. J. Am. Chem. Soc. 2017, 139 (37), 12895-12898.

12. Greenberg, A., Gold Nanoparticles as Sensors for Electrolytes in Sports Drinks. 1-6.

13. Roduner, E., Size Matters: Why Nanomaterials Are Different. Chem. Soc. Rev. 2006, 35 (7), 583-592.

14. Henglein, A., The Reactivity of Silver Atoms in Aqueous Solutions (A $\gamma$-Radiolysis Study). Ber. Bunsen. Ges. Phys. Chem. 1977, 81 (6), 556-561. 
15. Plieth, W. J., Electrochemical Properties Of Small Clusters Of Metal Atoms And Their Role In The Surface Enhanced Raman Scattering. J. Phys. Chem. 1982, 86, 3166-3170.

16. Ivanova, O. S. Z., F. P., Electrochemical Size Discrimination of Gold Nanoparticles Attached to Glass/Indium-Tin-Oxide Electrodes by Oxidation in Bromide-Containing Electrolyte. Anal. Chem. 2010, 82, 5844-5850.

17. Brainina, K. Z.; Galperin, L. G.; Galperin, A. L., Mathematical Modeling And Numerical Simulation Of Metal Nanoparticles Electrooxidation. J. Solid State Electrochem. 2010, 14 (6), 981-988.

18. Ward Jones, S. E.; Campbell, F. W.; Baron, R.; Xiao, L.; Compton, R. G., Particle Size and Surface Coverage Effects in the Stripping Voltammetry of Silver Nanoparticles: Theory and Experiment. J. Phys. Chem. 2008, 112 (46), 17820-17827.

19. Jones, S. E. W.; Toghill, K. E.; Compton, R. G.; Zheng, S. H.; Morin, S., The Stripping Voltammetry Of Hemispherical Deposits Under Electrochemically Irreversible Conditions: A Comparison Of The Stripping Voltammetry Of Bismuth On Boron-Doped Diamond And $\mathrm{Au}(111)$ Electrodes. J. Phys. Chem. 2009, 113 (7), 2846-2854.

20. Brainina, K. Z.; Galperin, L. G.; Vikulova, E. V., Electrochemistry Of Metal Nanoparticles: The Effect Of Substrate. J. Solid State Electrochem. 2012, 16 (7), 2357-2363.

21. Masitas, R. A.; Zamborini, F. P., Oxidation Of Highly Unstable <4 Nm Diameter Gold Nanoparticles $850 \mathrm{Mv}$ Negative Of The Bulk Oxidation Potential. J. Am. Chem. Soc. 2012, 134, 5014-7.

22. Tang Lei, L.; Li, X.; Cammarata, R. C.; Friesen, C.; Sieradzki, K., Electrochemical Stability Of Elemental Metal Nanoparticles. J. Am. Chem. Soc. 2010, 132 (33), 11722-6.

23. Tang, L.; Han, B.; Persson, K.; Friesen, C.; He, T.; Sieradzki, K.; Ceder, G., Electrochemical Stability Of Nanometer-Scale Pt Particles In Acidic Environments. J. Am. Chem. Soc. 2010, 132 (2), 596-600.

24. Kumar, A.; Buttry, D. A., Size-Dependent Anodic Dissolution of Water-Soluble Palladium Nanoparticles. J. Phys. Chem. 2013, 117 (50), 26783-26789.

25. Pattadar, D. K.; Zamborini, F. P., Size Stability Study of Catalytically Active Sub-2 nm Diameter Gold Nanoparticles Synthesized with Weak Stabilizers. J. Am. Chem. Soc. 2018, 140 (43), 14126-14133.

26. Oh, J.-H.; Park, D. H.; Joo, J. H.; Lee, J.-S., Recent Advances In Chemical Functionalization Of Nanoparticles With Biomolecules For Analytical Applications. Anal. and Bioanal. Chem. 2015, 407 (29), 8627-8645.

27. Huttanus, H. M.; Graugnard, E.; Yurke, B.; Knowlton, W. B.; Kuang, W.; Hughes, W. L.; Lee, J., Enhanced DNA Sensing Via Catalytic Aggregation Of Gold Nanoparticles. Biosens. Bioelect. 2013, 50, 382-6. 
28. Chen, S.; Gao, H.; Shen, W.; Lu, C.; Yuan, Q., Colorimetric Detection Of Cysteine Using Noncrosslinking Aggregation Of Fluorosurfactant-Capped Silver Nanoparticles. Sens. Act. Chem. 2014, 190, 673-678.

29. Ghasemi, F.; Hormozi-Nezhad, M. R.; Mahmoudi, M., A Colorimetric Sensor Array For Detection And Discrimination Of Biothiols Based On Aggregation Of Gold Nanoparticles. Analy. Chim. Act. 2015, 882, 58-67.

30. Chen, P.; Xu, W.; Zhou, X.; Panda, D.; Kalininskiy, A., Single-Nanoparticle Catalysis At Single-Turnover Resolution. Chem. Phys. Lett. 2009, 470 (4), 151-157.

31. Senkan, S.; Kahn, M.; Duan, S.; Ly, A.; Leidholm, C., High-Throughput Metal Nanoparticle Catalysis By Pulsed Laser Ablation. Cataly. Tod. 2006, 117 (1), 291-296.

32. Qiu, D.; Wang, S.; Zheng, Y.; Deng, Z., One At A Time: Counting SingleNanoparticle/Electrode Collisions For Accurate Particle Sizing By Overcoming The Instability Of Gold Nanoparticles Under Electrolytic Conditions. Nanotechnology 2013, 24 (50), 505707.

33. Huang, C. Z.; Liao, Q. G.; Gan, L. H.; Guo, F. L.; Li, Y. F., Telomere DNA Conformation Change Induced Aggregation Of Gold Nanoparticles As Detected By Plasmon Resonance Light Scattering Technique. Analy. Chim. Act. 2007, 604 (2), 165-169.

34. Hu, L.; Hu, S.; Guo, L.; Tang, T.; Yang, M., Optical And Electrochemical Detection Of Biothiols Based On Aggregation Of Silver Nanoparticles. Anal. Methods 2016, 8 (24), 4903 4907.

35. Rees, N. V.; Zhou, Y.-G.; Compton, R. G., The Aggregation of Silver Nanoparticles in Aqueous Solution Investigated via Anodic Particle Coulometry. ChemPhysChem 2011, 12 (9), $1645-1647$.

36. Ngamchuea, K.; Tschulik, K.; Eloul, S.; Compton, R. G., In Situ Detection of Particle Aggregation on Electrode Surfaces. ChemPhysChem 2015, 16 (11), 2338-2347.

37. Cloake, S. J.; Toh, H. S.; Lee, P. T.; Salter, C.; Johnston, C.; Compton, R. G., Anodic Stripping Voltammetry of Silver Nanoparticles: Aggregation Leads to Incomplete Stripping. ChemistryOpen 2015, 4 (1), 22-26.

38. Villarreal, E.; Li, G. G.; Zhang, Q.; Fu, X.; Wang, H., Nanoscale Surface Curvature Effects on Ligand-Nanoparticle Interactions: A Plasmon-Enhanced Spectroscopic Study of Thiolated Ligand Adsorption, Desorption, and Exchange on Gold Nanoparticles. Nano Lett. 2017, 17 (7), 4443-4452.

39. Wikipedia, Electrophoretic Deposition.

40. Corni, I.; Ryan, M. P.; Boccaccini, A. R., Electrophoretic Deposition: From Traditional Ceramics To Nanotechnology. J. Eur. Cer. Soc. 2008, 28 (7), 1353-1367.

41. De Riccardis, M. F., Ceramic Coatings Obtained by Electrophoretic Deposition: Fundamentals, Models, Post-Deposition Processes and Applications InTech 2012, 10.5772, 4368. 
42. Hamaker, H. C., Formation Of A Deposit By Electrophoresis. Trans. Faraday Soc. 1940, $35,279-287$.

43. Sarkar, P., Nicholson, P. S., Electrophoretic Deposition (EPD): Mechanisms, Kinetics, and Application to Ceramics. J. Am. Cer. Soc. 1996, 79, 1987-2002.

44. Vandeperre, L. J., Van der Biest, O., Electric Current And Electric Field for Electrophoretic Deposition From Non-Aqueous Suspensions. Cer. Trans. 1998, 85.

45. Van Tassel, J. J. R., C. A., Mechanisms of Electrophoretic Deposition. Key Eng. Mat. 2006, 314, 167-174.

46. Koelmans, H., Overbeek, J., Stability and Electrophoretic Deposition of Suspensions in Non-Aqueous Media. Disc. Faraday Soc. 1954, 18, 52-63.

47. Černohorský, O.; Grym, J.; Yatskiv, R.; Pham, V. H.; Dickerson, J. H., Insight into Nanoparticle Charging Mechanism in Nonpolar Solvents To Control the Formation of Pt Nanoparticle Monolayers by Electrophoretic Deposition. ACS App. Mater. Interf. 2016, 8 (30), 19680-19690.

48. Chava, R. K.; Raj, S.; Yu, Y.-T., Synthesis And Electrophoretic Deposition Of HollowTio2 Nanoparticles For Dye Sensitized Solar Cell Applications. J. Alloy Compd. 2016, 672, 212222.

49. Bennett, B. L.; Harris, C. T.; Wyatt, E. C., Fabrication of Thickness-Controlled Hematite Thin Films via Electrophoretic Deposition and Subsequent Heat Treatment of Pyridine-Capped Maghemite Nanoparticles. Ind. and Eng. Chem. Res. 2016, 55 (44), 11583-11588.

50. Giersig, M.; Mulvaney, P., Formation Of Ordered Two-Dimensional Gold Colloid Lattices By Electrophoretic Deposition. J. Phys. Chem. 1993, 97 (24), 6334-6336.

51. Giersig, M.; Mulvaney, P., Preparation Of Ordered Colloid Monolayers By Electrophoretic Deposition. Langmuir 1993, 9 (12), 3408-3413.

52. Leordean, C.; Marta, B.; Gabudean, A.-M.; Focsan, M.; Botiz, I.; Astilean, S., Fabrication Of Highly Active And Cost Effective SERS Plasmonic Substrates By Electrophoretic Deposition Of Gold Nanoparticles On A DVD Template. App. Surf. Sci. 2015, 349, 190-195.

53. Zhang Rongli, R.; Zhu, Y.; Huang, J.; Xu, S.; Luo, J., Electrochemical Sensor Coating Based on Electrophoretic Deposition of Au-Doped Self-Assembled Nanoparticles. ACS App. Mat. and Interf. 2018, 10 (6), 5926-5932.

54. Zarazúa, I.; Esparza, D.; López-Luke, T.; Ceja-Fdez, A.; Reyes-Gomez, J.; Mora-Seró, I.; de la Rosa, E., Effect Of The Electrophoretic Deposition Of Au NPs In The Performance Cds Qds Sensitized Solar Cells. Electrochim. Acta 2016, 188, 710-717.

55. Sakurada, O.; Suzuki, K.; Miura, T.; Hashiba, M., Bubble-Free Electrophoretic Deposition Of Aqueous Zirconia Suspensions With Hydroquinone. J. Mat. Sci. 2004, 39 (5), 1845-1847. 
56. Henglein, A., Physicochemical Properties Of Small Metal Particles In Solution:

"Microelectrode" Reactions, Chemisorption, Composite Metal Particles, And The Atom-ToMetal Transition. J. Phys. Chem. 1993, 97, 5457-5471.

57. Yan, C.; Zharnikov, M.; Gölzhäuser, A.; Grunze, M., Preparation and Characterization of Self-Assembled Monolayers on Indium Tin Oxide. Langmuir 2000, 16 (15), 6208-6215.

58. Jana, N. R., Gearheart, L., Murphy, C. J., Wet Chemical Synthesis of High Aspect Ratio Cylindrical Gold Nanorods. J. Phys. Chem. 2001, 105, 4065.

59. Block, B. P., Gold Powder and Potassium Tetrabromoaurate (III). Inorg. Syn. 1953, (4), 14-17.

60. Turkevish, J., Stevenson, P. C., Hillier, J., The Formation of Colloidal Gold. Discuss. Faraday Soc. 1951, (11), 55-75.

61. Liu, X.; Xu, H.; Xia, H.; Wang, D., Rapid Seeded Growth Of Monodisperse, QuasiSpherical, Citrate-Stabilized Gold Nanoparticles Via H2O2 Reduction. Langmuir 2012, 28 (38), 13720-6.

62. Hainfeld, J. F.; Dilmanian, F. A.; Slatkin, D. N.; Smilowitz, H. M., Radiotherapy Enhancement with Gold Nanoparticles. J. Pharm. Pharmacol. 2008, 60, 977-985.

63. Crooks, R. M.; Zhao, M. Q.; Sun, L.; Chechik, V.; Yeung, L. K., DendrimerEncapsulated Metal Nanoparticles: Synthesis, Characterization, and Applications to Catalysis. Accounts Chem. Res. 2001, 34 (3), 181-190.

64. Ibañez, F. J.; Zamborini, F. P., Chemiresistive Sensing with Chemically Modified Metal and Alloy Nanoparticles. Small 2012, 8 (2), 174-202.

65. Chen, J.; Wu, J.; Ge, H.; Zhao, D.; Liu, C.; Hong, X., Reduced Graphene Oxide Deposited Carbon Fiber Reinforced Polymer Composites for Electromagnetic Interference Shielding. Compos. Part A Appl. Sci. Manuf. 2016, 82, 141-150.

66. Sharma, J. N.; Pattadar, D. K.; Mainali, B. P.; Zamborini, F. P., Size Determination of Metal Nanoparticles Based on Electrochemically Measured Surface-Area-to-Volume Ratios. Anal. Chem. 2018, 90 (15), 9308-9314.

67. Fenger, R.; Fertitta, E.; Kirmse, H.; Thünemann, A. F.; Rademann, K., Size Dependent Catalysis with CTAB-Stabilized Gold Nanoparticles. Phys. Chem. 2012, 14 (26), 9343-9349.

68. Zhou, X.; Xu, W.; Liu, G.; Panda, D.; Chen, P., Size-Dependent Catalytic Activity and Dynamics of Gold Nanoparticles at the Single-Molecule Level. J. Am. Chem. Soc. 2010, 132 (1), 138-146.

69. Zhang, Y. W.; Song, P.; Chen, T. K.; Liu, X. D.; Chen, T.; Wu, Z. M.; Wang, Y.; Xie, J. P.; Xu, W. L., Unique Size-Dependent Nanocatalysis Revealed at the Single Atomically Precise Gold Cluster Level. Proc. Natl. Acad. Sci. U. S. A. 2018, 115 (42), 10588-10593.

70. Wang, S. W.; Omidvar, N.; Marx, E.; Xin, H. L., Overcoming Site Heterogeneity in Search of Metal Nanocatalysts. ACS Comb. Sci. 2018, 20 (10), 567-572. 
71. Back, S.; Yeom, M. S.; Jung, Y., Active Sites of Au and Ag Nanoparticle Catalysts for $\mathrm{CO}_{2}$ Electroreduction to CO. ACS Catal. 2015, 5 (9), 5089-5096.

72. Masitas, R. A.; Allen, S. L.; Zamborini, F. P., Size-Dependent Electrophoretic Deposition of Catalytic Gold Nanoparticles. J. Am. Chem. Soc. 2016, 138, 15295-15298.

73. Pickard, W. F., Remarks on the Theory of Electrophoretic Deposition. J. Electrochem. Soc. 1968, 115 (4), 105C.

74. Corni, I.; Ryan, M. P.; Boccaccini, A. R., Electrophoretic Deposition: From Traditional Ceramics to Nanotechnology. J. Eur. Ceram. Soc. 2008, 28 (7), 1353-1367.

75. Hamaker, H. C., Formation of a Deposit by Electrophoresis. Trans. Faraday Soc. 1940, $35,279-287$.

76. An, S. J.; Zhu, Y.; Lee, S. H.; Stoller, M. D.; Emilsson, T.; Park, S.; Velamakanni, A.; An, J.; Ruoff, R. S., Thin Film Fabrication and Simultaneous Anodic Reduction of Deposited Graphene Oxide Platelets by Electrophoretic Deposition. J. Phys. Chem. Lett. 2010, 1 (8), 12591263.

77. Lopez, I.; Vazquez, A.; Hernandez-Padron, G. H.; Gomez, I., Electrophoretic Deposition (EPD) of Silver Nanoparticles and Their Application as Surface-Enhanced Raman Scattering (SERS) Substrates. Appl. Surf. Sci. 2013, 280, 715-719.

78. Angelov, S. D.; Koenen, S.; Jakobi, J.; Heissler, H. E.; Alam, M.; Schwabe, K.; Barcikowski, S.; Krauss, J. K., Electrophoretic Deposition of Ligand-Free Platinum Nanoparticles on Neural Electrodes Affects Their Impedance in Vitro and In Vivo with no Negative Effect on Reactive Gliosis. J. Nanobiotechnol. 2016, 14, 3.

79. $\quad$ Černohorský, O.; Grym, J.; Yatskiv, R.; Pham, V. H.; Dickerson, J. H., Insight into Nanoparticle Charging Mechanism in Nonpolar Solvents To Control the Formation of Pt Nanoparticle Monolayers by Electrophoretic Deposition. ACS Appl. Mater. Interfaces 2016, 8 (30), 19680-19690.

80. Chava, R. K.; Raj, S.; Yu, Y.-T., Synthesis and Electrophoretic Deposition of Hollow$\mathrm{TiO}_{2}$ Nanoparticles for Dye Sensitized Solar Cell Applications. J. Alloy Compd. 2016, 672, $212-$ 222.

81. Bennett, B. L.; Harris, C. T.; Wyatt, E. C., Fabrication of Thickness-Controlled Hematite Thin Films via Electrophoretic Deposition and Subsequent Heat Treatment of Pyridine-Capped Maghemite Nanoparticles. Ind. Eng. Chem. Res. 2016, 55 (44), 11583-11588.

82. Giersig, M.; Mulvaney, P., Formation of Ordered Two-Dimensional Gold Colloid Lattices by Electrophoretic Deposition. J. Phys. Chem. 1993, 97 (24), 6334-6336.

83. Bailey, R. C.; Stevenson, K. J.; Hupp, J. T., Assembly of Micropatterned Colloidal Gold Thin Films via Microtransfer Molding and Electrophoretic Deposition. Adv. Mater. 2000, 12 (24), 1930-1934. 
84. Zhang, R.; Zhu, Y.; Huang, J.; Xu, S.; Luo, J.; Liu, X., Electrochemical Sensor Coating Based on Electrophoretic Deposition of Au-Doped Self-Assembled Nanoparticles. ACS Appl. Mater. Interfaces 2018, 10 (6), 5926-5932.

85. Zarazúa, I.; Esparza, D.; López-Luke, T.; Ceja-Fdez, A.; Reyes-Gomez, J.; Mora-Seró, I.; de la Rosa, E., Effect of the Electrophoretic Deposition of Au NPs in the Performance CdS QDs Sensitized Solar Cells. Electrochim. Acta 2016, 188, 710-717.

86. Augusto, T.; Teixeira Neto, E.; Teixeira Neto, A. A.; Vichessi, R.; Vidotti, M.; Córdoba de Torresi, S. I., Electrophoretic Deposition of Au@PEDOT Nanoparticles Towards the Construction of High-Performance Electrochromic Electrodes. Sol. Energ. Mat. Sol. C 2013, 118, $72-80$.

87. Rosseinsky, D. R.; Mortimer, R. J., Electrochromic Systems and the Prospects for Devices. Adv. Mater. 2001, 13 (11), 783-793.

88. Dalton, L. R.; Sullivan, P. A.; Bale, D. H., Electric Field Poled Organic Electro-Optic Materials: State of the Art and Future Prospects. Chem. Rev. 2010, 110 (1), 25-55.

89. Rauh, R. D.; Wang, F.; Reynolds, J. R.; Meeker, D. L., High Coloration Efficiency Electrochromics and Their Application to Multi-Color Devices. Electrochim. Acta 2001, 46 (1314), 2023-2029.

90. Sarkar, P.; Nicholson, P. S., Electrophoretic Deposition (EPD): Mechanisms, Kinetics, and Application to Ceramics. J. Am. Ceram. Soc. 1996, 79 (8), 1987-2002.

91. De Riccardis, M. F., Ceramic Coatings Obtained by Electrophoretic Deposition: Fundamentals, Models, Post-Deposition Processes and Applications InTech 2012, 10.5772, 4368.

92. Van Tassel, J. J.; Randall, C. A., Mechanisms of Electrophoretic Deposition. Trans Tech Publications, Ltd.: Zurich-Uetikon, Switzerland, 2006, 314, 167-173.

93. Van Tassel, J. J.; Randall, C. A., Electrophoretic Deposition and Sintering of Thin/Thick PZT Films. J. Eur. Ceram. Soc. 1999, 19 (6), 955-958.

94. Van Tassel, J. J.; Randall, C. A., Potential for Integration of Electrophoretic Deposition into Electronic Device Manufacture; Demonstrations Using Silver/Palladium. J. Mater. Sci. 2004, 39 (3), 867-879.

95. Hamaker, H. C.; Verwey, E. J. W., The Role of the Forces between the Particles in Electrodeposition and Other Phenomena. Trans. Faraday Soc. 1940, 35, 180-185.

96. Petrucci, R. H., General Chemistry: Principles and Modern Applications 9ed.; Pearson: 2007, 606.

97. Henglein, A., Physicochemical Properties of Small Metal Particles in Solution: "Microelectrode" Reactions, Chemisorption, Composite Metal Particles, and the Atom-to-Metal Transition. J. Phys. Chem. 1993, 97, 5457-5471. 
98. Plieth, W. J., Electrochemical Properties of Small Clusters of Metal Atoms and Their Role in the Surface Enhanced Raman Scattering. J. Phys. Chem. 1982, 86, 3166-3170.

99. Brainina, K. Z.; Galperin, L. G.; Galperin, A. L., Mathematical Modeling and Numerical Simulation of Metal Nanoparticles Electrooxidation. J. Solid State Electrochem. 2010, 14 (6), 981-988.

100. Kumar, A.; Buttry, D. A., Size-Dependent Anodic Dissolution of Water-Soluble Palladium Nanoparticles. J. Phys. Chem. C 2013, 117 (50), 26783-26789.

101. Ward Jones, S. E.; Campbell, F. W.; Baron, R.; Xiao, L.; Compton, R. G., Particle Size and Surface Coverage Effects in the Stripping Voltammetry of Silver Nanoparticles: Theory and Experiment. J. Phys. Chem. C 2008, 112 (46), 17820-17827.

102. Tang, L.; Han, B.; Persson, K.; Friesen, C.; He, T.; Sieradzki, K.; Ceder, G., Electrochemical Stability of Nanometer-Scale Pt Particles in Acidic Environments. J. Am. Chem. Soc. 2010, 132 (2), 596-600.

103. Tang, L.; Li, X.; Cammarata, R. C.; Friesen, C.; Sieradzki, K., Electrochemical Stability of Elemental Metal Nanoparticles. J. Am. Chem. Soc. 2010, 132 (33), 11722-11726.

104. Jana, N. R., Gearheart, L., Murphy, C. J., Wet Chemical Synthesis of High Aspect Ratio Cylindrical Gold Nanorods. J. Phys. Chem. B 2001, 105, 4065-4067.

105. Turkevish, J., Stevenson, P. C., Hillier, J., A Study of the Nucleation and Growth Processes in the Synthesis of Colloidal Gold. Discuss. Faraday Soc. 1951, 11, 55-75.

106. Sakurada, O.; Suzuki, K.; Miura, T.; Hashiba, M., Bubble-Free Electrophoretic Deposition of Aqueous Zirconia Suspensions with Hydroquinone. J. Mater. Sci. 2004, 39, 1845 1847.

107. Liu, B.; Liu, J., DNA Adsorption by Indium Tin Oxide Nanoparticles. Langmuir 2015, 31, 371-377.

108. Ye, R.; Zhukhovitskiy, A. V.; Kazantsev, R. V.; Fakra, S. C.; Wickemeyer, B. B.; Toste, F. D.; Somorjai, G. A., Supported Au Nanoparticles with N-Heterocyclic Carbene Ligands as Active and Stable Heterogeneous Catalysts for Lactonization. J. Am. Chem. Soc. 2018, 140 (11), 4144-4149.

109. Knight, D. A.; Nita, R.; Moore, M.; Zabetakis, D.; Khandelwal, M.; Martin, B. D.; Fontana, J.; Goldberg, E.; Funk, A. R.; Chang, E. L.; Trammell, S. A., Surface Plasmon Resonance Promotion of Homogeneous Catalysis Using a Gold Nanoparticle Platform. $J$. Nanopart. Res. 2014, 16 (6), 2400.

110. Zhou, M.; Yu, Y.; Hu, K.; Xin, H. L.; Mirkin, M. V., Collisions of Ir Oxide Nanoparticles with Carbon Nanopipettes: Experiments with One Nanoparticle. Anal. Chem. 2017, 89 (5), 2880-2885.

111. Ngamchuea, K.; Clark, R. O. D.; Sokolov, S. V.; Young, N. P.; Batchelor-McAuley, C.; Compton, R. G., Single Oxidative Collision Events of Silver Nanoparticles: Understanding the Rate-Determining Chemistry. Chem. Eur. J. 2017, 23 (63), 16085-16096. 
112. Alligrant, T. M.; Dasari, R.; Stevenson, K. J.; Crooks, R. M., Electrocatalytic Amplification of Single Nanoparticle Collisions Using DNA-Modified Surfaces. Langmuir 2015, 31 (42), 11724-11733.

113. CRC Handbook of Chemistry and Physics, 87th ed. Editor-in-Chief: David R. Lide (National Institute of Standards and Technology). CRC Press/Taylor and Francis Group: Boca Raton, FL. 2006. 2608 pp. 139.95. ISBN 0-8493-0487-3. J. Am. Chem. Soc. 2007, 129 (3), 724.

114. Tang, L.; Han, B.; Persson, K.; Friesen, C.; He, T.; Sieradzki, K.; Ceder, G., Electrochemical Stability of Nanometer-Scale Pt Particles in Acidic Environments. J. Am. Chem. Soc. 2010, 132, 596-600.

115. Tang, L.; Li, X.; Cammarata, R. C.; Friesen, C.; Sieradzki, K., Electrochemical Stability of Elemental Metal Nanoparticles. J. Am. Chem. Soc. 2010, 132, 11722-11726.

116. Levard, C.; Hotze, E. M.; Lowry, G. V.; Brown, G. E., Environmental Transformations of Silver Nanoparticles: Impact on Stability and Toxicity. Environ. Sci. Technol. 2012, 46 (13), 6900-6914.

117. He, D.; Bligh, M. W.; Waite, T. D., Effects of Aggregate Structure on the Dissolution Kinetics of Citrate-Stabilized Silver Nanoparticles. Environ. Sci. Technol. 2013, 47 (16), 9148 9156.

118. Henglein, A., Physicochemical Properties of Small Metal Particles in Solution: "Microelectrode" Reactions, Chemisorption, Composite Metal Particles, and the Atom-to-Metal Transition. J. Phys. Chem. 1993, 97, 5457-5471.

119. Plieth, W. J., Electrochemical Properties Of Small Clusters Of Metal Atoms And Their Role In The Surface Enhanced Raman Scattering. J. Phys. Chem. 1982, 86, 3166-3170.

120. Masitas, R. A.; Khachian, I. V.; Bill, B. L.; Zamborini, F. P., Effect Of Surface Charge And Electrode Material On The Size-Dependent Oxidation Of Surface-Attached Metal Nanoparticles. Langmuir 2014, 30 (43), 13075-84.

121. Ivanova, O. S.; Zamborini, F. P., Electrochemical Size Discrimination of Gold Nanoparticles Attached to Glass/Indium-Tin-Oxide Electrodes by Oxidation in BromideContaining Electrolyte. Anal. Chem. 2010, 82 (13), 5844-5850.

122. Masitas, R. A.; Allen, S. L.; Zamborini, F. P., Size-Dependent Electrophoretic Deposition of Catalytic Gold Nanoparticles. J. Am. Chem. Soc. 2016, 138, 15295-15298.

123. Masitas, R. A.; Zamborini, F. P., Oxidation Of Highly Unstable <4 Nm Diameter Gold Nanoparticles $850 \mathrm{Mv}$ Negative Of The Bulk Oxidation Potential. J. Am. Chem. Soc. 2012, 134, 5014-5017.

124. Brainina, K. Z.; Galperin, L. G.; Vikulova, E. V.; Stozhko, N. Y.; Murzakaev, A. M.; Timoshenkova, O. R.; Kotov, Y. A., Gold Nanoparticles Electrooxidation: Comparison Of Theory And Experiment. J. Solid State Electrochem. 2011, 15 (5), 1049-1056. 
125. Ward Jones, S. E.; Campbell, F. W.; Baron, R.; Xiao, L.; Compton, R. G., Particle Size and Surface Coverage Effects in the Stripping Voltammetry of Silver Nanoparticles: Theory and Experiment. J. Phys. Chem. C 2008, 112 (46), 17820-17827.

126. Park, J. H.; Thorgaard, S. N.; Zhang, B.; Bard, A. J., Single Particle Detection by Area Amplification: Single Wall Carbon Nanotube Attachment to a Nanoelectrode. J. Am. Chem. Soc. 2013, 135 (14), 5258-5261.

127. Anderson, T. J.; Zhang, B., Single-Nanoparticle Electrochemistry through Immobilization and Collision. Accounts Chem. Res. 2016, 49 (11), 2625-2631.

128. Robinson, D. A.; Duay, J.; Kondajji, A. M.; Stevenson, K. J., Mechanistic Aspects Of Hydrazine-Induced Pt Colloid Instability And Monitoring Aggregation Kinetics With Nanoparticle Impact Electroanalysis. Faraday Discuss. 2016, 193, 293-312.

129. Robinson, D. A.; Kondajji, A. M.; Castaneda, A. D.; Dasari, R.; Crooks, R. M.; Stevenson, K. J., Addressing Colloidal Stability for Unambiguous Electroanalysis of Single Nanoparticle Impacts. J. Phys. Chem. Lett. 2016, 7 (13), 2512-2517.

130. Rosi, N. L.; Mirkin, C. A., Nanostructures in Biodiagnostics. Chem. Rev. 2005, 105 (4), 1547-1562.

131. Zhao, W.; Brook, M. A.; Li, Y. F., Design of Gold Nanoparticle-Based Colorimetric Biosensing Assays. ChemBioChem 2008, 9 (15), 2363-2371.

132. Sonnichsen, C.; Reinhard, B. M.; Liphardt, J.; Alivisatos, A. P., A Molecular Ruler Based On Plasmon Coupling Of Single Gold And Silver Nanoparticles. Nat. Biotechnol. 2005, 23 (6), 741-745.

133. Moaseri, E.; Stover, R. J.; Changalvaie, B.; Sepeda, A. J.; Truskett, T. M.; Sokolov, K. V.; Johnston, K. P., Control of Primary Particle Spacing in Gold Nanoparticle Cluster for Both High NIR Extinction and Full Reversibility. Langmuir 2017, 33, 3413-3426.

134. Giovanni, M.; Pumera, M., Size Dependant Electrochemical Behavior of Silver Nanoparticles with Sizes of 10, 20, 40, 80 and 107 nm. Electroanalysis 2012, 24 (3), 615-617.

135. Hormozi-Nezhad, M. R.; Abbasi-Moayed, S., A Visual Colorimetric Probe for NakedEye Detection of Pamidronate Disodium in Human Plasma Based on Aggregation of CitrateCapped Gold Nanoparticles. Plasmonics 2015, 10 (4), 971-978. 


\title{
APPENDIX
}

\author{
Title: Aggregation-Dependent \\ Oxidation of Metal Nanoparticles \\ Author: Stacy L. Allen, Jay N. Sharma, \\ Francis P. Zamborini \\ Publication: Journal of the American \\ Chemical Society \\ Publisher: American Chemical Society \\ Date: Sep 1, 2017 \\ Copyright (c) 2017, American Chemical Society
}

\section{PERMISSION/LICENSE IS GRANTED FOR YOUR ORDER AT NO CHARGE}

This type of permission/license, instead of the standard Terms \& Conditions, is sent to you because no fee is being charged for your order. Please note the following:

- Permission is granted for your request in both print and electronic formats, and translations.

- If figures and/or tables were requested, they may be adapted or used in part.

- Please print this page for your records and send a copy of it to your publisher/graduate school.

- Appropriate credit for the requested material should be given as follows: "Reprinted (adapted) with permission from (COMPLETE REFERENCE CITATION). Copyright (YEAR) American Chemical Society." Insert appropriate information in place of the capitalized words.

- One-time permission is granted only for the use specified in your request. No additional uses are granted (such as derivative works or other editions). For any other uses, please submit a new request. 


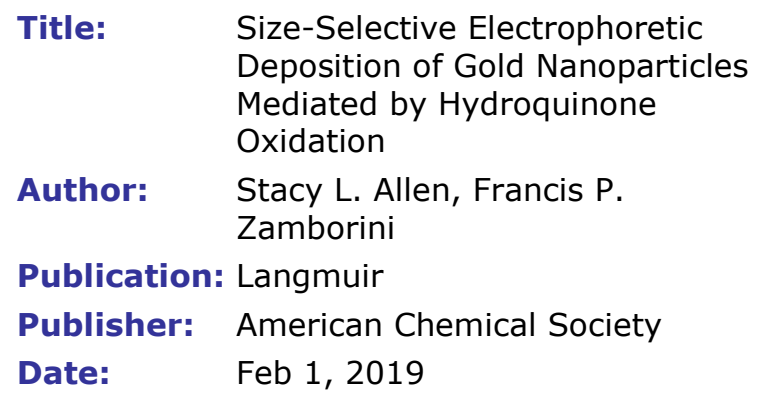

\section{PERMISSION/LICENSE IS GRANTED FOR YOUR ORDER AT NO CHARGE}

This type of permission/license, instead of the standard Terms \& Conditions, is sent to you because no fee is being charged for your order. Please note the following:

- Permission is granted for your request in both print and electronic formats, and translations.

- If figures and/or tables were requested, they may be adapted or used in part.

- Please print this page for your records and send a copy of it to your publisher/graduate school.

- Appropriate credit for the requested material should be given as follows: "Reprinted (adapted) with permission from (COMPLETE REFERENCE CITATION). Copyright (YEAR) American Chemical Society." Insert appropriate information in place of the capitalized words.

- One-time permission is granted only for the use specified in your request. No additional uses are granted (such as derivative works or other editions). For any other uses, please submit a new request. 


\title{
CURRICULUM VITAE
}

\author{
Stacy Allen \\ 332B Wildwood PI., Louisville, KY $\cdot 859.229 .8100$ \\ Stacyallen684@gmail.com
}

\section{EXPERIENCE}

JANUARY 2017 - PRESENT

GRADUATE RESEARCH ASSISTANT, UNIVERSITY OF LOUISVILLE, LOUISVILLE, KY

- Research emphasis in electrophoretic deposition as well as Au nanoparticle stability and aggregation

-In charge of instrument maintenance and troubleshooting

- Managed and edited group webpage

JANUARY 2014 - PRESENT

GRADUATE TEACHING ASSISTANT, UNIVERSITY OF LOUISVILLE, LOUISVILLE, KY

-Taught beginner and intermediate level analytical chemistry lab sessions

- Tutored students in chemistry courses

MARCH 2013 - DECEMBER 2013

LAB TECHNICIAN, VETERINARY DIAGNOSTIC LABORATORY, LEXINGTON, KY

-Analyzed biological and material samples for various analytes and contaminants

AUGUST 2006 - AUGUST 2009

CLINICAL COORDINATOR, PARK AVENUE ORTHODONTICS, NEW YORK CITY, NY

-Treated patients for orthodontic care including x-rays, impressions, and adjustments 
-Assisted doctor, organized monthly marketing meetings, and trained new employees

\title{
EDUCATION
}

\author{
SPRING 2019 \\ PhD IN CHEMISTRY, UNIVERSITY OF LOUISVILLE, LOUISVILLE, KY \\ Dissertation: The Use of Anodic Stripping Voltammetry to Study the Electrophoretic \\ Deposition and Aggregation-Dependent Oxidation of Metal Nanoparticles \\ GPA: 3.8
}

JULY 2017

MASTER'S DEGREE IN CHEMISTRY, UNIVERISTY OF LOUISVILLE, LOUISVILLE, KY

GPA: 3.8

DECEMBER 2013

BACHELOR'S DEGREE IN FORENSIC SCIENCE, EASTERN KENTUCKY

UNIVERSITY, RICHMOND, KY

MAY 2006

BACHELOR'S DEGREE IN PHILOSOPHY, CENTRE COLLEGE, DANVILLE, KY

\section{SKILLS \& ACCOMPLISHMENTS}

- Experience with various instrumentation: scanning electron microscopy, UV-vis spectroscopy, infrared spectroscopy, gas chromatography, atomic absorption, potentiostat, and mass spectrometry

- Proficient in Word, Excel, PowerPoint, Sigma Plot
- Co-President of Chemistry Graduate Student Association 2015-2017

- Presenter at Pittcon Conference 2017

- Presenter at Graduate Student Regional Research Conference at University of Louisville 2017 and 2018

\section{PUBLICATIONS}

Allen, S., Zamborini, F., Size-Selective Electrophoretic Deposition of Gold Nanoparticles Mediated by Hydroquinone Oxidation. Langmuir, 2019. 
Allen, S., Sharma, J., Zamborini, F., Aggregation Dependent Oxidation of Metal Nanoparticles. J. Am. Chem. Soc., 2017, 139 (37), pp 12895-12898

Masitas, R., Allen, S., Zamborini, F., Size-Dependent Electrophoretic Deposition of Catalytic Gold Nanoparticles. J. Am. Chem. Soc., 2016, 138 (47), pp 15295-15298

Masitas, R., Allen, S., Zamborini, F., Unique Stripping Voltammetry of $<2.0 \mathrm{~nm}$ Diameter Au Nanoparticles. In Preparation.

Pattadar, D., Nambiar, H., Allen, S., Zamborini, F., Assembly Aggregation Dependent Oxidation Au Nanoparticles. In Preparation. 